\title{
Walking the Map \& Tracing the Territory
}

\author{
by \\ Patricio Davila, BDes \\ Ontario College of Art \& Design
}

2002

A thesis project presented to

Ryerson University and York University

\author{
in partial fulfillment of the \\ requirements for the degree of \\ Master of Arts \\ in the Program of
}

Communication and Culture

Toronto, Ontario, Canada, 2008

(C) Patricio Davila 2008 


\section{AUTHOR'S DECLARATION}

I hereby declare that I am the sole author of this thesis.

I authorize Ryerson University and York University to lend this thesis or dissertation to other institutions or individuals for the purpose of scholarly research.

\section{Patricio Davila}

I further authorize Ryerson University and York University to reproduce this thesis or dissertation by photocopying or by other means, in total or in part, at the request of other institutions or individuals for the purpose of scholarly research.

Patricio Davila 


\begin{abstract}
Patricio Davila

Master of Arts

Communication and Culture

Ryerson University and York University

"Walking the Map \& Tracing the Territory" is a locative media project created to investigate the relationship between the visual representation and aural/physical experience of space through the roles of mapper and walker. Both forms of knowing a space have biases that privilege certain aspects of space. While visual representation on a map totalizes space and emphasizes the spatial relationship between objects, aural/physical experience emphasizes the evanescent quality of walking and narrative. This exploration has led to the idea that space is physical but also represented, experienced and recreated constantly through its use. The project has drawn on the work of various locative artists such as Janet Cardiff and Rimini Protokoll to understand the way that story, listening and walking can inform one's perception of space. The work of Michel de Certeau has also been used to understand how one creates space through the subjective negotiation of place. Finally, the creation process of the installation, using consumer electronics, open-source software and programming languages has also been used as a way of looking at how space is articulated through this technology and how it mediates the mapper's and walker's perception of map and territory.
\end{abstract}




\section{ACKNOWLEDGEMENTS}

I would like to thank Dr. Greg Elmer, my advisor, for his support during the past year and a half, his initial encouragement to enter the Communications \& Culture program, and his valuable feedback through this process. I would also like to thank Dr. Caitlin Fisher and Andrew Roth, at York University's Augmented Reality Lab for their support and help in acquiring key technology needed to complete this project. I would also like thank Dr. Isabel Pedersen for her valuable input at the start of the project. Special thanks go to my collaborators Rob King and Ken Leung who generously shared their vast knowledge and to Jim Munroe, Paul Hong, Michael Cho, Edward Wilkinson-Latham and Joe Tabah for their enthusiasm and creativity. Finally, I am forever grateful to my wife Patricia Pasten for her patience and support through a very challenging but rewarding year. 
TABLE OF CONTENTS

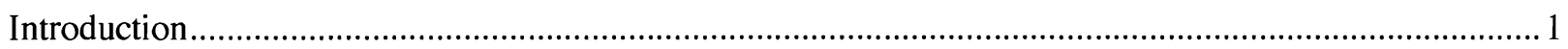

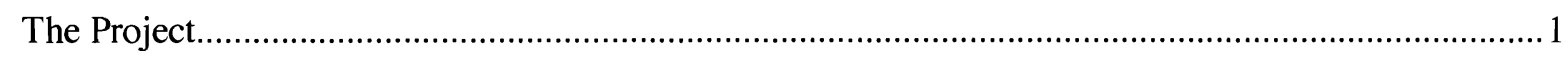

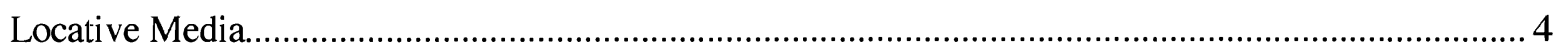

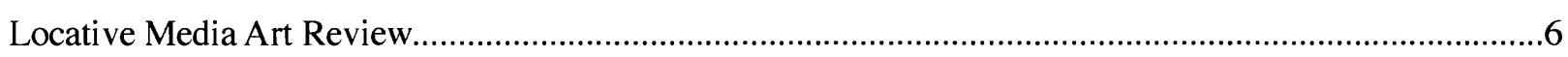

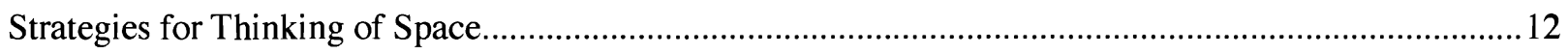

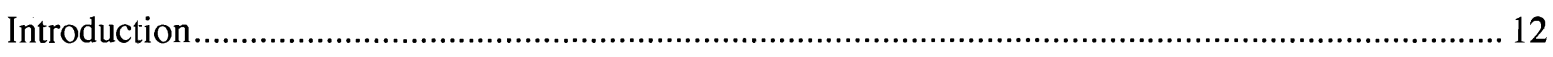

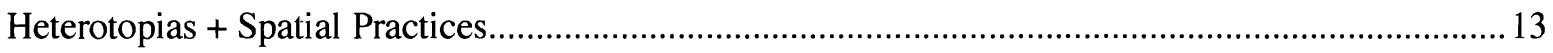

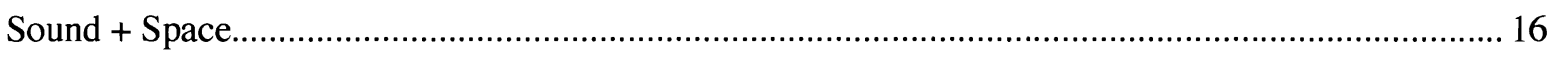

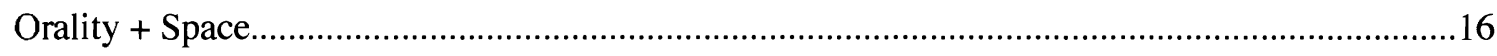

Aurality + Space

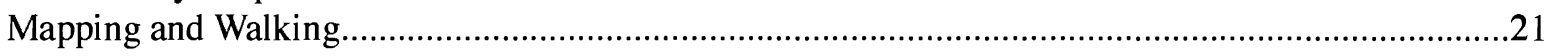

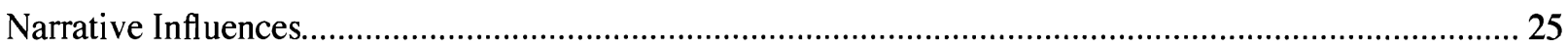

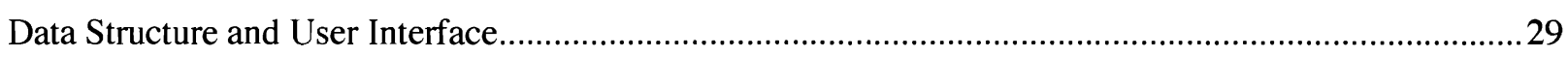

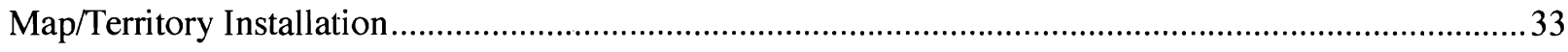

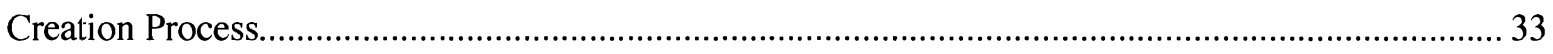

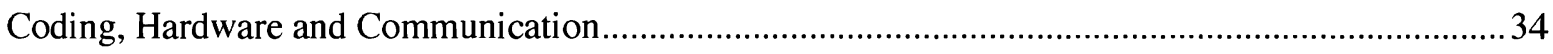

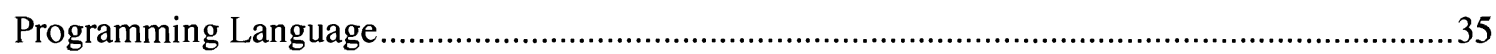

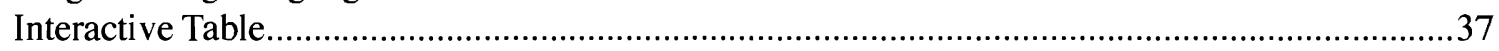

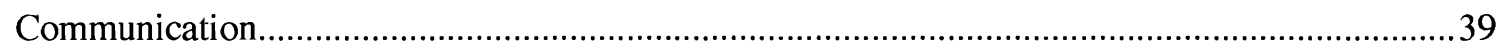

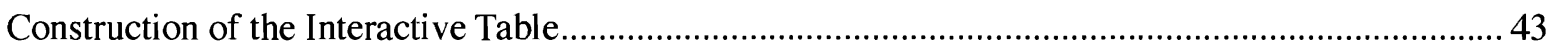

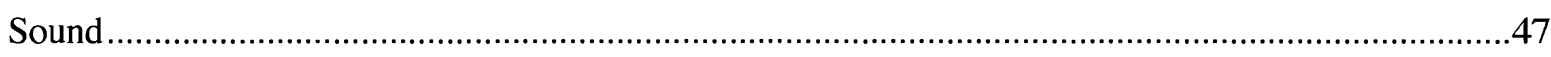

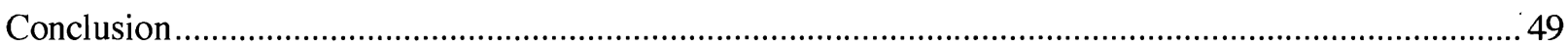




\section{LIST OF FIGURES}

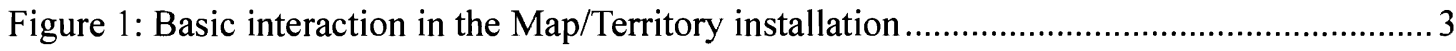

Figure 2: Reactivision Tangible User Interface.............................................................. 38

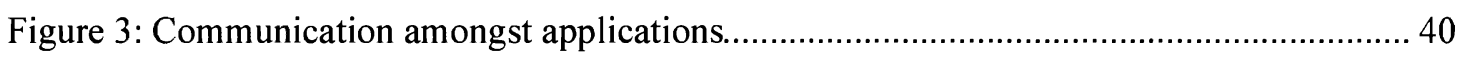

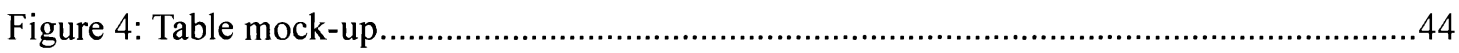

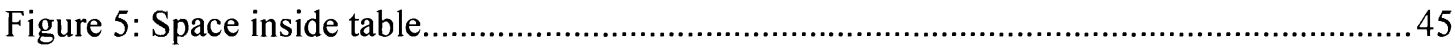

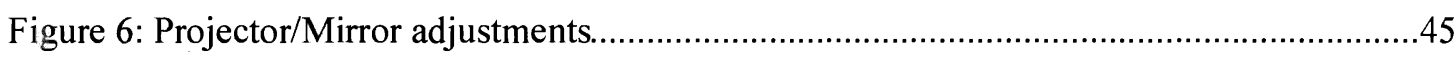

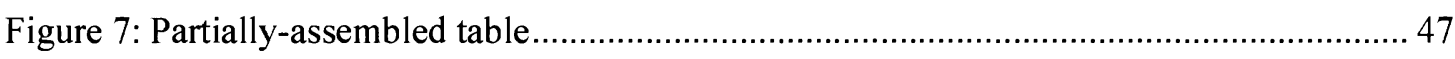

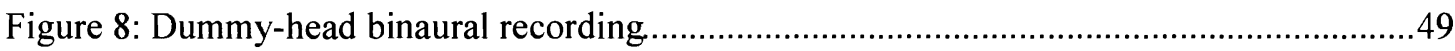




\section{LIST OF APPENDICES}

Appendix A: Stories \& Locations.

.53

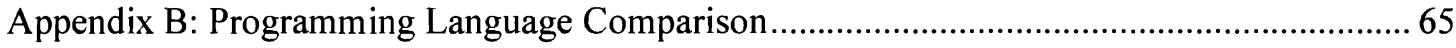

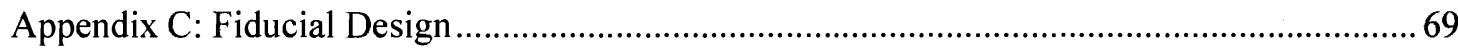

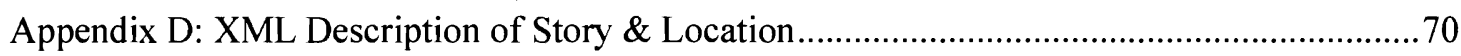

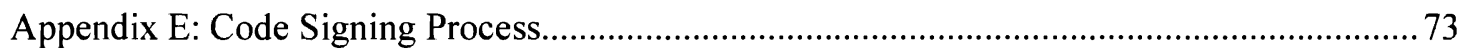




\section{INTRODUCTION}

\section{The Project}

One of the foremost tasks of art has always been the creation of a demand which could be fully satisfied only later. The history of every art form shows critical epochs in which a certain art form aspires to effects which could be fully obtained only with a changed technical standard, that is to say, in a new art form. (Benjamin, 1969, p. 237)

Digital technologies have rendered the city navigable through an overlay of information that adds meaning to physical configurations of space. These are locative and mobile technologies that have afforded users a distinct way of occupying space that allows for simultaneous and active involvement in physical and conceptual (or virtual) space. Devices such as mobile phones, GPS receivers, PDAs as well as personal audio players (Walkman, Discman, iPod) provide users with the ability to overlay a secondary interactive and informational space on top of the physical space they inhabit.

The notion of locative technology allowing simultaneous access to a virtual and physical space borrows from an earlier conception that space is already articulated in two ways: through its literal and practised manifestations. That is to say, space is defined physically in the streets, parks, and buildings but it is also defined through the movement of bodies through these structures and the social practices that are performed in physical space - what we do creates meaning for that space.

Space is therefore doubled or more accurately multiplied by the way we use and imagine it. By creating an imaginary space on top of a physical space an alternative to the established ordering of space is made possible. Locative technology provides a unique strategy for accessing these imaginary spaces by connecting users through the network and by giving voice to hidden local histories or alternative visions of the city.

This report documents the creation of the "Walking the Map \& Tracing the Territory" locative new media installation - an installation that engages various forms of articulating space at the Queen Street and Ossington Avenue intersection in Toronto. Taking Korzybski's (1958) famous observation that "a map is not the territory" as a point of departure this installation attempts to show how our understanding of space is shaped through experience and representation as mediated through interactive and locative media.

"Walking the Map \& Tracing the Territory", referred to in this report as the Map/Territory project, exists at the intersection of various lines of theoretical writings, research and art practice. First, it is an exploration of the way we represent and experience space, visually, aurally and physically. Our current technological context presents us with various tools and strategies for both these spatial activities which in turn allow for greater agency and entanglement, in other words, a greater ability to participate in a 
shared representation and practice of space as well as a greater visibility and implication in a network that is not under our individual control. This aspect works in tandem with a further consideration for the properties of sound and how this sense, contrary to interactive media's overemphasis on vision, can be used to create virtual space. Second, this project is an exploration of the way that narratives and systems are combined in interactive experiences and how our expectations of linear storytelling are challenged by treating stories as raw information and arranging it in accordance to the logic of query and database.

At its most basic level the installation consists of two main components: one seen in the gallery and one heard while walking in the neighbourhood. Users will find installed in the gallery an interactive map table that lets users view a digital display of the surrounding neighbourhood. Users are encouraged to stay in the gallery and view the display and/or borrow one of two mobile devices (and headphones) and begin a walk outside. The connection between the two components lies in how the map in the gallery determines what is heard out on the street (by the users with the mobile devices) and how it records and plots in realtime the paths taken by walkers. Using small objects users in the gallery can place various collections of narrated stories on the map which immediately become available to the users walking on the street. The stories are arranged into 5 categories ("This Space and Other Places", "Looking", "Connections", "Symbols" and "Time") each represented by a small object. Each category contains approximately 5 self-contained audio-base stories each running between 1 minute and 5 minutes. The story themes range from reconstructed memories to fictions created around a specific feature of the neighbourhood to deconstructions of networked experience itself. (See Appendix A for a selection of story scripts) The stories placed on the map directly correspond to places in the neighbourhood therefore users walking on the street must find the stories using audio cues and a small map on their device. (See Figure 1 for basic illustration of the interaction)

The goal is to create an interactive experience that on the one hand illustrates the ways maps inherently privilege certain aspects of space through visual representation and that on the other hand provokes an embodied apprehension of the way we understand space through simultaneously walking a physical space and navigating a virtual space. What will also hopefully become apparent through the experience is the comparison of bifurcating travel lines and narrative lines made possible through locative media. The lines on the map are at once the accumulated history of past walks and the realtime display of the current walker. This map view is manipulatable through still other objects on the table that allow the view to be changed and reveal additional visualizations of timelines and data.

Finally, the Map/Territory installation is a creative project where as an artist I have written, recorded, edited, designed, programmed, built and collaborated with others to bring to completion an interactive work that engages the theoretical issues dealing with the articulation of space. 


\section{Locative Media}

Various terms are currently used in the attempt to specifically describe a space mediated through new media objects, networks and practices. If we are to understand what is meant by locative media we need also to understand other terms and concepts with which it overlaps or from which it borrows. Spatiality, reality/virtuality, visuality/aurality/physicality all intersect in the field of locative media. This report will expand on these concepts but briefly we can understand that: spatiality considers the knowledge of, representation of and movement in space; reality and virtuality represent the contested notion that there is an definable opposition between material existence and imaginary existence; and visuality/aurality/physicality identifies the senses with which we gain an embodied knowledge of our body in relation to our surroundings.

These concepts all hinge on human perception that is increasingly mediated through various assemblages of technology. For instance, virtual reality (VR) refers to the creation of a purely digital space that encourages the user to forget his/her physical body and inhabit a world described in visual terms (aural and haptic senses are also used but to a much lesser extent). Augmented reality (AR) refers to the enhancement of physical space through the overlaying of information or limited virtualization of physical objects. The user in this space interacts with objects and screens that present a digitally connected reality (Bolter \& Grusin, 2000).

Research in virtual reality and augmented reality have largely focused on experiences that keep the user relatively immobile, or at the very least moving in a small room, and looking through an apparatus that surrounds the field of vision with either completely digital imagery or an overlay of digital information onto physical objects. Not unlike Plato's analogy of the cave, these users are bound to a restricted physical space while their ocular senses are fed reflections of another space.

The disembodiment of the user that is encouraged in these kinds of experiences is reversed in work of ubiquitous computing (Ubicomp) and locative media. Instead, embodied knowledge - the apprehension of reality through the body and its various senses - is exploited as a main strategy for creating interactive experiences. Borrowing from Paul Milgram, Galloway places these media (AR, VR, ubicomp) along a continuum between reality and virtuality and considers any media that fits between these two poles to constitute mixed-reality and create a hybrid environment (Galloway, 2004b).

Also positioned along this continuum is locative media. This recently coined term refers to any combination of wearable, context-aware, pervasive or ubicomp technologies (Galloway \& Ward, 2006). The National Institute for Standards and Technology defines pervasive computing as being "numerous, casually accessible, often invisible computing devices, frequently mobile or embedded in the environment, connected to an increasingly ubiquitous network structure" (McCullough, 2004, p. 7). Context-aware refers to mobile technology that is able to "read" its context through the use of an ad hoc network created with other devices existing in the field. This requires specific technology to locate the 
user (or device's) position and the proximity to other devices. For instance, Global Positioning System (GPS) receivers can be used to acquire longitude, latitude, altitude and heading information and Bluetooth devices can be used to create wireless network connections with other Bluetooth devices. The assembly of these locative technologies amount to a medium that can create a hybrid environment that orchestrates the communication between digital and physical objects.

For the purposes of this report, it is also useful to include personal audio players and voice-only cell phones. Current technologies rely increasingly on visual information, GPS, mapping and a network connection to mediate space but the basic reliance on aural information to navigate physical space has not disappeared. Furthermore, with regard to the Map/Territory project, examining the tension between oral/ aural space and physical space is important for understanding the multiple layers of mediation that newer technologies offer. As we will see later on in this report, orality and aurality must also be considered in conjunction with visuality in the context of locative experiences - how things are voiced and heard as well as how things are visualized.

Following Russell (2004), I will use the term locative media to suggest communication technologies that mediate social and spatial relations and specifically how these technologies allow a user to experience an overlay of information on his/her physical space and create, using Galloway's definition, a hybrid environment that is both virtual and real. 


\section{LOCATIVE MEDIA ART REVIEW}

Locative media art, although a relatively new development, is a genre in which artists deal with themes and issues that are both specific to the medium and resonant with a wider set of issues. The technology used in locative media can create genuinely novel experiences but they invariable link to recurring themes in art. Not unlike other art practices locative media engages issues of place, history and narrative and how they intertwine with issues of representation, technology and power. Before and during the development of the Map/Territory project the works of various artist were reviewed in order to contextualize the installation within a larger locative media art context and understand how these issues are engaged.

Place is the starting point for most locative projects since it is here that a user locates and moves his/her body. These works often respond to the place's physical aspects as well as its history. Janet Cardiff's audio-walk "Her Long Black Hair" takes the user through a specific route through Central Park in New York City. Cardiff's narration weaves observations of the landscape, history and fiction with the trajectory through the route. German artist collective, Rimini Protokoll created a phone-theatre project titled "Call Cutta" where users in Berlin followed an audio narrative delivered via cellphone by a callcentre worker in India. In this locative experience, the audience-walker ambled around the Kreuzberg district in the city of Berlin while s/he was directed by a voice on the phone to turn left, go forward, or to listen to an anecdote.

In another example, the Mobile Digital Commons Network (MDCN) project "The Haunting" located an interactive game on Mont Royal in Montreal and made specific use of its features to develop the narrative. The large cemetery in the park, the various trails, underpasses and the local history all contributed to the creation of a story that mixed fact and fiction. The location also set the mood for the experience. Having taken place at dusk, the park became much darker and sinister looking. Sound cues became more effective. Less people on the trails kept the illusion of the game more intact.

Inevitably, any investigation of place evokes history and memory. History, in locative media projects, tends to be treated in the form of localized events with some tying to larger socio-political narratives. The "Call Cutta" walk, for instance, presented story fragments about Subhas Chandra Bose presented to the walker through live narration delivered by phone and photography planted in the environment. Bose, a key player in the Indian independence movement, also has a history in Berlin. In an attempt to garner support for a war against the British, Bose appealed to Hitler for military and communications support. Allegedly, Bose had set up his office and the radio station "Free India" in the Kreuzberg area. Walking, listening and interacting in Calcultta allowed users to investigate place and history and reproduce a narrative that unearthed a hidden history and disrupted the quiet memory of this Berlin suburb. 
Working through official history and local memory raises issues of access and participation. Despite the perennial promise of communication technology democratizing the production and reception of information access to technology continues to be uneven. Many locative projects have taken this concern as a starting point for the development of the work and have built in specific processes that acknowledge or even attempt to repair problems of accessibility. For instance, "Murmur", a project created in Toronto, by Gabe Sawhney, Shawn Micallef and James Roussel, used the basic functionality of cellphones to disseminate local stories. By affixing a sign to a specific location Murmur encouraged passers-by to call the number advertised to hear a variety of stories. By creating an interaction that required only the most basic mobile phone the project was made accessible to a wide range of users. Mark Shepard's project, Tactical Sound Garden (TSC), on the other hand, used more specialized equipment but attempted to create a similar dynamic. TSC, an open-source sound collaboration platform, allowed users to upload and map onto a virtual map whatever soundscapes they believed fit a particular location. Maps of San Diego, Zurich or Belo Horizonte could be accessed through a web-browser and played in situ using a handheld computer and WiFi connection. Shepard's aim was to show how citizens could, using available technology, participate in the representation of public space.

Alternatively, "Call Cutta" created a participatory work through the involvement of performers and users rather than the documentation, storage and dissemination of user-created content. Playing on the authoritative narration of local and international history the artists intentionally left spaces in the script that allowed the performer (the Indian call-centre worker) to invent stories, embellish the narrative and chat with the audience-walker - at once subverting official history and adding an authentic first-person account. For example, at a certain point in the interaction a narrator asked a listener, "Have you ever lied on the phone or used a false name?" (Phalnikar, 2005) inviting the audience to create a more intimate link with the call-centre worker. In other instances, narrators retold specific details of memories they had of their own city at times coinciding with the urban space the walker was experiencing.

In an interview with the artist collective the directors pointed out that the call-centre worker's script was only a guide that helped them navigate the audience-walker through the streets of Berlin (Malzacher, 2005). It is important to note that the performers had never visited Berlin but nonetheless provided an authoritative account of the everyday history of the urban space of Kreuzberg. Conversely, the participants, ostensibly Berliners, knew the area quite well. This tension invited a reflection of what constitutes outsider knowledge and native knowledge.

Participation is also created through a user's movement through a locative installation. Narrative can unfold dynamically through the path that a user takes and therefore create a unique experience. Adriene Jenik, in collaboration with the University of California San Diego, created SpecFlic, a multiscreen, performance-based media event held in downtown San Diego that employed walking as a way of creating non-linear narratives. By using an overarching narrative that borrowed from science fiction literature and cinema Jenik created a distributed outdoor network of performances and audio/visual 
transmissions that used multiple screens and devices as potential storytelling tools for public and private consumption. Users walked throughout various nodes in the installation tying together fragments that amount to subjectively constructed narratives.

Locative projects have also taken the shape of games to exploit the participatory potential of mobile technology. U.K.-based artist collective and interactive design studio, Blast Theory, in collaboration with the Mixed Reality Lab at the University of Nottingham, developed "Uncle Roy All Around You" a roleplaying game that used locative media as its central technology. The goal of the game was to find Uncle Roy within the allotted 60 minutes. The street player was set loose on the streets of London with a handheld device showing a map and the virtual positions of online players. Aided through a series of messages containing clues players attempted to find Uncle Roy while online players either helped or hindered their progress. In the case of MDCN's "The Haunting" GPS tracking, Bluetooth communication and audio-visual media were used to create a game experience where players assumed the role of ghosthunters. Players collected ghosts by following clues and using a map showing their position relative to that of the ghosts. In both these examples the narrative was the game logic and premise which players used to "win" the game.

Unlike projects in virtual reality and augmented reality, locative media projects tend to deemphasize total immersion in an interface. Despite this trend sound is often used as a relatively low-tech method of placing the user in a virtual space. Shepard's TSC, for instance, encouraged users to upload and experience pre-recorded soundscapes that either complemented or challenged the existing soundscape. Essentially, users wearing headphones clicked on a hotspot on a digital map to play sound files.

Cardiff's "Her Long Black Hair", using far more low-tech methods, had the user simply borrow an audio player and headphones from a kiosk and start walking. Cardiff used binaural sound recording techniques to reproduce a three-dimensional effect of sound placement accomplished by placing one omnidirectional microphone on either side of a mannequin's head to record the left and right sides the end-user's experience. To record the soundscape Cardiff walked through the path that would ultimately be followed by the user. In effect, the user would be listening to a soundscape from approximately the same physical location but from several months before. Layered on top of this sound-bed, Cardiff's voice instructs the user to walk left or walk right, to stop and take out a photograph. At times, during the narration, she reflects upon a certain memory or feeling associated with a location and at others she provides factual information. Both Cardiff's audio-walk and Shepard's TSC present an immersive sound experience that comes in and out of sync with the sound emanating from the actual environment and therefore create a tangible tension between fiction and fact.

How we see in a locative project is also crucial to the experience. It plays a role in evoking the history of the location as well as supplementing the narrative. Cardiff, for instance, to create an oscillating sensation between present and past used printed photographs of events that took place in the location or views that looked familiar from the current position of the walker. Rimini Protokoll planted photographs 
in the surrounding neighbourhood to be found, inspected and placed back by the users. MDCN's "The Haunting" used animations and movie clips to reinforce the narrative in the game.

Visualizing the area and the location of the user(s) is also becoming more common as the technology becomes more accessible. The MDCN project used consumer-grade GPS receivers to find the location of the players in order to plot their position on a map and display their proximity to ghosts in the area. Dutch artist collective, de Waag Society, used GPS-tracking as the central focus of their installation "Amsterdam Realtime". Participants were asked to travel around Amsterdam wearing a GPS unit which transmitted his/her current location through GPRS (cellphone internet connection) to a server. The information from various participants was mapped in realtime on a high-resolution projection in the gallery. Without any cartographic data indicating the city itself the paths taken by the participants began to illuminate the various streets and spaces in the city. Although the collective set out to highlight the surveillance potential of GPS and cellphone equipment they also set out to make visible the various ways that individuals read an urban space through their very unique and meaningful journeys.

Other artists work exclusively on the forms that can be created through GPS technology. "GPS Drawing", initiated by Hugh Pryor and Jeremy Wood, is a gallery that showcases users' work. Like "Amsterdam Realtime" the drawings are a result from the movement of people negotiating the physical configuration of urban space or, in the case of "GPS Drawing", often rural space.

Apart from place, movement or specifically walking is perhaps the second most important element in a locative media project. Ironically, it is perhaps also the least technology-dependent aspect. Many artists have engaged walking as a core element that creates the form in their work. As noted above, it can be tracked to create visual forms, used as an ordering principle for the presentation of a dynamicallycreated narrative or used as the motion that propels a linear narrative in an audio-walk. But without GPS receivers, databases, mobile devices or even audio players a locative project must rely on the basic elements in walking to create an experience.

Before "locative media" was coined as term to describe spatial practices mediated by technology the Situationists, led by Guy Debord, devised a way of creating experiences through walking that defied . the normative structure of urban space. Through the dérive walkers, let go of common assumptions that shaped their access to space. Instead, they followed a smell or a colour or any criteria that allowed them (usually a group) to travel across the usual routes defined by neighbourhoods, streets and city borders. In a similar and much more recent gesture, Dutch artist collective Social Fiction, devised "Algorithmic Walking" that used a series of generic instructions (e.g. walk two blocks forward, turn right 90 degrees, walk three blocks forward, etc.) to create what they term generative walks. Making the ordering principle of space arbitrary by forcing the users to follow an algorithm allowed them to ignore their preconceived notions or desires thus letting the neighbourhood acquire, for them, a new significance and level of detail.

Walking can also be used as a performance and intervention in a space. Belgian artist, Frances Alÿs, in various works traced his path through the streets of Mexico using objects that would be difficult to put 
in the category of "technology". In one work, he used a melting block of ice to mark his path. In another he used a string of yarn coming from a quickly-disappearing sweater to show traces of his movement. And in still another, he used a leaking can of paint to literally mark the path on the ground he covered. A basic notion that connects all these works and other locative works is the acknowledgement that walking itself is an act of creation that affects the walker as well as the environment (physically or virtually).

Although there are many artists that engage in the various aspects of locative media, the above artists mark out a conceptual space that touches upon the most important aspects for the development of the Map/Territory project. First, the forward motion of walking and narrative creates an almost natural connection between both activities. As exemplified in Cardiff's audio-walks, the rhythm of walking reinforces the experience of the storytelling. This mutual relationship is further enhanced through sound which allows for the simultaneous experience of physical space and virtual space. Also evidenced in Shepard's Tactical Sound Project, this technique has particularly influenced the way the stories in the Map/Territory project have been recorded, edited and ultimately delivered. Sound has therefore become a central method in the project to represent space.

Second, the mapping of paths and the experiencing of a territory provide an artistically productive tension between the representation and the thing itself. Walking, as illustrated by Debord's derive, allows for a knowledge of space to be gained through a variety of bodily senses. Mapping, on the other hand, mostly makes use of the visual sense to understand a space. In the Map/Territory project this opposition has been used to present two approaches to the same space - letting the user bridge the differences. Furthermore, situated between representation and experience, the trace as the product of walking manifested as a drawing, is used to help bridge these two aspects.

And finally, the amalgamation of technological tools that makes a locative experience of a place possible is itself a space that deserves investigation. Since many of the artists mentioned above have used available consumer-grade and/or open-source technologies to realize their projects it was conceivable that an installation could be built with limited available resources. Open-source programming and hacking were therefore adopted as key methods for developing the Map/Territory project. As demonstrated in MDCN's "The Haunting" and de Waag Society's "Amsterdam Realtime" cell networks, GPS units and open-source programming could be combined by artists to create locative experiences. The development of the project would also provide an opportunity to understand how these technologies interconnect.

The Map/Territory project therefore builds upon these three aspects by tracing movement and mapping narrative through an interactive audio and visual experience. The project spans the distance between the simplicity of tracing, walking and talking and the complexity of networked communication, protocols, and programming. The purpose of the project is to raise issues related to our experience of these two extremes. Since some of the most successful projects have actively reminded the users of the constructedness of the experience and its mediation through technology (cellphone, GPS coordinates or photographs and $\mathrm{CD}$ players) the Map/Territory project also endeavours to reveal its own construction. In 
this way, users will potentially reflect on their own reading of the construction of representation and experience of space. 


\section{STRATEGIES FOR THINKING OF SPACE}

\section{Introduction}

Locative media are by design intended to engage people and place, thus this agenda overlaps with research in human geography and the analysis of spatial practices - research that is useful in conceptualizing strategies as well as tactics for creating locative interactive installations. How space is created and represented by theorists, designers/planners and users is therefore a central concern. Theorists, for instance, have attempted to conceive of space in such a way that it may accurately reflect reality. Users have created space by everyday living, working, playing and moving in it. Designers, on the other hand, have represented and created space through its visual or aural virtualization. Rather than operating separately these practices and discourses have interacted, influenced each other and changed within their social and technological contexts.

Space has been traditionally described as absolute space that conforms to Euclidean geometry and where a point, vector or shape can be described in terms of $x, y, z$ (Hubbard, 2002, p. 13). This conception of space is the foundation for an approach that defines reality in empirical and positivist terms. Moreover, it is deemed necessary for the visual representation of nature, the quantification of human movement and its objective analysis. It also makes the visualization and manipulation of data on a map possible. Without the reduction of space to its mathematical representation interactive mapping systems could not be created, nor global satellite positioning be used, nor the analysis of quantitative location-based data be processed.

The power of applying empirical and objectivist methods to space has meant that this approach has tended to dominate research in spatial issues. This approach was criticized for neglecting the relational aspect of space where humans give meaning to space through human action (Hubbard, 2002, p. 13). The result of this polemic has been an opposition of material versus humanistic concerns - a dualism that is, in turn, criticized for not acknowledging their inherent connection.

To more accurately describe the tension between material and humanistic issues Henri Lefebvre split space into the products of three levels of human activity: spatial practice, spatial representation and representational space. These levels roughly break down into the concerns of the daily routines, movements and practices of people, the planning and conception of space by social engineers, and the symbolic construction of space by artists, philosophers and citizens (Lefebvre, 1991, p. 38).

Edward Soja expands on Lefebvre's triad of spatiality by insisting that when considering space and human activity dualisms such as objectivity and subjectivity, real and imagined, space and place tend to ignore other important aspects (Cresswell, 2004, p. 38). He identifies two kinds of space, firstspace and secondspace, empirical and imagined, respectively. According to Soja, these represent the dualistic mode of thinking and necessitate a more nuanced conception that incorporates the lived and imagined as an 
inseparable process of production - a thirdspace.

It is important, with regard to how the Map/Territory project deals with space, to note how Michel de Certeau uses the terms space and place. Place, according to de Certeau, refers to the pre-existing structure in which people move and thus create a space - in other words social spatial practice loads places with meaning thus creating a space that hovers above it (de Certeau, 1984). His definitions imply that place is essentially empty until someone negotiates its physical presence. This puts the emphasis back on the citizen to create meaning through his/her movement rather than an hegemonic ordering of space by authoritative bodies such as governments and corporations. It is through the everyday spatial practices of citizens that the relationship of space to place is articulated. Place therefore can mean the Queen \& Ossington neighbourhood and space can mean the act of walking in the neighbourhood according to a daily itinerary or according to a special event such as the experience of a locative media installation.

Place and space also outline what is visible and invisible. Experience and walking comprise a "poetic and mythical experience of space" that sharply contrasts the "'geometrical' or 'geographical' space of visual, panoptic, or theoretical constructions" (de Certeau, 1984, p. 93). As mentioned above the empirical view of space is contrasted with the relational view of space but rather than a mere opposition, de Certeau posits that practice resists representation.

The relationship between the visualization and the experience of space is therefore a central tension in the Map/Territory project and is represented by interaction between mapper and walker, respectively. In the following sections this relationship between spatial representation and spatial practice is investigated by looking at how social/imaginary space can coexist with physical space, how the experience of space can be enhanced through sound, and how specific biases of mapping and walking affect the articulation of space.

\section{Heterotopias + Spatial Practices}

The capacity of portable sound to create a space that hovers above the physical space of a listener effectively doubles space. To understand the effect of this process Michel Foucault's notion of heterotopia and Michel de Certeau's spatial practices provide useful ways of thinking through the doubling or overlapping of coexisting spaces that occurs in the experience of walking and listening as mediated through locative technology.

De Certeau, in "The Practice of Everyday Life", conceived of walking as writing with its attendant styles and rhetoric (1984, p. 131) (de Certeau, 1984). A sentence is composed, de Certeau explained, as a walker passes through various named streets on his way to his mother's house. Essentially, de Certeau posited that through the navigation of the city and its official terms of orientation (e.g. street names, neighbourhoods, plazas) the walker writes over a personal narrative. A walker negotiates a path through the pre-established structure of the city and through his/her use these places' names slowly loose their 
historical referent and gain an alternative meaning.

Place is the relatively stable location that is negotiated through walking and where space can be articulated (de Certeau, 1984, p. 117). In other words, there can be only one physical place but many spaces that are determined by how people use that place. De Certeau saw this as an important strategy of re-appropriation - the counter-hegemonic potential of everyday practice by the citizens in a city. Place, through walking it, is therefore re-articulated space with alternative meaning.

Various locative projects have as their goal the disruption of the official ordering of a space. The act of virtually placing sound, narratives, or images in a place allows citizens to add their memories and fictions to a place for others to hear or view. Janet Cardiff and Rimini Protokoll, for example, both maintained artistic control by writing the new stories that inhabit that space. On the other hand, projects such as Murmur and Tactical Sound Garden, encouraged the input of participants in the rewriting of space.

Through the act of walking the user possesses and occupies the land s/he traverses - a way of owning the place that is a very different strategy than surveying that place. To illustrate this point, de Certeau observed that the view from the top of the World Trade Center offers a perspective that makes the viewer a voyeur that distances him/her from the rabble and flow of the city below. Marla Carlson, explained that de Certeau found this omniscient and god-like view lead to a misunderstanding and misinterpretation of the traces of city dwellers as patterns rather than noticing "how they rewrite the city as they walk its streets" (Carlson, 2006, p. 395).

These two distinct modes of apprehending space have correlates in the way we remember space as well. De Certeau observed that people recall space using configurations such as maps and tours. Research psychologists have also documented this tendency of humans to recall space through a collage of surveys (maps) and routes (tours) (Tversky, 1993). Maps lay out a plane projection that totalize a view of space. While tours are operational in the sense that they describe space through a series of steps (de Certeau, 1984, p. 119).

Mobility finds a common place in spatial practice and the flow of narrative. Metaphorically, there is a connection between storytelling and walking which links the acts of covering a conceptual space to travelling a physical space as reiterated by de Certeau's comment, "What the map cuts up, the story cuts across. In Greek, narration is called diegesis: it establishes an itinerary (it guides) and it passes through (it transgresses)" (as quoted in Conley, 2002, p. 491). Mobility (specifically walking), is therefore the integral operation that doubles space - creating narrative on top of place.

Foucault described a heterotopia as a space, in contrast to utopia, that exists through a practice that counters the physical or official place (as quoted in Foucault, 2005, p. 491). Much like de Certeau's notion of space, heterotopias exist through their enactment or performance and in this way they exist as multiple spaces in one place. The distinction lies in Foucault's extension of his concept to include 
heterochrony. Various pasts and senses of time can also occupy a space much like a cemetery holds various lifetimes (those of past inhabitants and the visitors). This notion also acknowledges the coexistence of local, subaltern histories and dominant histories.

The potential for re-inscription of alternate spaces and times lies in the failure of design to impose an absolute mode of use. The design of spaces, Foucault reminds us, only have a supporting function in the oppression or liberty of people and the practice of liberty determines to a greater extent the relations between people (Foucault, 2005). In this regard, de Certeau's spatial practices exploit the weaknesses of urban planning to create other meanings. Examples of this abound in locative media projects. For instance, projects such as "The Haunting" by MDCN, "Her Long Black Hair" by Cardiff and "Call Cutta" by Rimini Protokoll, exploit these weakness and create meaning through the walker's experience of the installation and through the unearthing of multiple histories.

What results is a virtual space that is visualized and experienced, for instance, in the Map/Territory project through the placement of narratives on a digital map and the hearing of stories in the locations. Accumulatively, the virtual space is imagined, seen and experienced - a potentially powerful process as Rob Shields states,

The virtual troubles any simple negation because it introduces multiplicity into the otherwise fixed category of the real. As such the tangible, actually real phenomenon ceases to be the sole, hegemonic examples of reality. (Shields as quoted in Mackenzie, 2006, p. 93).

Virtuality works in tandem with Foucault's notion of heterotopia and heterochrony. For Foucault this virtual space, like a mirror, represents non-place that is at once real and imagined and which more importantly works to reconstitute the self (Foucault, 2005). A dialectical relationship between imagining a place and experiencing part of it is exploited in many locative projects by presenting information that is constructed on top of the physical place it is referencing. A notion that is also echoed by Benedict Anderson (1991) who argues that imagining is a powerful practice that posits an idea of a nation (or place) but which also transforms the real according to the idea which in turn manifests a physical form that informs the imagination.

Interestingly, Carlson's (2006) analysis of Cardiff's work pointed out that the audio-walk creates a sensation of here and not-here out of a real and non-real experience and, using Foucault's heterochronical logic, now and then. In this regard, audio has the unique capacity of layering levels of reality both historical and present. Cardiff, describing the experience she wants to create, states that "our minds are constantly flipping back and forth, in and out of reality" (as quoted in Carlson, 2006, p. 404). At one point in the audio-walk, Cardiff says, "there are so many layers in front of my eyes" (Cardiff, 2004). The place itself that the user is experiencing has multiple versions laid on top. The sensorial perception of the environment by the listener/walker has not changed yet it is his/her schema of it that has changed 
resulting in the multiple meaningful layers processed by him/her.

The ambiguity of reality, time and place is further emphasized in the audio-walk by Cardiff's narration: "It's loud here, isn't it?" (Cardiff, 2004) In the experience it is uncertain whether she is talking about the time and space that is represented in the recording or the present time and space the user presently occupies, or both. Similarly, in the Map/Territory project various recorded sound cues trigger a sensation of witnessing an historical event in the present.

$$
\text { Sound }+ \text { Space }
$$

What? What are you talking about? The Sony Walkman has done more to change human perception than any virtual reality gadget. I can't remember any technological experience since that was quite so wonderful as being able to take music and move it through landscape and architecture. (William Gibson as quoted in Bull, 2004, p. 109)

Sound and voice, aural and oral information are used in the Map/Territory project to organize space. Sound can be used to separate out and create a space by drowning out ambient sound with a new sound (e.g. by using headphones) (Bull, 2004). In addition three-dimensional, stereo, and binaural sound can create the sensation of perceiving sound events from specific positions in space. Our capacity to apprehend aural data and visual data simultaneously is also used as a central strategy. Unlike, for instance, compositions of textual and pictorial information which are difficult to read simultaneously — one tends to dominate the other forcing the viewer to bounce between one element and another (Arnheim, 1969, p. 74) - sound can coexist with an image as sensory input. This principle is evidenced in the filmic convention that uses a soundtrack to convey emotional cues for the understanding of visual data, e.g. a wide-angle establishing shot of a landscape is accompanied by a long, swelling symphonic movement to evoke the notion of epic.

Oral information plays a specific role in the interaction by reproducing human voices which narrate various stories through out a walk. Not unlike Cardiff's "Her Long Black Hair" and Rimini Protokoll's "Call Cutta" the Map/Territory project uses oral storytelling to present a narrative to engage the listener and to occupy the space walked. The following two sections explore the role of orality and aurality in a process of embodied creation of space.

Orality + Space

Space is created by a two-fold effect of orality: participation and performance. First, orality invokes a relationship between speaker and listener thus creating a social space through the participation between 
these two roles. Second, de Certeau's spatial concept of the tour which represents how a user recreates space through the recall of a path-like structure also puts an emphasis on performance. Movement, whether imagined or physical, recreates space. The constantly changing and temporally-based forward motion, precisely that fleeting property that makes it difficult to visually represent, is also the structure of the oral narrative.

It is useful to look at Walter Ong's work on literacy and orality to understand the way that speaking and listening (the predominant activity of the Map/Territory walker) functions differently from seeing and reading (the predominant activity of the Map/Territory mapper). Ong identified a shift from hearingdominance to sight-dominance in Western civilization that gradually takes place from a focus on oral rhetoric to writing to printed text. He explained that orality involves the utterance of words and thus constitutes a specific mode of communication that is both related to and distinct from chirographic (handwritten) or printed text. While written text still has the linear vestiges of spoken words - a sequential flow of words - the printed text largely erases these links by making reading a function of identifying text laid out in two-dimensional space (Ong, 2002, p. 118). A broken link that is also echoed by Foucault's assertion that the shift to writing from orality severed the link between names and things (Foucault, 1973).

It is well understood that communication technology affects the form and content of the message transmitted as well as the consciousness of its users (Ong, 2002; McLuhan \& Fiore, 1967; Innis, Godfrey, \& Innis, 1986). Oral storytelling, although not a communication technology like writing, also manifests characteristics particular to its mode of transmission. Empirical studies have shown quantifiable effects of the mode of communication on the form of the message. Bruce Rosenberg observed, for instance, that the form of the narrative is affected by the way it will be used. He found that if the narrative needs to be memorized, as in oral stories, and the original source is no longer available then its structure will reflect this need for ease of memorization. Conversely, if the original source is continually available, as in recorded text, then the structure will bend to this mode of retrieval (Rosenberg, 1987, p.80).

Repetition, for instance, is used to commit things to memory and is a recurring characteristic of oral narratives (metrical, syntactical, semantic elements). Oral narratives also tend to be simpler in plot and focus on the actions of protagonists. Within written culture, according to Ong, we see more reflexive protagonists, detailed description and more complex plots - two characteristics that are due, in part, to the form of storytelling. Writing allows the author to write alone, to revise text endlessly and to focus on the pacing of a story according to pages and paragraphs. Thus Ong stated that orality tends towards action and print towards description (Ong, 2002, p. 125).

Orality, from its narrative content to its verbal form, therefore constantly entails a performance that is largely defined by the fact that it is time-based, contingent and at times improvised. It is also evanescent and "exists only when it is going out of existence" (Ong, 2002, p. 70). In other words, it has a temporal quality that requires a forward flow for it to exist where the fleeting present is the crucial point 
in the experience/narrative - much like walking.

Furthermore, orality and walking, link performance to context. Orality, according to Ong resists abstraction as evidenced by the fact that "oral cultures tend to use concepts in situational, operational frames of reference that are minimally abstract in the sense that they remain close to the living human lifeworld (Ong, 2002, p. 49). Following de Certeau's notion of the tour, walking and orality constitute a spatial practice - resistant to rationalized accounts and totalized visions of space such as the map. Maps can only represent a tracing of the ephemeral quality of oral narratives and walking result in imagined flows - sequences of events that can never be fully represented in all its complexity (van Loon, 2002).

The production of social space requires a set of individuals to relate to each other. Hearer and speaker, a basic relation in orality, create in their communicative exchange a space. If we use Ong's historical classifications we see that this is a main feature of primary orality that is lessened in subsequent chirographic, typographic and post-typographic periods. The advent of electronic information, what Ong called post-typography, pushes the characteristics of print culture to something once again akin to orality. Ong called this secondary orality recalling the previous period and to signal its hybrid nature. Audio recordings, radio, and television, for instance, all depend on writing in order to communicate orally. But like primary orality, secondary orality creates a sense of group by linking hearer and speaker. But unlike primary orality, secondary orality connects with a vast audience at the expense of physical proximity and interaction (Ong, 2002, p. 134).

The appeal of listening to oral/aural communication is in part this connection to group. Mike Bull, for instance, borrowing from Adorno and Horkheimer, noted that Walkman users (or listeners of recorded sound and music in general) desire to be part of a we-ness (Bull, 2004). Listening to the radio or a performance automatically infers a sense of being part of an audience thus creating a social space while still maintaining a certain degree of solitude.

Telephony also facilitates a social space by fulfilling the expectation of participating in what is happening on the other end. Usually this is most poignant for a important social event like a grandparent's birthday, New Year's Eve, etc. - the desire to take part in a ritual or performance. This is not exclusively a contemporary impulse as Peter Lunenfeld noted that Marcel Proust in 1911 subscribed to Paris' Théâtrephone in order to listen to operas by Wagner and Debussy (Lunenfeld, 2000, p. 73) surely to feel a part of the spectacle.

Social space, constituted by the connection between a listener and group, is imposed on the physical space and the social space that is already in progress in his/her immediate environment. Within the context of mobile communication technology this process is activated wherever the listener/user happens to be. As Adriana de Souza e Silva noted, a doubling or enfolding of space is thus created through the use of a mobile phone. She explained that this occurs in the coexistence of contiguous space and remote space, i.e. when a mobile phone user is walking on the street navigating among other people 
and talking to someone in another city (de Souza e Silva, 2006).

This also ties into the way people connect to a network of people when using cell phones. De Souza e Silva termed this hybrid space as opposed to augmented reality in order to indicate how a social and physical space join to create a third space. Although her focus was mainly on internet-capable mobile devices her observation is relevant to the creation of social space between a mobile user and his/her contact on the other end.

In the Map/Territory project this relationship is formed through the interaction between the walker and the mapper. In this case it takes the implied hybrid space of mobile connectedness among peers and distorts it to raise issues of control, visualization and experience.

Aurality + Space

As discussed above, on a basic level, locative media can be understood as the use of a media technology to relate to a physical space. A powerful way of relating the two is through the practice of walking and speaking/hearing. How a user relates to space can be shaped through mobile aural strategies - sound, as a sensory perception, can be used to not just shape space but create or dominate it (Bull, 2004).

Recent research revealed that portable audio player (Walkman) users use sound and music to reappropriate the space they inhabit. By playing music of their choice they imposed a meaningful and personalized soundscape on their environments thus colonizing and collapsing the distance between the outside and themselves or re-inscribing habitable space (Bull, 2004, p. 113).

The layering of a privatized soundscape (through earphones) on a physical landscape can also be interpreted as an act of rebellion against the imposed space or of domination over a space (Bull, 2004, p. 108). For example, users on public transit tend to employ this strategy to create a separation between themselves and the crowd of people around them. Bull explains:

These technologies of "accompanied solitude" appear successfully to deliver a desirable and intoxicating mixture of noise, proximity, and privacy for users whilst on the move. The use of these sound technologies informs us about how users attempt to "inhabit" the spaces of the city they move through. Mobile privatization is about the desire for proximity, for a mediated presence that shrinks space into something manageable and habitable. Sound, more than any other sense appears to perform a largely "utopian" function in this desire for proximity and connectedness. Mediated sound reproduction enables consumers to create intimate, manageable, and aestheticized spaces in which they are increasingly able to, and desire to, live. As consumers increasingly inhabit "mediasaturated" spaces of intimacy, so they increasingly desire to make the public spaces passed through mimic their desires. (Bull, 2004, p. 106) 
Bull's account describes a mainly defensive strategy but these behaviours and methods of use are nevertheless now commonplace with personal audio equipment in urban environments. When this mode of listening is combined with walking the effect described by Bull is amplified to encompass a physical space as well as the privatized space in the listener's control. The listener is always at the centre of the sound experience and thus the centre of his/her overlaid space.

Listening and seeing (while walking) work through two principles identified by Ong: interiority and exteriority. According to Ong, interiority is emphasized in sound due to the immersive sensation of hearing. Vision, on the other hand, emphasizes exteriority by always establishing a distance between self and the observed. To explain this distinction in historical terms Ong contrasts the tendencies of orally- and visually-dominant cultures. Ancient oral cultures, according to Ong, placed the individual at the centre of the world since auditory sensation is perceived as an effect that surrounds the body (Ong, 2002, p. 72). Visual cultures, especially through the dissemination of maps through print, conceptualized space as a thing placed before the individual and limited only by the width of an individual's peripheral vision.

Interiority, as an effect of sound perception, is heightened with the use of headphones. So much so that the body can feel to disappear from its immediate physical/social context through the experience of immersive sound. As Bull writes, "Walkman users appear to achieve a subjective sense of public invisibility. The users essentially 'disappear' as an interacting subject, withdrawing into their chosen privatized and mobile states" (Bull, 2004, p. 12).

The sense of immersion through audio can be very powerful and seductive but the dematerialization of the body in an aural space can also be pulled back into a connection with the physical context. For instance, to counteract this tendency to disappear in a completely virtual space Cardiff, in her work, insists on participation and walking. She states that "With the audio walks I want people to be inside the film and have the real physical world as the constantly changing visuals of the screen. Every person will have a different experience of the piece depending on what happens around them or where and when they walk. I want the pieces to be disconcerting in several ways, so that the audience can't just forget about their bodies for the duration of their involvement like we do in a film" (as quoted in Egoyan, 2002).

The oscillating experience of forgetting and remembering one's body allows the walker/listener to inhabit two spaces - a virtual space coexisting with the physical one. As Bull remarks, "Through the power of sound the world becomes, intimate, known, and possessed" (2004, p. 109). The virtual "world" is therefore possessed through interiorization while the physical "world" possesses the walker/listener. The Map/Territory project uses the potential of sound to partially immerse users in a virtual space. The walker sees the environment and listens to the narratives which creates a secondary aural space commingling with the primary visual/physical space and in this respect allows for the potential subversion of the normative meanings of a space by re-inscribing it with alternate meaning. 


\section{Mapping and Walking}

The two core interactive components of the Map/Territory project are the map interface located in gallery and the audio interface used for walking. The first presents the viewer with an overview of the neighbourhood area, a realtime view of a participant's movement and allows him/her to assume the role of mapper and manipulate the categories and presence of data, thus controlling what is available to the other participant(s). The second presents the participant, the walker, with a dynamic sequence of audio tracks (as made accessible by the map in the gallery) which deliver stories related to a specific location in the neighbourhood or descriptions of the construction of the project's interface. The aim of designing two distinct but related tools and experiences was to make tangible the entanglement between experience and its representation as well as the inherent dynamics of control and interaction between walker and mapper.

The roles of mapper and walker roughly correspond to de Certeau's notion of map and tour (de Certeau, 1984, p. 121). De Certeau picks up these two terms from work done by Linde and Labov on how space is represented in language and thought. Maps, in this initial sense, refer to how some people describe space by stating their respective spatial relation, e.g. "the chair is on the left next to the kitchen." Tours, alternatively, refer to how others describe space procedurally, e.g. "go down the corridor, turn left at the kitchen follow the wall to where the chair is." But de Certeau expands upon these terms to describe a dichotomy that stems from the difference between "scientific discourse" and "ordinary culture" - in other words between objectivist rationalist analysis and lived practice. The map, according to de Certeau, comprises a "plane projection totalizing observations" while the tour comprises a "discursive series of operations." Not only does he situate them at two extremes but he also argues that one has gradually begun to dominate the other:

The map thus collates on the same plane heterogeneous places, some received from a tradition and others produced by observation. [...] The map, a totalizing stage on which elements of diverse origin are brought together to form the tableau of a "state" of geographical knowledge, pushes away into its prehistory or into its posterity, as if into the wings, the operations of which it is the result or the necessary condition. It remains alone on the stage. The tour describers have disappeared. (de Certeau, 1984, p. 121)

Maps, according to de Certeau, arrange objects of knowledge in such a way as to make them legible. The complex narratives of living in a space, the tour, are omitted or at least greatly simplified because they cannot be visualized and spatialized on a surface. This is the tension that is exploited in the Map/Territory project. The tour, on the one hand, is manifested through the arrangement and experience of stories throughout the neighbourhood. The map, on the other hand, is created through the display of 
story categories and walker movements as well as the manipulation of data objects that affect the walker's experience. Although the power relation is made literal through opposition of these two roles this is not a reductive dualism of powerful against powerless rather it is intended to highlight the limits of representation inherent in the experience of each position and the role-playing involved in the re-creation of space.

Experiencing the neighbourhood in the Map/Territory project through different visualizations that show patterns of walking, locations of stories and other layers of information can potentially affect the future memory of that space (especially when combined with walking that space). Maps, as virtual spaces, have historically been used to impart a view of reality to others. And if, as de Certeau suggests, mapping is a translation of a wider spectrum of spatial experience (touring) into a narrower and visually legible form then the use of maps as a proxy for reality can itself profoundly affect our experience of that space.

Cartographic studies since the mid-twentieth century have tended to be focused on the way that maps communicate geographical facts (Crampton, 2001, p. 235) with a focus on transmission of information that has usually omitted any consideration of the act of assembly, of what constitutes fact or of the social-political effects of representing space. A famous example of this disconnect is the comparison of the Mercator map projection (created by Flemish geographer Gerardus Mercator in 1569) to the Gall-Peters map projection. Controversy arose when Arno Peters suggested that his map be used as an alternate to the Mercator map since it better represented the sizes of land masses. In the Mercator map (long used for nautical navigation) North American and European land masses are equal to or greater than Africa, South America and Asia. Peters argued that this reflected and propagated a view of WesternEuropean dominance in the world (Dietz, 2006, p. 200) - especially problematic if we consider how maps are used as pedagogical tools in primary and secondary education.

Another example is the London Underground map designed by electrical engineer Harry Beck in 1933. This map is repeatedly used as one of the highest achievements in information design where legibility and orderliness result in accessibility and speed. In order to efficiently get commuters to their destinations this map was designed with only one thing in mind: the outline of the stations and subway lines that service these stations. All information regarding the surface of the city was omitted except the curves of Thames River. Street names, landmarks, buildings were almost completely removed in order to focus on transportation along the already complex subway system. The map's resemblance to an electric circuit that manages the flow of signals from one end to the other equates the movement of people to the management of signal processing (Elliman, 2006). Rather than a city with streetscapes that date back to the middle ages the "circuit" map represents an ideal version of London where the flow people is rationalized and efficiently managed. This map has entered popular culture and has come to symbolize London - so much so that it has influenced a myriad of other informational maps and visualizations of London.

Artists, on the other hand, have tended to acknowledge the constructed nature of maps. For 
instance, Uruguayan artist Joaquín Torres García founder of the Escuela del Sur (School of the South), used a map to symbolically reconfigure relations of power. In a now famous gesture, he inverted a map of South America in order to conceptually reorient the flow of intellectual and cultural influence between centre and periphery, from the Western-European North to the global South. Argentine artist, Guillermo Kuitca, used paintings of maps and architectural blueprints stripped of the traces of human involvement to signal the process of forgetting and re-creating that plays such a central role in history. Their promise to convey facts in a stable grid of time and space is undermined - specifically in pieces that reference the stadiums used for torture and evoke the collective memories of Latin American dictatorships (Tuer, 2005).

If the map is viewed through Bolter and Grusin's term remediation then what becomes apparent is the hybrid nature of the map. It is a combination of illustration and table of data - a spatialization of visual objects which create relationships among visual representations and written language. It is also a hybrid object. Bolter and Grusin, borrowing from Bruno Latour (1993), describe hybrid objects as objects that are both real and imagined and that therefore deeply affect reality. In this sense maps are both real and mediated (Bolter \& Grusin, 2000, p. 58). A map of the London Underground mediates people's perception of the city and thus actualizes an imagined space into a real object. An inverted map of South America is also real and mediated - an object that disrupts assumptions of top and bottom.

Experiencing the territory through walking makes up the other side of the Map/Territory installation. It is the component that asks users to commit their bodies to the interaction. And by doing so opening up the experience to become a mixture of narration and movement. More precisely, it is the perception of movement which involves the proprioceptive sense (limbs and muscles in movement) and exteroceptive senses (visual, aural, haptic, olfactory, balance) (Adams, 2005). Walking engages, more actively, all these senses to remind the user that they are situated in a context and at the centre of that context. Similarly, like a "heart in the organism," Merleau-Ponty (1962) argues that how we perceive our body moving in space is precisely how we become part of a larger system composed of subject and object and gain a greater sense of self.

The "system" in the case of the Map/Territory installation is the urban neighbourhood containing the streets, buildings, traffic, etc. It is a structure that through walking is negotiated. De Certeau (1984) likened walking in the city to speaking a language - an appropriation where the user takes elements from an existing system to create a new form. The walker in this installation negotiates the space of the neighbourhood through a combination of moving between the physical structures and searching for the locations of the narratives and thus creates a unique expression within the urban system and the installation.

In addition, our bodily sense of our location and movement through space is often said to naturally aid active thinking. Conjuring ideas through the narration in the installation while the user walks taps into a long tradition within philosophy. For instance, Schaub (2005) notes that many philosophers were known for their love of walking (and thinking while walking). The Peripatetics and Stoics, Kant, Hegel, 
Rousseau and Kierkegaard all used walking to work through concepts in solitude - the body's movement aiding the successive movement between ideas (Schaub, 2005).

The speed of walking, averaging somewhere around 4 to $5 \mathrm{~km} / \mathrm{h}$ for humans, seems to be not just an integral part of how we think but also how we feel. Some writers suggest that walking speed is a human proportion required to maintain spiritual health:

A white explorer in Africa, anxious to press ahead with his journey, paid his porters for a series of forced marches. But they, almost within reach of their destination, set down their bundles and refused to budge. No amount of extra payment would convince them otherwise. They said they had to wait for their souls to catch up. (Chatwin, 1988, p. 230)

Alternatively, walking can also set the pace for narratives much like film editing can set the pace for the development of a plot or the emotional quality of a scene. Cardiff, makes use of this deep connection in her audio-walks to modify the rhythm of her narratives. "One thing I try to do is to slow the walker down, so that it becomes the speed of the thinking walker. If I want to create a bit of tension I increase the speed of the gait" (Cardiff as quoted in Schaub, 2005, p. 74).

In thinking through how walking plays a part in the Map/Territory installation I have attempted to carefully consider the distances and intervals between the locations of narratives. By planting the field with relatively close narrative locations I could approximate a constant rhythm throughout but also allow space for the user to think and experience the surroundings between locations. 


\section{NARRATIVE INFLUENCES}

Apart from theoretical concerns regarding space, network and new media several works of fiction, specifically from authors Borges and Calvino, have also influenced the development of the Map/Territory project. Before contemplating the creation of the installation the work of these writers inspired a poetic, fantastical and pseudo-historical take on space. Their literature created possible worlds that played with the possibility of actually having existed. And more specifically, with ways of remembering places, spaces and journeys.

The relationship between the form and structure of their work also influence the structure of the Map/Territory installation. Calvino's short stories were in fact more like short descriptions or diary entries that in their entirety amounted to a narrative. The stories can be read out of order and many were organized into categories rather than chapters. Borges' short stories were written as if they are the document itself bringing into question their status as truth. Some entries have copious captions detailing their provenance (Borges, 1999), others arranged as encyclopaedic entries (Borges, Guerrero, \& Hurley, 2005 ) and still others ensconce themselves in existing factual accounts of history (Borges, 1983). The following section describes the specific ways that Borges' and Calvino's writing influenced the ideas and creation of the project.

The work of Jorge Luis Borges has been referenced widely in writings on new media. This is largely due to the fact that he has been especially prescient in uncovering some of the key ideas of interactivity/variability, knowledge/archive/database, representation, place/space through his numerous short stories. For instance, Borges illustrated how the pursuit of a total spatial representation can lead to a technology that, in an insight predating McLuhan, reverses its original intent. Cartography, in "On Exactitude in Science," is literally extended to its most absurd limits.

On Exactitude in Science ... In that Empire, the Art of Cartography attained such Perfection that the map of a single Province occupied the entirety of a City, and the map of the Empire, the entirety of a Province. In time, those Unconscionable Maps no longer satisfied, and the Cartographers Guilds struck a Map of the Empire whose size was that of the Empire, and which coincided point for point with it. The following Generations, who were not so fond of the Study of Cartography as their Forebears had been, saw that that vast Map was Useless, and not without some Pitilessness was it, that they delivered it up to the Inclemencies of Sun and Winters. In the Deserts of the West, still today, there are Tattered Ruins of that Map, inhabited by Animals and Beggars; in all the Land there is no other Relic of the Disciplines of Geography. - Suarez Miranda,Viajes de varones prudentes, Libro IV, Cap. XLV, Lerida, 1658 (Borges, 1999)

It is not just the material constraints of making a map the size of the territory that is problematic. 
This also raises the issue of accessibility and the framing of knowledge so that patterns can be recognized across a map. This is made clear by Umberto Eco in his response to Borges' map which reached absurd levels as he tried to painstakingly detail the theoretical and mechanical possibilities (and impossibilities) of actually making a map on a scale of 1:1 (Eco \& Weaver, 1994). Perhaps most interestingly, Borges left us with the notion that some representations of the territory now exist on top of the real areas they aim to represent alongside or on top of others that represent other places echoing a main concern in locative media - to double the space by locating the trace and the representation in the same place.

In the short story "The Garden of Forking Paths" Borges (1964) explored the choices made by the protagonist as he flees an assassin. The garden referred to in the title is both a labyrinth and a book with many beginnings and endings. It is often used as an illustration of hypertext and hyperlinking. Gilles Deleuze also referred to it to explain the power of virtual worlds and the coexistence of contradictory events (Bogue, 2003, p. 115). But what is most striking about this story is the revelation that a book and a labyrinth are discovered to be one work - meaning that narratives are mapped in a space that allow for an endless array of bifurcating paths. Tracing one path can uncover one set of happy events while exploring another can uncover a plot that may have started similarly but through a series of different choices ends in tragedy.

In all fictional works, each time a man is confronted with several alternatives, he chooses one and eliminates the others; in the fiction of Ts'ui Pên, he chooses - simultaneously — all of them. He creates, in this way, diverse futures, diverse times which themselves also proliferate and fork (Borges, 1983, p. 26).

Bifurcating paths illustrate the endless possibilities of a choice-based narrative as wells as the connection between walking and the path that a story can take. In the Map/Territory project there is no one protagonist that you can follow to an end but the stories are, in part, connected by the movement of the traveller. The short stories/descriptions that are located in space that can be accessed in many different orders in which time of day, approach (North, South, East, West), sequence of narratives and context all contribute to different experiences.

Borges was also fascinated with institutions and processes of knowledge creation and preservation such as archives and libraries, indexes and taxonomies. In "The Analytical Language of John Wilkins" Borges (1998) noted a Chinese encyclopedia entitled "Celestial Empire of benevolent Knowledge" that uses a special kind of taxonomy:

In its remote pages it is written that the animals are divided into: (a) belonging to the emperor, (b) embalmed, (c) tame, (d) sucking pigs, (e) sirens, (f) fabulous, (g) stray dogs, (h) included in the present classification, (i) frenzied, (j) innumerable, (k) drawn with a very fine camelhair brush, (l) 
et cetera, (m) having just broken the water pitcher, (n) that from a long way off look like flies. (Borges, 1998)

Borges' illustration of how classification is more a product of imagination and less a result of the self-evident essence of objects influenced the map interface of the Map/Territory project. As each mapper can assemble a different combination of categories on the screen $\mathrm{s} / \mathrm{he}$ learns that the organization of data follows a more subjective understanding of how things fit together.

Foucault (1973) also marvelled at how Borges' story humorously pitted different modes of thought against each other and brought into question the modernist impulse for a rational, structural organization of phenomena. Foucault also noted that Borges illuminated how this arrangement of objects could only exist in a spoken language (or its transcription) and that each object lives in its context. Borges maintained this connection and vitality afforded by speech and removes the operating table (Foucault, 1973, p. xviii) which represents the neutral site upon which things are torn apart from their context and promptly named, ordered and taxonomized.

The conquest of knowledge is often illustrated as the conquest of space and Italo Calvino's collection of stories and descriptions in "Invisible Cities" captures this notion very well. The protagonist, Marco Polo, is asked to report back to Kublai Khan with an account of every city in his empire. Each city, although described in profound detail, is actually invisible. Like spectres each city exists in the same city, Venice. They only become visible through one's own approach to the city. Personal experience, memory, agendas, and social level all contribute to a subjective position that reveals a distinct city.

Much like Borges' "Chinese encyclopaedia" Calvino's layers of descriptions of the same city are used as an inspiration for the design of the navigation interface of the Map/Territory installation. The interface attempts to tap into this notion of subjective criteria to reveal certain versions or skins of the city. Each category assembles a loose set of stories that are linked according to a personal understanding of their relevance to each other and to the locations onto which they are mapped.

Calvino also explored the colonization of space through movement, measurement and representation. By playing the two protagonists against each other Calvino compared movement and narration to measurement and control. The explorer and narrator of experience is contrasted with the ruler of an empire. For instance, Kublai is enchanted by Polo's memories and narrations but he is frustrated by their lack of permanence. By analogy to a game of chess Calvino showed how the ruler attempts to fix the essence of living cities and thus plot them on a rational space:

[Kublai] thought: "If each city is like a game of chess, the day when I have learned the rules, I shall finally possess my empire, even if I shall never succeed in knowing all the cities it contains." (Calvino, 1978, p. 121) 
But Kublai realizes that the endless configurations of stories and perspectives mean that any conception of physical space is dependent on a subjective and temporal dimension:

At times he thought he was on the verge of discovering a coherent, harmonious system underlying the infinite deformities and discords, but no model could stand up to the comparison with the game of chess. Perhaps, instead of racking one's brain to suggest with the ivory pieces' scant help visions which were anyway destined to oblivion, it would suffice to play a game according to the rules, and to consider each successive state of the board as one of the countless forms that the system of forms assembles and destroys. (Calvino, 1978, p. 122)

Throughout these works by Borges and Calvino the dichotomy of tour and map is recalled and evokes the relationship between time and space. Journeys through bifurcating paths are represented as choices in a labyrinth. Bits of an infinite map are to be encountered overlaying the territory. Polo's travels defy classification and total representation.

The map's inability to represent all information on the ground, especially that which relates to time and context, is used as a tension between the knowledge of the mapper and walker in the Map/Territory project. The interactive table in the installation works upon this metaphor used by Foucault to involve the user (mapper) in a relationship with the description, measurement, and order of space and data. The audio-walk component explores how bifurcating paths can lead to subjective readings or a territory. Both Borges' and Calvino's fictional explorations have seeded the Map/Territory project with the possibilities of using narrative to explore how we come to understand the way we use space. 


\section{DATA STRUCTURE AND USER INTERFACE}

The interrelationship of structure and user interface was exploited in the Map/Territory project in order to produce an engaging experience that also refers back to its construction through interaction revealing the assembly of constituent parts and processes that together make the installation function. The immersive audio employed in the installation that potentially makes users forget the technical aspects is partially disrupted through various narrations that describe the relationship of the walker to the mapper and the technological network used to link the two roles. The access to these descriptions is mediated through the walker's path and the set of categories configured on the table. Depending on what objects are on the table in the gallery the walker will hear a particular combination of narratives. These descriptions, plucked from a database of narrations and locations, are encountered by the user according to his/her own set of choices. Revealing the process of manipulation of data in space and the relationship between mapper and walker makes the interface, to a large extent, the content of the interaction.

In the installation, fictions, facts and opinions which describe neighbourhood locations and computer processes, were written as small chunks that could be heard while walking. In addition, the interactive aspect of the project required the data to be dynamically configurable depending on one of two variables: configuration of the map and location of the walker. To allow this to occur the stories need to be stored as individual files in a directory. A key file tags each file with a name, group name, physical location (longitude and latitude) and file location (directory path). The way these files are stored is akin to how databases store information - no structure apart from their location in computer memory.

The database recalls the table or tabula rasa that promises a clean slate onto which elements can be sorted. As Foucault comments, "On what 'table', according to what grid of identities, similitudes, analogies, have we become accustomed to sort out so many different and similar things?" (Foucault, 2007, p. xxi) The database holds objects of data by removing them from their context and suspending them until retrieved and sorted according to a search criteria. Suspended, the data is meaningless.

Database, in this respect, is contrasted with narrative to represent two modes of organizing information. Lev Manovich argues that these two modes are at odds. He states, "Database and narrative are natural enemies. Competing for the same territory of human culture, each claims an exclusive right to make meaning in the world" (Manovich, 1999). For Manovich that which structures the data in a database is the algorithm - in other words a series of steps (or instructions).

If we take this notion into the realm of locative media then the steps can literally be the steps followed by the walker that weaves back together the separated parts. An operation that echoes Hayles' assertion that disembodied information (a database or matrix of data) can be reconstituted through narrative that is inherently historical, located, and personified (Hayles, 1999). Walking embodies these 
traits as well - it has a chronological thrust, it is physically located and it is performed by a subject. In this respect, the over-arching narrative is created by walking and since each individual walker will choose slightly different routes for walking the neighbourhood each experience will be slightly different.

Narrative and database do coexist in new media under, among other things, the category of database cinema. Although it tends to not include locative media it does serve well as a concept to explore the genealogy of works which use interaction for the dynamic construction of narratives. For instance, Manovich argued that database cinema is not unique to the computer age but that it existed in forms of cinema, most notably in Dziga Vertov's "Man with a Movie Camera" and Peter Greenaway's many films including "Prospero's Books" (Manovich, 2002). The "database" in these works refers to the raw material of footage that is arranged according to a logic that goes beyond linear narrative convention. Vertov's film is, for instance, self-referential and works by exposing the manner in which a camera sees and assembles motion-picture documents. Greenaway, Manovich explained, uses other criteria such as books or numbers or lists to organize his narratives (Manovich, 2002). Marsha Kinder, on the other hand, noted that evidence of database cinema can be found throughout the history of film-making (Kinder, 2003). In her analysis what constitutes database is also the method of assembling the various shots from an inventory of media into a linear form but more importantly it is how these films reveal the act of assembling within the story itself.

Revealing the processes of assembling technology and content in the Map/Territory project was a fundamental aesthetic decision that was made early on in the ideation, design and planning stages affecting interaction, narrative form and immersion. Apart from the desire to insert a critical distance between user and interface this decision was also influenced from an observation that the most successful locative projects tended to acknowledge the construction of the experience. It seemed that attempts to create an immersive experience where all factors were controlled to sustain a suspension of disbelief were doomed to fail as technology, often operating at varying levels of efficiency, interfaced with unscripted and unpredictable events in the outside world. This decision led to the investigation of the usefulness of creating a seamless interface and the potential of a user experience that highlighted the devices, the network and the layers of information and the act of walking.

The task of creating an immersive experience where the technology and the unscripted parts of reality merge seamlessly is exceedingly difficult if not impossible. And for the purposes of this installation, it is ultimately undesirable. That is not to say the technology itself in the Map/Territory project must work without pausing or crashing and, in this sense, work seamlessly but the scope of what is controlled is very small. Instead, the installation, through audio and visual information, constantly refers to its own construction, the methods used, the technology employed and the active layering of information on to physical space. It is a subtle employment of a Brechtian interruption that alerts the participant to the artifice of the whole experience. This strategy amounts to a response to the discourses in 
the fields of augmented reality, virtual reality, and ubicomp that have traditionally been dominated by the aspiration to achieve complete immersion and seamlessness in an experience.

Mark Weiser, a pioneering scholar in ubicomp research, is famous for stating that, "A good tool is an invisible tool. By invisible, I mean that the tool does not intrude on your consciousness; you focus on the task, not the tool" (Weiser, 1994, p. 7). Invisibility is a key aspect of what he terms calm technology that aims to work through a balance of the human perception of central and peripheral information. This is in contrast to other technology such as pagers and cellphones which constantly attempts to attract one's complete attention (Weiser \& Seely Brown, 1996).

According to Chalmers and MacColl (2003) the notion of invisibility has been interpreted by researchers and industry to mean seamless integration of a growing ecology of computing devices and sensors and, in this regard, has been taken up as a central goal in ubicomp. Ironically, Weiser advocated a design of "seamful systems, with beautiful seams" that acknowledged the difference between tools, devices, and contexts and argued that seamlessness destroyed the difference between the important inherent qualities of tools (as cited in Chalmers et al., 2004).

Weiser's call for calm technology working through invisible interfaces and ubicomp's push for seamlessness represent a view that technology can successfully mimic systems existing in the natural world. To achieve true ubiquity, invisibility and seamlessness a system would need to mediate all aspects of reality representing everything through computer code. These systems would need to be vastly complex and sophisticated to, in effect, represent reality on a 1:1 scale - similar to the goals of Borges' map-makers.

This view is not particular to the field of design in ubiquitous computing it also appears in interactive new media art discourse. For instance, Peter Weibel, director of the ZKM Center for Art and Media, likened some of the most successful interactive works to systems which mimic life itself:

However, its dynamic system features have given this variable, virtual picture yet another characteristic. It behaves like a living system, it reacts to the input of a context, it alters its state and its output through the viewer's input. The interactivity of this media art thus consists of the three elements of the digital image: virtuality (of information storage), variability (of pictorial content) and viability (of pictorial function). Accordingly, the image transforms itself into a dynamic system whose behaviour imitates real life. If a living organism is a system that reacts independently to individual existence, then the dynamic image system consists of multi-sensory variables and reacts to input is also a living organism. (Shaw \& Weibel, 2003, p. 180)

These visions of calm technology, seamless integration and digital media organisms share the desire to create life-like experiences by assembling hardware and software components into increasingly complex systems. This impulse is not new and harkens back to an earlier aspiration of film as identified 
by André Bazin. He stated that cinema has always worked towards the myth of being "a total and complete representation of reality; they [cinema's various inventors] saw in a trice the reconstruction of a perfect illusion of the outside world in sound, color, and relief' (Bazin, 1967, p. 20). Total cinema, according to Bazin, is the primordial myth that has driven technological innovation since before the invention of the various technologies employed by cinema to create the illusion of reality.

Interactive systems, as described above, take the impulse of a total cinema to the next level to incorporate movement of the body, physical and social context and human-computer interaction. The incorporation of these other aspects has meant that this impulse has hit another technological wall. Encounters with unscripted reality and unprepared objects in an unknown context will undoubtedly cause a system to fail. Much like how artificial intelligence research failed to produce a computer mind, ubicomp research has failed to produce a smart environment that anticipates human behaviour and consistently and correctly interprets physical and social context (Rogers, 2006).

In ubicomp research, the way that various bits of unscripted (uncoded) reality or unconnected resources cause a mixed reality system to either ignore an object or disrupt the experience has been described as heterogeneity. Heterogeneity is the antithesis of seamlessness because it abruptly foregrounds the interface as well as the system's limits - a problem sought to be managed and minimized in traditional ubicomp research (Rogers, 2006, p. 142). Alternatively, some researchers have recently suggested that we should exploit the messiness of phenomena and embrace a seamful design approach (Chalmers \& Galani, 2004; Broll, Benford, \& Oppermann, 2006) that engages users through its visible interface (Rogers, 2006).

The Map/Territory project attempts to acknowledge the seams between technologies and processes by directly addressing issues of network, narrative and coding throughout the stories located in space. Going beyond the idea of seamfulness as an appropriate user-interface design strategy resulting from the failure of a ubicomp this project describes the seams in order to promote a user's critical distance while still experiencing the effects of the system. It draws from Lovink and Garcia's concept of a new media art that engages its own existence: "Tactical Media are never perfect, always involved, performative and pragmatic, in a continual process of questioning the premises of the channels they work with" (Lovink \& Garcia, 1998). Critically viewing the premises of the installation is encouraged by foregrounding and making visible the seams between devices, processes, mediated and unmediated reality and allowing the user to perform through the system to weave various bits of data - essentially making the interface the content. 


\section{MAP/TERRITORY INSTALLATION}

\section{Creation Process}

The creation process for this project involved working on several levels at once. Artist, designer, researcher, and co-ordinator are the main roles that I played through the life of the project. In addition, my experience working in mobile research projects such as the Mobile Digital Commons Network and Portage (both at the Ontario College of Art \& Design) afforded me a certain sense of how a locative media project within an academic setting would be conceived, planned and produced.

Initially, the impulse to engage with places, interactivity and storytelling came from a realization of the creative potential of connecting aspects of these disparate notions through one installation. It was also intended to address the need for a counterpoint to the disembodiment, dislocation, utopianism that marks so much of network-based interactive work. By delving into these ideas certain theoretical frameworks began to surface such as spatiality, network, narrative, orality/aurality and interactivity. But rather than subject the initial idea to various bodies of theoretical work I temporarily put it aside and focussed on the experience and construction of the installation.

One of the main creative processes used in this project is the hack, a creative and exploratory form of working that finds the path of least resistance and/or makes use of limited available resources. Traditionally, it meant an amateur or a tinkerer, usually with no formal education, who would work intuitively on a problem (Galloway, 2004a, p. 151). The term is mainly used in reference to work done in computing or electronics (Wark, 2004) and is only relatively recently that it has been used in reference to an artistic process (Raymond, 2003; Levy, 1994). It is important to note that there is a distinction between a hacker and a cracker - a hacker creates things and is spurred by the challenge of problem-solving and a cracker destroys things and looks to exploit security loopholes in existing infrastructures (Raymond, 2001). Still, even this basic distinction has been thrown into question. While some writers try to create a hard distinction between hackers and crackers or lawful activity and criminal activity (Raymond, 2003) it becomes increasingly hard to maintain as artist hackers begin to deal with issues of copyright, security and political resistance (Critical Art Ensemble, 1994).

Hacking, in its various forms, has become possible and more popular because of the revolution in cheap consumer electronics (Lovink \& Garcia, 1998) and more importantly the growing amount of obsolete electronics that populate surplus stores. These are the materials which hackers recombine to create objects or functions originally unintended by the manufacturer. The descriptions of the programming and construction processes below will illustrate how hacking virtually became the only way of proceeding with the project considering the human, financial and time resources available.

Once the programming and construction process was underway the location, visualization, narrative and audio work was started. Although the Queen Street West and Ossington Avenue 
neighbourhood in Toronto was selected early on as the location of the installation the bulk of the writing process began in the Spring/Summer of 2008. At a basic level the neighbourhood had to be walked over and over to uncover interesting architectural features, notice patterns of use or simply let events occur which could lead to interesting narratives. Due to how the narratives mixed fact and fiction the locations provided more of a inspirational role than a concrete material base on which to lay historical accounts. Appendix A contains the scripts of individual stories as well as their respective locations.

\section{Coding, Hardware and Communication}

From a design and technical perspective several challenges presented themselves at the outset of a project that depended on databases, internet connections, mobile devices, desktop computers, audio-visual data and a tangible user interface. These include hardware selection, programming language selection and use, communication issues amongst the various hardware and software components, coding process and user experience. Each issue is ultimately connected to the others therefore it was not possible to solve these questions sequentially then promptly begin coding. Instead, it was discovered that the challenges represented themselves throughout the whole process which required constant negotiations between the design, the code and the intended experience.

The programming or coding process began with sketching several small applications to test the concept and the viability of producing an interaction that used mobile phones, a cell-based internet connection, and a web server. The coding portion of the project was later completed through the collaboration with programmers Rob King and Ken Leung. King and Leung reviewed the initial programming sketches for the project and helped program higher-performance and more robust versions for the final installation.

Sketching, in this context, meant roughing out very simple programs that, for instance, communicated basic information such as GPS location to a database server and that retrieved that information in order to draw a line on the screen and when a coordinate matched a list of pre-determined coordinates a sound would be played. Rather than begin programming from scratch I began by reviewing a wide range of other programs that performed tasks similar to what I had in mind. This research led to literally cutting and pasting several chunks of code into a larger sketch that, albeit clumsily, performed the basic interaction. Using this recombinant strategy was also very useful in learning more about the programming language - a method I've used successfully in past workshops (McIntosh \& Davila, 2008). Through further stages of rewriting (with King and Leung) the programming code was refactored to reduce redundant instructions, improve efficiency and readability, and prevent future errors occurring during the final installation.

The initial sketch, although not exhaustive or completely representative of the whole interaction, 
did reflect the original vision of the project. Inevitably though, the reality of the installation changed through a constant negotiation between what was technically feasible, what made a satisfying user experience and what constituted the overriding artistic/theoretical concerns. Rather than treat this as a compromise or corruption of a pure artistic vision my strategy was to use this tension as a productive process where an artist responds to the materials with which s/he is creating a work.

The choice of hardware, language and application combination was based on available technology and its suitability to the tasks required to run the Map/Territory installation. The basic hardware combination required purchasing a custom-built Windows-based PC and borrowing two Nokia N95 mobile phones and two GlobalSAT GPS receivers from the Mobile Lab at the Ontario College of Art \& Design (OCAD). This triad of devices also determined the scope of programming languages and network technologies available for consideration. For instance, the Nokia N95 mobile phones are able to run applications written in a variety of programming languages ( $\mathrm{C}++$, Java and Python). The Windows-based $\mathrm{PC}$, on the other hand is able to run applications written in these same programming languages plus many more - a advantage when evaluating flexibility and compatibility among devices. In addition, the GPS receivers utilize a Bluetooth connection to transmit data therefore it was necessary for the mobile device to have this feature. A provisional set up using these devices (and platforms) was made in order to begin the process of choosing software.

\section{Programming Language}

When considering a programming language I needed to evaluate characteristics such as compatibility, structure, experience, appropriateness to task, ease of scripting, and user community. In addition to these criteria, the ease of learning was also very important since I had some programming experience but not enough to easily migrate from one to another. Generally, two open-source languages are suggested for learning first: Java and Python (Raymond, 2001). Java, developed by Sun Microsystems, is one of the most popular languages in use today and although it is easier to learn than many programming languages it is still suffers from a steep learning curve. Python, developed by Guido van Rossum, is also becoming a very popular language although not to the extent of Java's popularity. In contrast to Java it is designed to be a first programming language that is very suitable for demonstrating basic programming techniques, data structures and flow control (Raymond, 2001).

Through this selection process I discovered that a programming language's ease of learning and flexibility, efficiency and power are often related. Languages tend to fall into three different categories representing a spectrum that stretches from human-readable code to computer-readable code: high-level, mid-level and low-level programming languages. If a language is considered high-level it is generally assumed that it is very easy to read by humans, requires little training to use and often works across multiple computer platforms (e.g. Processing, Python, HTML, PHP, ASP). The trade-off with these languages is that they usually require more computing power and have a more limited set of commands 
that, in turn, need to be translated into computer-readable code before being executed. Low-level languages, on the other hand, tend to use very cryptic syntax and complex programming structures. Readability is often sacrificed in favour of efficiency and access to basic hardware functions such as memory and processor management. Low-level languages such as machine code and assembly language require very little translation in order to run on a computer and run much faster but also tend to be specific to particular operating systems and/or processor types. Middle-level languages (e.g. Java, C, C++) usually employ features from both kinds of languages allowing programmers to access very powerful commands but still retain a degree of human-readable code and flexibility across multiple platforms. (For a comparison of programming language syntax see Appendix B.)

From an ease of learning and scripting, and flexibility point of view Python seemed to be the clear choice. Python features a simplified syntax and highly readable language that does not require the constant inputting of semicolons or the use of cryptic commands (Python Software Foundation, 2008). Commands are generally descriptive so that the programming concepts they employ are more easily remembered and identified. But due to the limited implementation of Python on mobile devices it was decided to only use this language in a limited role as an intermediary tool that passed information between the mobile phones and the interactive table - something it accomplishes very efficiently.

Instead it was decided that Java be used as the programming language for mobile and server applications. Java boasts being the ultimate cross-platform programming language currently supporting PC, Mac, Linux, mobile, servers, and even small microcontrollers (Sun Microsystems, 2008b). Using the Java Virtual Machine (JVM) allows Java applications to run on almost any machine. The JVM allows programmers to "write applications once to run on any computer" thus theoretically reducing development time for mass deployment of applications (Sun Microsystems, 2008a). Seen as an advantage that minimizes retraining, Java employs a syntax similar to $\mathrm{C}++$ but removes the need to manually manage memory or processor computer resources (Mackenzie, 2006, p. 104).

The short period of time available to program and construct the Map/Territory installation meant that Java, despite its advantages, would be very difficult to use. Processing, an open-source programming language developed by Casey Reas and Ben Fry at MIT Media Lab, promised to be a suitable compromise. This language was based on Java but reduced the more complex features that made learning more time-consuming. Processing was also made expressly for learning and experimenting following how designers and artists commonly work (Reas \& Fry, 2007).

Two other aspects made Processing the ideal candidate: mobile platform compatibility and user community. Processing, a few years after its release, was used as a base by Francis Li to develop Mobile Processing for the purpose of developing applications on mobile devices (Reas \& Fry, 2007). This meant that programming in Processing was very similar to programming in Mobile Processing cutting down on learning time. In addition, the open-source release of Processing resulted in the growth of a very large community of enthusiasts, artists, designers, programmers who contributed software libraries, teaching 
guides, tips and tricks to that project. This indicated that there was a substantial knowledge-base from which to draw in case there were any programming difficulties during the project.

The programming process for the Map/Territory began with the assumption that Processing and Mobile Processing would be used to develop both server-side and mobile-side applications. This approach worked well during the sketching phase and first few months of development but later in the process the installation ran into a specific problem with regards to memory management on the server application running the interactive table. Specifically, the installation required more efficient 3D rendering and graphic-acceleration card optimization in order to simultaneously display the complex visualization of location data (GPS), audio/video and user interface. At this juncture the decision was made to turn to vvvv, developed by Meso group, a visual programming language specifically designed for generative, data visualizing, interactive works. vVvv offered superior control of rendering effects, a visual interface that simplified rapid prototyping, and most importantly the ability to use the other components that had already been built and put in place.

Throughout the development process the benefits and limits of several programming languages were revealed. As noted above, this occasionally lead to abandoning one language for another in midstream. Because of the exploratory nature of the whole creation process this was to be expected although maintaining key criteria for language selection (community, flexibility and communication with other languages) kept this to a minimum.

\section{Interactive Table}

Although not a programming language another key component of the interactive table is the objectbased interface (See Figure 2). The map table makes use of an application based on Reactivision, an open-source project developed for creating tangible user interfaces (Kaltenbrunner \& Becina, 2007). Reactivision includes two main software components that perform the majority of the computation needed to design a touch-table interface: an image-processing application and a suite of software libraries for use in a variety of programming environments. The Reactivision application manages user input (through a video camera) and output (through a projector) to both detect the position of specially-marked objects and simultaneously display information related to their movement. As part of the Reactivision project Kaltenbrunner and Becina (2007) also briefly describe how the recognition of gesture physically works but stop short of detailing exactly how to build a touch-table. The main reasons for using Reactivision were its cost (free), its community of users and developers, and its ability to connect to a variety of programming languages. 


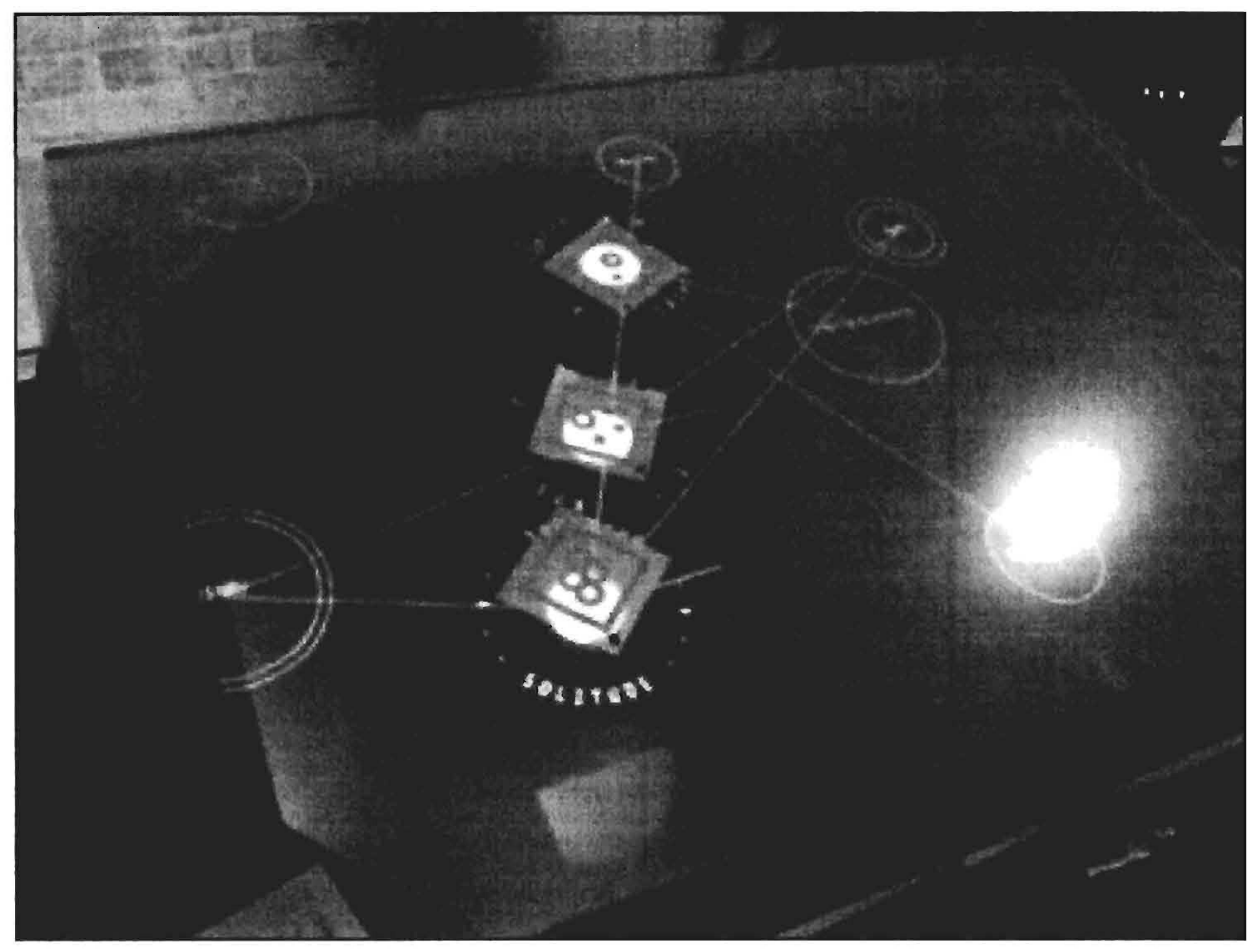

Figure 2 - Reactivision Tangible User Interface

The Reactivision software offers an open-source and cost-effective alternative to the current commercial surface interfaces. These commercial applications are designed to allow groups of people to view geographic space, movement of people, natural phenomena and collaborate, analyse and co-ordinate objects and people acting this space. As with many visualization technologies one of the first developments were designed for military use. The Touch Table (Abrams, 2006, p. 130) created by Applied Minds, Inc. and defence company Northrop Grumman in 2004 uses a horizontal projection surface and two vertical screens that allows users to view geographic data, overlay various datasets and direct.

The manipulation of information and views on the Map/Territory table is executed through the positioning of physical objects and the recognition of gesture on the surface of the table. Recent research in the development of touch surfaces for computing has brought this interface into mainstream imagination. Bill Buxton (1985) pioneered much development in multi-touch surfaces focusing on the interface that would allow humans to use gesture to execute computing tasks. These early prototypes used arrays of capacitors arranged in rows and columns to calculate positioning and were limited to input devices only (Buxton, 1985, p. 21). Jeff Han (2007) recently presented at the 2007 TED conference a prototype of a touch-table interface (FTIR, frustrated total internal reflection) which both detected positioning of fingers on the surface as well as displayed the information on the same surface creating an immediate correlation between finger and GUI interface.

Commercially, there has been a recent increase in the number of multi-touch input devices (e.g. 
Apple iPhone, Microsoft Touchlight and Surface, Mitsubishi DiamondTouch, GestureTek). More significantly, there has also been a sharp corresponding increase in the number of open-source projects by students, researchers, artists, designers and hackers that either try to reverse engineer prototypes such as those by Han, create hardware setups (Kaltenbrunner \& Becina, 2007) that have very similar interfaces and/or create software libraries for the design of custom interfaces (Hutterer, 2008; Natural User Interface Group, 2008).

Although these commercial products offer features such as robust interfaces with relatively errorfree operation they tend to be expensive black boxes that do not offer the same opportunity to investigate the underlying mechanics. By contrast, open-source projects such as Reactivision and Natural User Interface Group's TouchLib offer no customer support and have a steeper learning curve but result in more educational benefits, flexible applications and creative freedom.

\section{Communication}

In retrospect, I realized that the passing of information from one component to another within the installation was one of the most important technical aspects of the project. Communication needed to occur across components within programs, across programs within computers, across computers and devices within a network in order for meaningful interaction to occur. Common to all these flows of data was the need to establish protocols that worked through shared language and initiated, maintained and terminated connections among objects. Often these protocols will depend upon other protocols forming layers where each manages a portion of the communication act (Galloway, 2004a, p. 39).

First among these paradigms is the program itself. Processing (based on Java) and Python are both object-oriented programming languages. This means that rather than write one program that proceeds through a series of linear steps one program is actually a collection of objects (mini-programs) that communicate by passing data through function parameters and/or variables to each other. One of the main advantages of an object-oriented programming language is the ability to re-use code through the use of classes (templates) that are generic enough that they can be slightly modified into objects to produce different results. This was particularly useful when collaborating with King and Leung throughout the programming process. On many occasions I would program a small program that would have a specific function (e.g. play music, play video) that would then be incorporated into the larger program.

Similarly, flow-based programming functions through the use and reuse of basic nodes (that contain functions) and through the control of communication between these nodes. More linear in its structure than object-oriented languages, vvvv, for instance, regulates a constant flow of data from whatever inputs it is monitoring (mouse, internet, data channels, etc.). By literally shifting the flow from one node that performed one function to another allowed us to very quickly test multiple possibilities without the need to reprogram.

The second environment that communicates is larger in scale and scope and occurs among 
applications. Reactivision, for instance, is described as a distributed application framework (Kaltenbrunner \& Becina, 2007) that relies on communication among programs:

Communication between components is achieved using a published protocol. This design simplifies use for novice programmers and facilitates integration with popular programming environments such as Processing and Pure Data [similar to vvvv]. The architecture also allows the execution of framework components on different machines, which can be useful in certain installation contexts. (Kaltenbrunner \& Becina, 2007, p. 1)

Data, for instance, is required to pass from a program that processes video-input and determines position of objects on a surface to a program that waits for certain objects to be in a specific positions in order to play video. TUIO, a protocol developed by Reactivision's creators, is used to exchange information between the main Reactivision program and other programs. (See Figure 3) TUIO establishes a set of rules that must be followed by any other program that wishes to know whether an object is on the table surface, where it is and/or how it is rotated (Kaltenbrunner, Bovermann, Bencina, \& Costanza, 2005). This constitutes the data layer of the communication among programs specific to tangible user interfaces. It depends on other protocols which manage the transport of data and maintenance of the connection, specifically OSC (Open Sound Control) and UDP (User Datagram Protocol) (Kaltenbrunner et al., 2005).

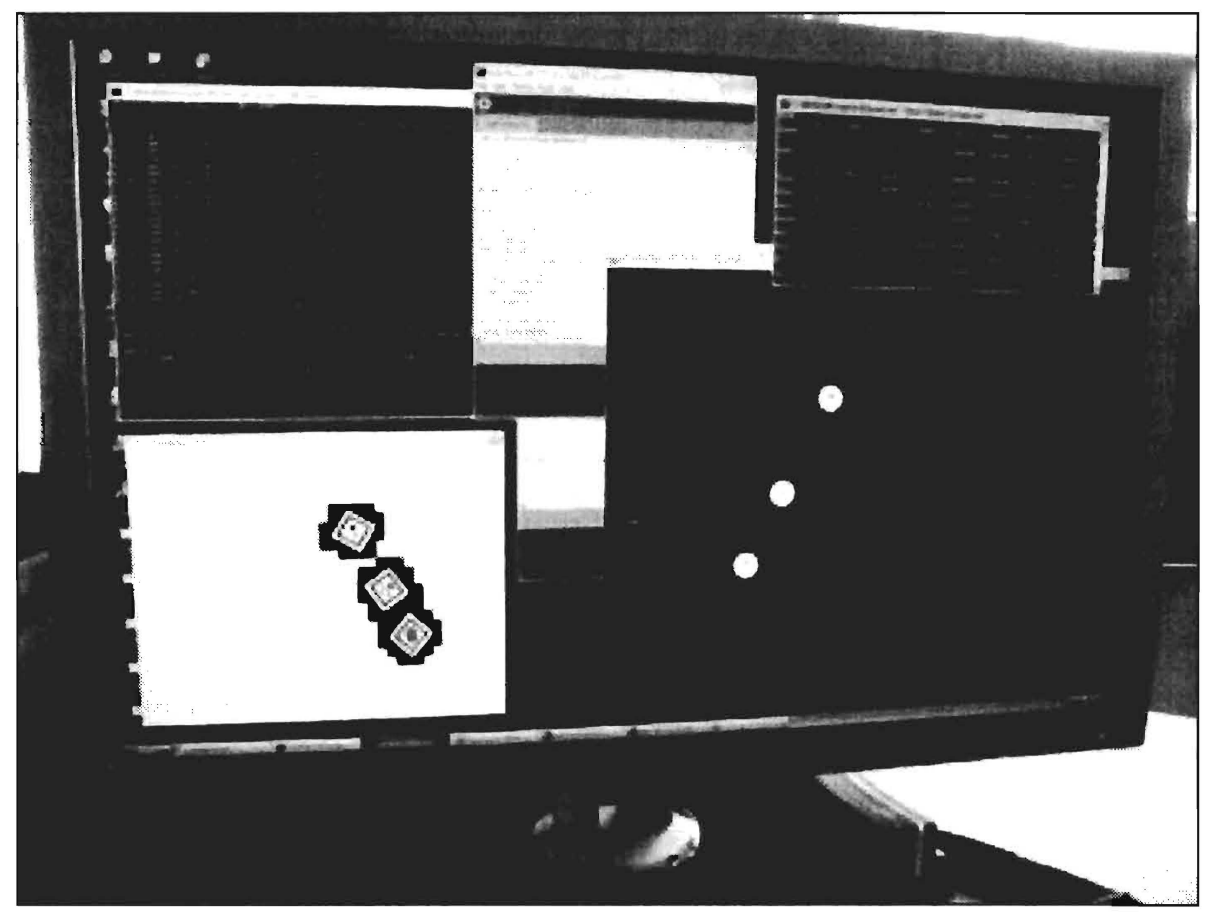

Figure 3 - Communication amongst applications 
Part of the entire communication process also takes place through the Reactivision software from an analog mark to a digital record. Under each object used on the table there is located a twodimensional barcode called a fiducial (Kaltenbrunner, Becina, \& Jorda, 2005). Each fiducial was designed to represent one category of stories using a topological design system. (See Appendix C for examples.) The software controlling fiducial recognition through the video camera distinguishes levels of enclosed spaces - much like the lines of topographic map which describe elevation - and counts how many levels exist in a specified area. The software, according to the number of levels, distinguishes one fiducial from another then transmits the corresponding ID, $x$ - and $y$-position, and rotation to any other TUIOcompliant application listening on the OSC/UDP channel.

A major challenge in this communication process was ensuring consistent and error-free recognition which is largely determined through the clear video-recording of the fiducials. First of all, lines and dots in the fiducials needed to be sufficiently thick to register on the video camera. Secondly, infrared (IR) illumination needed to be installed in order to increase the visual contrast on the surface of the table. Further refinements were made in the software interface of the video camera where shutter, exposure and gain control were adjusted.

User control of the objects meant that the map could be reconfigured at any moment - especially during the walk. In order to allow this to occur communication is required to trigger map changes and to display walker location in real-time. Essentially, data needs to be transferred from mobile device (walker) to table (mapper) and back again to make interaction possible. This communication is enabled through a cell-phone internet connection and a landline-based internet connection (TCP/IP). The Global System for Mobile Communication (GSM), fast becoming the global technological standard for mobile telephony, uses General Packet Radio Service (GPRS), an internet protocol specifically designed for GSM cell networks, to establish and maintain internet connections by ensuring a constant link between device and network as a user physically moves in space and consequently from node to node on the cell network (Kalden, Meirick, \& Meyer, 2000). The GPRS backbone functioning through the GSM cell network maintains a unique ID for each device and allows it to connect to the external network (i.e. internet) (Samjani, 2002).

Once the link between mobile device and network is established communication can occur between walker and mapper. The Hypertext Transfer Protocol (HTTP), used on the internet for web-browsing, form submissions, etc., (W3C, 2008) provides a method for exchanging location data and story/location data. Through a very basic GET command (common on most HTML input forms found on web pages) walker location data is both sent to the server and story/location data is retrieved.

A very small network was also set up to facilitate communication between mobile device and GPS receiver. A GlobalSat BT-359, used to retrieve the longitude, latitude and heading of the user, wirelessly transmits this data to the Nokia N95 mobile phone through a Bluetooth connection. The Bluetooth 
technology in these two devices communicate via a specific radio frequency $(2.4 \mathrm{GHz})$ and is designed to create small networks among small devices at short distances ( 10 metres) that require low power consumption. Since the data is transmitted by the GPS receiver that was specially formatted for navigation systems a small program had to be written to parse the data (in NMEA format), extract the coordinates and send it to the map visualizing programs (on the phone and on the table map).

Early on in the development of the project, it was discovered that for any uninterrupted communication to occur between mobile device and server, the mobile applications would need to be signed. Application development on mobile devices, especially the use of certain Application Programming Interfaces (API), is restricted by only allowing applications that have a verified origin and developer to access basic services such as phone calling, internet connection, GPS location data or file management. There exists various processes for signing applications. The process one chooses is mainly determined by programming language and development processes.

The Map/Territory project used a Java-based programming language therefore it was necessary to use a signing process that could encode a Java application with a digital signature. At least two options were available to Java developers: Sun Java Signing, a subscription-based signing process offered by Verisign, Inc., allows developers to sign applications themselves (Verisign, Inc., 2006); and Java Verified, a service offered by Sun Microsystems, provides a testing and signing process for applications (Sun Microsystems, 2004). Since the applications developed for the project were destined to be used on a very limited number of pre-selected devices they were signed using a one-year subscription from Verisign (provided by the Future Cinema Lab at York University). (See Appendix E for an example of the steps involved in code signing.)

Once the signing process is set up a further complication arises since carriers (e.g. Rogers, Bell, Telus) have a different set of allowable security clearances than manufacturers. In essence, if one acquires a secure ID it does not guarantee that all services (and APIs) will be accessible to the custom application. For instance, Nokia establishes a set of services that become available when an application is signed (Nokia, 2008b). There seems to be no common agreement between manufacturers and carriers with regards to what services should be available to developers since many carriers deviate from the recommendations set out by the manufacturer (Nokia, 2008a). This problem is most apparent when programming for carrier-branded phones which are often modified to limit features the carrier deems unnecessary or undesirable. In the case of the Map/Territory project generic (non-carrier branded) phones, commonly referred to as unlocked, were used to avoid this issue.

Finally, any meaningful interaction between the mapper and the walker requires that various kinds of data be not only communicated, as detailed above, but also stored and made readily available for retrieval. The main categories of data requiring storage are: walker location, map-state and story location. Walker location (current GPS coordinates described in degrees latitude and longitude) and map-state (story categories present on the table surface) is exchanged simultaneously by the mobile device and 
server through the mobile internet connection. In other words, in a single request to the server the mobile device communicates its GPS location and retrieves the current configuration of the table. Once this request is made it is then recorded in an SQL database on the server. SQLite, a very small database server application, is constantly running in the background performing writing tasks (recording coordinates) and query tasks (retrieving coordinates for presentation on the table display).

Stories and locations, on the other hand, are stored in an XML file (See Appendix D for an example of the final XML file). One basic and common file was designed to describe what categories contained what stories at what coordinates and were attached to what audio visual media. For example, the "Looking" category contains the "On the Threshold" story which is located at 43.64567 degrees latitude and at -79.41733 degrees longitude and plays the sound file named "threshold.wav" when triggered. Formatting this data in extensible markup language (XML) format allowed us to specially design the structure of the information and tag each part of the data in a way that was both easy for us to interpret and edit and for two different applications to use - a Java-based application (mobile device) and a vvvv application (table interface).

The process of navigating these communication issues between software objects and networked devices revealed to me the similarity between the various techniques used in computation and networks. Communication among all these sets of objects made use of the same strategy, namely, protocol - from the most basic unit I could manipulate in a program function to the highly complex arrangement between mobile networks and the internet. Knowledge of protocols and management of their use therefore acquires an importance equal to or greater than the production of content, the design of the interface or programming.

\section{Construction of the Interactive Table}

The design of the interactive table began with the assumption that a basic shape such as a box would allow for both the viewing of the interface and the storage of the hardware necessary for the installation (Kaltenbrunner \& Becina, 2007). A large box would serve as a table with the top side used as the display. The initial dimensions took into account average human heights, comfortable surface area size for the manipulation of small physical objects and the posture (sitting or standing) of the user. In this case, standing is suggested to be the preferred position for working with light objects located below the elbow (Helander \& Helander, 2006, p. 173).

The table was first constructed as a mock-up (Figure 4 - Table mock-up) in order to rough-in the shape of the table and adjust its dimensions. A main concern once the general proportions were established was the housing of the necessary hardware. Compromises were made between the overall size and the size of the equipment in the table. The combination of display and gesture/object recognition on the table required the use of a semitransparent display surface, an IR-capable camera, an IR-light source, 
a mirror and a data projector - all to be housed inside the table. For instance, the CPU was installed in an ultra-slim case (InWin BT611 Slim Tower) in order fit in the table without obstructing any of the other equipment. The projector (Dell 1409X DLP) was also chosen on the basis of its small size.

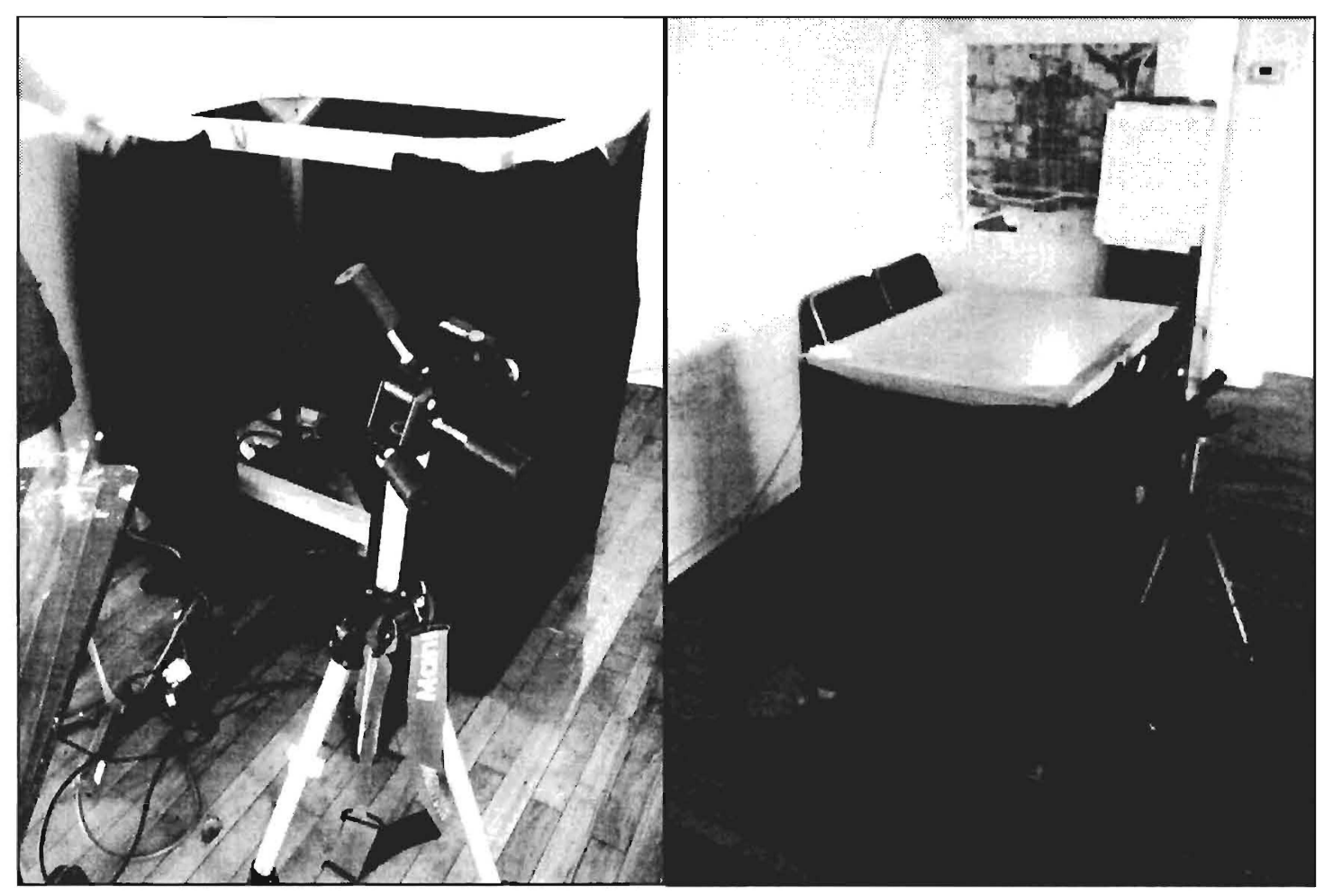

Figure 4 - Table mock-up

Another challenge was the space needed for the projected image that is seen on the top side of the table. Beyond size, the throw distance and size of projection of the projector was also a major consideration. The projector, in order to create an image on the surface of the table, needed to be positioned so that it could reflect its output onto a mirror on the bottom of the table (Figure 5 - Space inside table). The Dell 1409X projector was selected because it could project an image of approximately $36 " \times 27$ " at a distance of approximately 60 ". Including the length of the projector, the height of the mirror and the raised base of the table required that the table be approximately 44 " high. (Figure 6 Projector/mirror adjustments). 


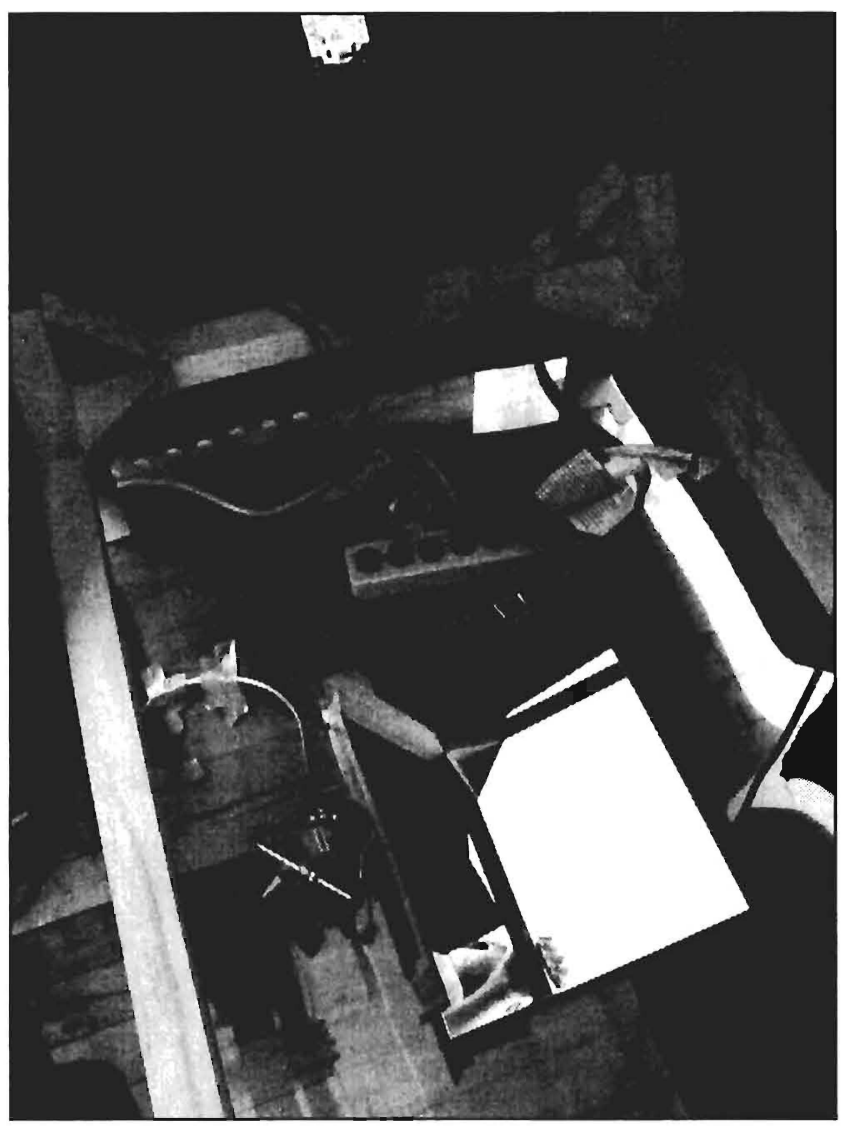

Figure 5 - Space inside table

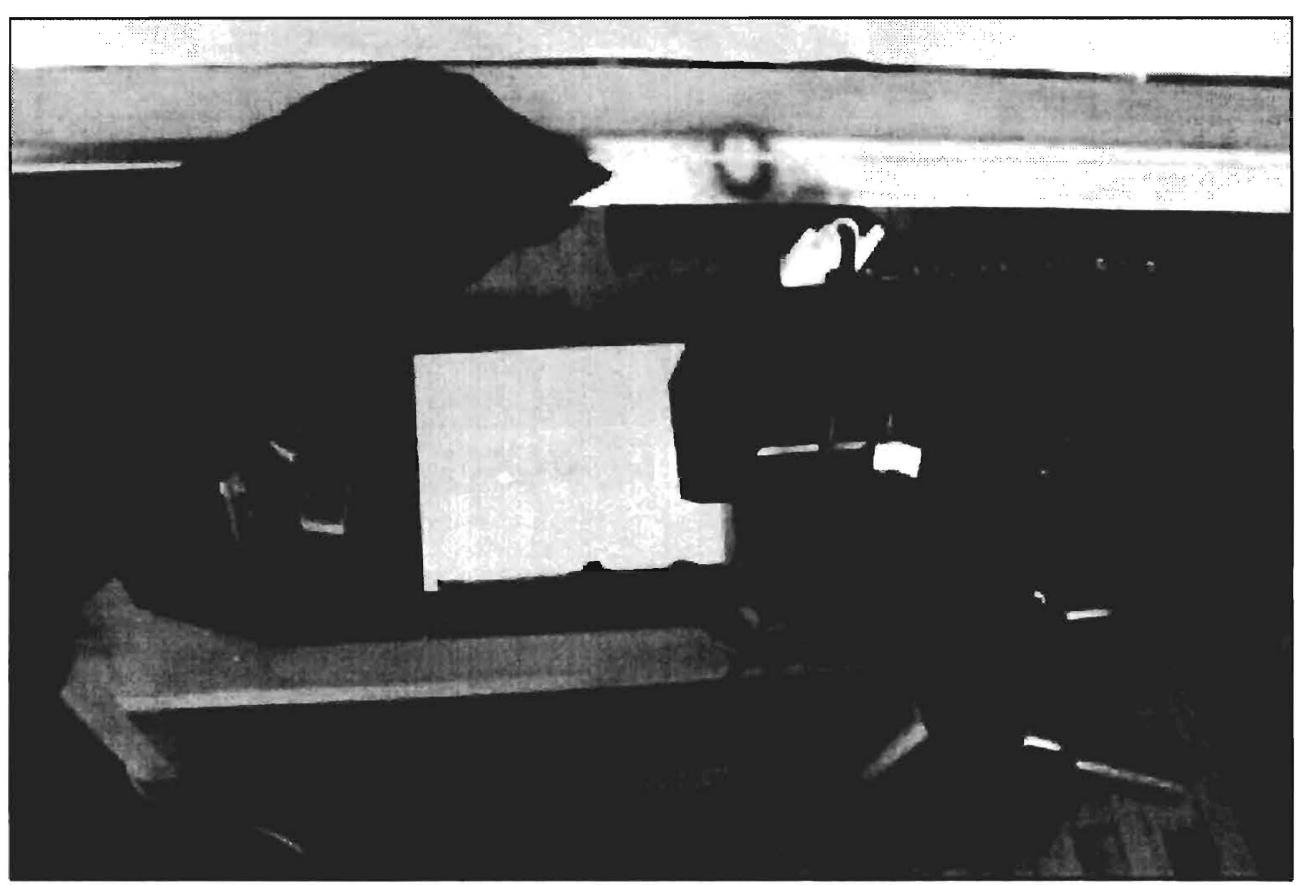

Figure 6 - Projector/Mirror adjustments 
Ventilation also became a concern once all the hardware components were accounted for in the table. The accumulated heat production of the CPU, the projector and the halogen lights would be enough to make the surface, after a long period of time, difficult to touch with one's hand. In addition, prolonged operation at high temperatures could affect the performance of the hardware and possibly cause damage. To mitigate these issues a series of vents were created at the bottom of the table.

In order to achieve gesture recognition and still be able to display graphics on the same surface projection and recognition need to operate in two distinct light spectrums (Kaltenbrunner \& Becina, 2007). The display for normal human-viewing works in the visible light spectrum while the camera system that detects the objects works in the infrared (IR) light spectrum. Alternatively, if visible light was used to illuminate the objects the data projector image would be washed out and become very difficult to read. The IR lights are locate on the inside of the two narrower walls of the table and are pointed directly to the centre of the table. The IR lights are consumer-grade halogen lights with a filter that blocks visible light and passes infrared (Klipstein, 2008). By using a combination of RoscoLux gels (\#19 Fire, \#83 Medium Blue, \#90 Dark Yellow Green) a filter was assembled at relatively low cost.

The final table was built by Joe Tabah, a Toronto-based freelance carpenter. Using the measurements and the mockup as guide for the finished table Tabah produced a modular table system made of medium density fibreboard (MDF) featuring locking walls and gravity-held top and base frames. The modularity of the final design allowed the table to be easily assembled, transported and re-assembled with minimal need for tools or special adjustments to the structure (Figure 7 - Partially-assembled table).

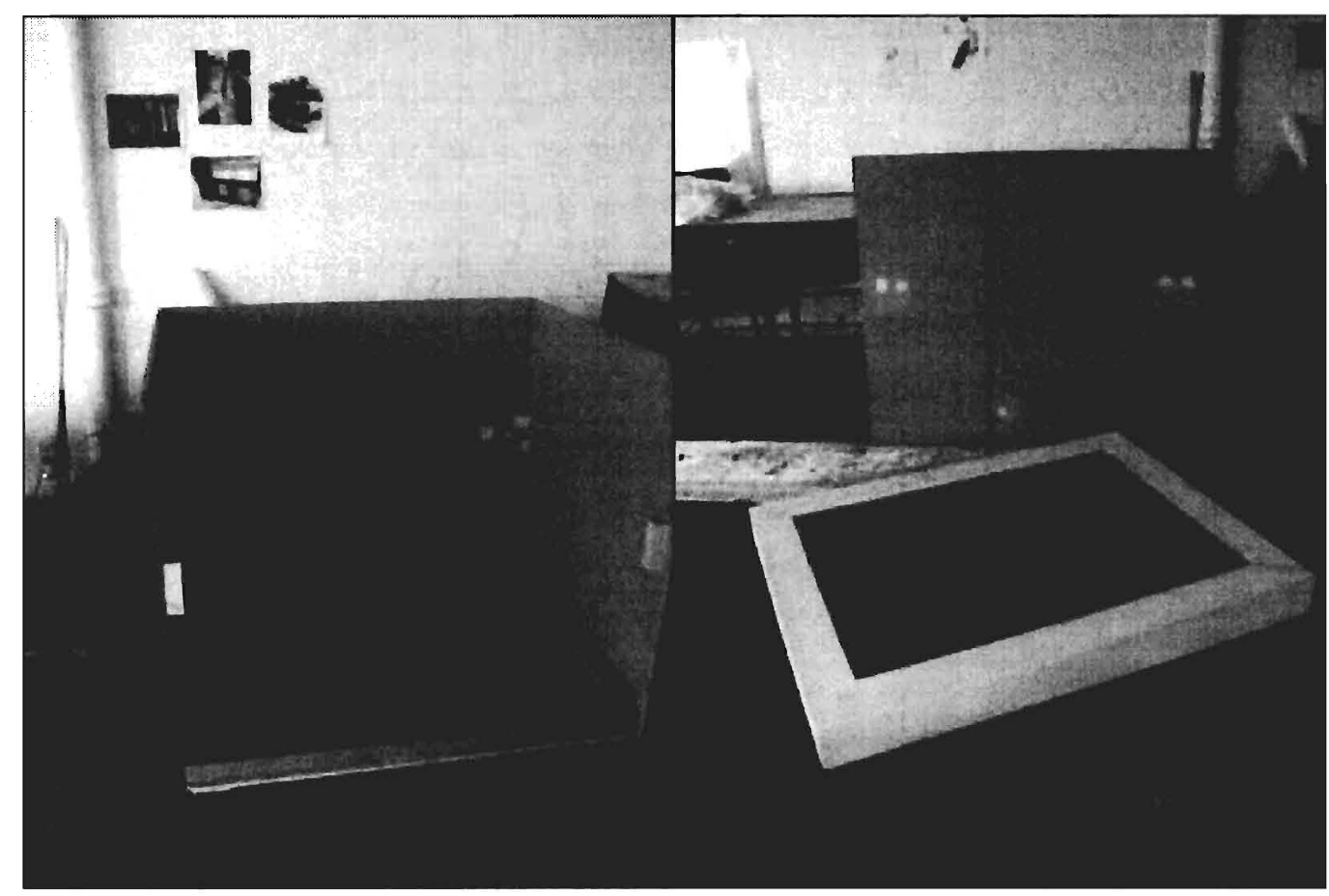

Figure 7 - Partially-assembled table 


\section{Sound}

As indicated earlier in the report, the aural aspect of the interactive experience in locative media is very important. Beyond the notion that listening to sound can create its own space, the method of recording and playback can also create the illusion of space. Spatial effects in sound can be created through single-channel, stereo, surround sound and binaural recordings among others.

The choice of using binaural recording methods to reproduce sound was directly influenced by experiencing Janet Cardiff's audio-works. Listening to her soundscape and narration gave me a visceral sensation of being somewhere else. Cardiff explained that she uses binaural audio precisely to induce that immersive and lifelike experience (Schaub, 2005, p. 15). Her technique, called dummy-head stereophony, is in its most basic form a human-sized and -shaped head with two microphones on each side approximately where the ear is located. Binaural recording mimics the hearing conditions of humans by isolating the sound coming in on the left from the sound coming in on the right and recording it onto two separate channels. This can further be enhanced through recreating the sound dynamics of the shape of the human head, such as the various parts of the ear (pinnae, auditory canal, eardrum) (Blauert, 1997, p. 51). Essential to recreating an immersive sound experience is also the use of headphone to hear the binaural audio with the left channel outputting to the left ear and the right channel outputting to the right ear. Listening to this kind of recording on loudspeakers would minimize the effect and result in creating a listening experience no different from listening to conventional stereo sound.

Very sophisticated and specialized equipment exists for professional binaural audio recording (e.g. Neumann KU-100 Binaural Head) but it is very expensive to purchase and difficult to rent. As an alternative and in a similar manner to the programming and construction of the table, hacking a binaural device proved to be much more feasible and ultimately more instructive and rewarding. Although, professional quality sound was not achieved in the recordings the much-needed three-dimensional effect was achieved. The final transmission device (microphone) comprised a Styrofoam mannequin head and headphones with two clip-on lapel microphones on each side (Figure 8 - photo of dummy head). The signal from this contraption was recorded on a digital audio recorder (Marantz PMD 660) and later transferred to the computer for processing and editing. 


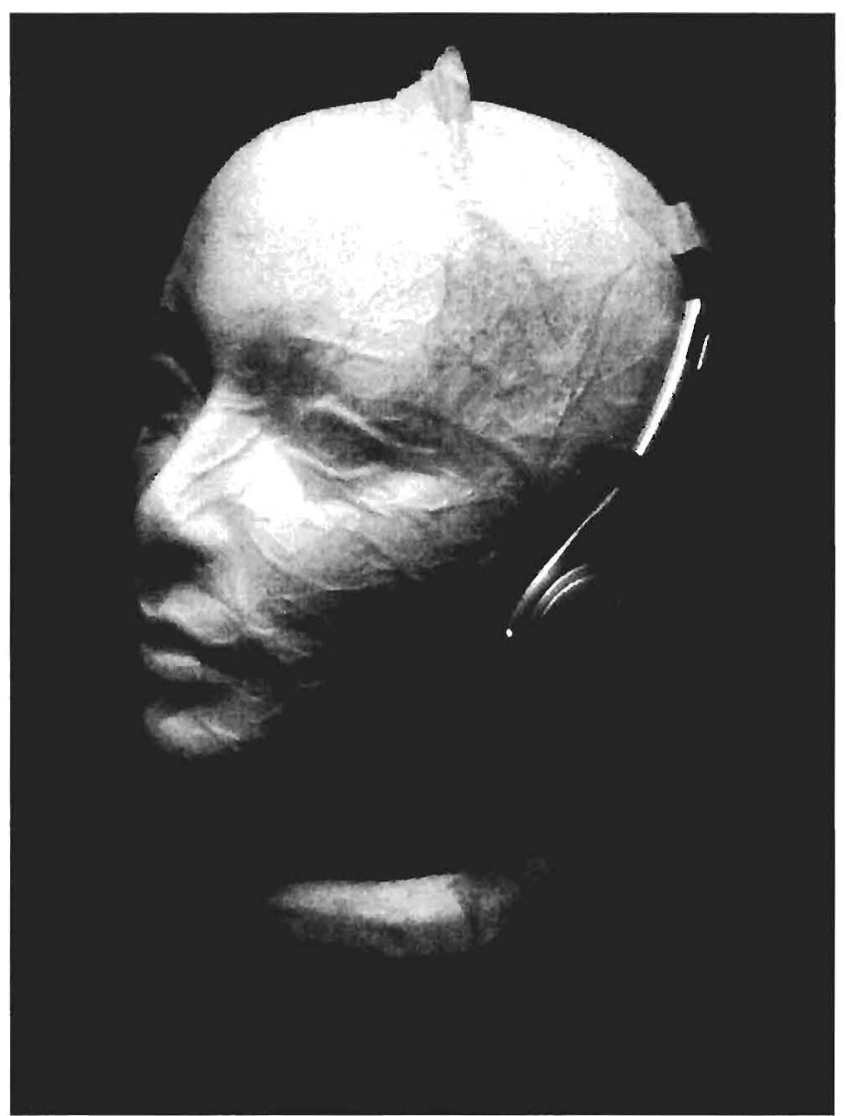

Figure 8 - Dummy-head binaural recording

Audio recordings were made in some of the selected locations in the Queen and Ossington neighbourhood, in various other locations for sound effects and in the studio/home office for voice narration. These various tracks were transferred to hard-drive, converted, cleaned-up, edited and mixed with other sound sources to produce the final sound files played on the table and the mobile phone. 


\section{CONCLUSION}

The Map/Territory project can be evaluated by looking at it as a new media art installation that ostensibly engages and entertains a user, but of equal or perhaps greater importance is the need to look at it as an art research project. That is to say, it must be looked at as both as a final object and an incomplete process. As an object the criteria would include originality, usability, clarity among others - all which point to a user's experience. On the other hand, as a process the criteria would focus more on growth and discovery which is more a function of the author's experience.

It is hoped that through the user experience of the installation many of the issues raised in this report, both theoretical and practical, will be evoked. Some issues, explored through theoretical work such as De Certeau's notion of space/place and Foucault's notion of heterotopia, alluded to through fiction or accounts of memories. While others such as the use of networks or coding are described more explicitly. Although it is difficult to gauge its success objectively the most salient aspect of the installation should emerge as the connection (or disconnection) between the visualization of the space on the interactive table and experience of the walk. While the tangible user interface offers highly visual (and tactile) representation of a very real space that is being "re-created" in realtime, the mobile interface mostly depends on the mind's eye to apprehend space.

Within a locative media art context, the Map/Territory project is situated between works which focus on narrative and space, and others which focus on new media and space. Creators such as Janet Cardiff and Rimini Protokoll use basic technology (CD player, phone) to produce stories and evoke an alternative representation of space. Other creators such as de Waag Society and Mark Shepard use the latest consumer technology (GPS, PDA, GPRS, WiFi) to both critically investigate its use and its mediation of space. Thus the Map/Territory project incorporates the concerns of both tendencies, it seeks to critique the technology on which it is based and the space it mediates through a set of narratives.

One of the major influences of the project was the work of Janet Cardiff. Ironically, her audiowalks, although sophisticated in regards to the creation of complexly layered soundscapes, tend to be very technologically simple. Equipped with only a CD-player and a set of photographs, users can experience a very immersive and rich experience. The power of her work also resides in the forward flow of walking and the linear narrative. The Map/Territory project, on the other hand, taking a cue from database cinema, cuts up the narrative into self-contained chunks to be re-ordered by the walker. It frustrates the impulse to tie things according to a strictly concrete linear logic. It emphasizes the immersive quality of soundscapes and narrations while combining it with a constantly changing collection of content. It eschews the impulse to wither the interface away and hide the complexity of the network instead the project makes it play a substantial role in the content of the narrations.

Like "Amsterdam Realtime" by de Waag Society, the Map/Territory also illustrates the relationship 
between the representation and the experience. In that project, the structure of the city is slowly revealed through the movement of people wearing GPS units. But in addition, the users in the Map/Territory project can play both roles of mapper and walker. This flexibility allows for a deeper experiential understanding of the relationship.

The emergent field of locative media is constantly growing to incorporate or respond to new technologies and by the time this project is completed many of the functions that were initially difficult to develop will be much more easily accessed. Within the span of 6 to 9 months features such as locationbased searches, location-tagging have become commonplace on platforms such as the iPhone $3 \mathrm{G}$ and G1 Google Phone. This may mean that more artists and designers will be able to use these functions to create projects that deal with the spatial issues raised in this report. The dichotomy between mapper and walker may, as a consequence, become less apparent as location-aware mobile devices and mapping and social software platforms become more ubiquitous. As mapping becomes an extension of the walker's range of available options the specificity of each role may become less clear. Nevertheless, while the roles may no longer be performed exclusively by different users or at different times what will remain is the difference between both modes of knowing space. For instance, something will always be left behind in the translation of experience into representation.

Where the installation makes it most meaningful contribution is in investigating the dialogue between the virtual and real in the articulation of space. This dialogue opens further dialogues among various other dichotomies of space: mobile and stationary; visual and aural; representation and experience; inside and outside.

As a process the project as a whole was very successful but it encountered several challenges. Some of which stemmed from scheduling work, securing facilities and co-ordinating the various efforts from collaborators. Planned to be exhibited in the first two weeks of September, the project was delayed by a few months due to faulty equipment, the need to change studio spaces, conflicting schedules with collaborators and extraordinary family obligations. This led to the demonstration occurring in December.

Since the installation involves an outdoor component the change in schedule also meant a change in the season which can potentially severely affect the experience. The average temperature in September is approximately $18^{\circ} \mathrm{C}$ but the average temperature in December is approximately $0^{\circ} \mathrm{C}$. At colder temperatures technology begins to fail, battery life reduces dramatically and above all users may be less willing to wander outside for prolonged periods of time.

Developing this project through approximately 8-9 months meant that a certain vision needed to push the project from start to end in order to maintain momentum. Although the main vision was the creation of a set of discrete tools that facilitate a mapping-walking interactive installation, the vision also came to be the exploration of the ways these technologies could get improved and further integrated. In fact, the exploration became as important as the final outcome. Although ultimately very rewarding as a learning process, the result of this exploration led to a extended development schedule and to what is 
often termed scope creep in the IT industry. Rather than producing a simple and robust tool the Map/ Territory project produced a functional but rough tool that include a set of features that go beyond its initial conception. This has resulted in more technical loose ends that have a greater potential of crashing during its operation and that require proportionately more time to debug. In the end, treating the project as an exploratory process also led to a level of technical complexity that could conceivably hamper usability.

Exploring diverse directions within the project also led to less attention being paid to specific aspects. For example, the narrations alone could have been undertaken as a project requiring a higher level of attention to detail, the commissioning of performances by actors, and the recording and mixing of multiple soundscapes to achieve the cinematic effect found, for instance, in Cardiff's audio-walks. Also, the number of location/narrations that populate the neighbourhood area could have been expanded substantially to achieve a more continuous flow of audio between each "hotspot". Instead, these aspects were left in their rough prototypical state. Like a hack, the project as a whole is left in a provisional state where aspects of it were only pursued to the extent that they functioned well enough.

As a result, future development of the project could occur in three distinct ways: refinement, extension, recombination. First, the provisional state of the installation begs a refinement process where more content from diverse writers and actors could be added to the database. The interface, both map and audio, could be polished to remove bugs, increase responsiveness, and become more user-friendly. Second, the features of the installation could be extended to include the input of content from diverse users. This would also possibly require the mobile application to be cross-platform (iPhone, G1 Google Phone, or Blackberry Storm). Third, the various components of the installation (i.e. table interface, GPS tracker, audio-walk database) can be separately re-incorporated into other projects which require unique interfaces, mobile-to-server communications, etc.

The project development process, despite the limits of the final result and the room left for development, provided an extraordinary opportunity to discover the links between hacking, remediation and hybrid objects. As stated in the "Creation Process" without hacking this project could not have been completed. The importance of being able to work with the materials from which we are generally alienated cannot be overstated. Hacking, as it involves the recombination of existing technologies, is constantly bringing together objects not originally intended to be combined. This practice of serious playfulness creates new forms that either subvert the original intentions of the device's manufacturer or extend its functionality in unforeseen directions. Above all, it affords the artist/designer a much greater understanding of how a particular technology is assembled and re-assembled from earlier forms and how it is dependent on a network of other technologies and practices. This process has, for instance, allowed me to gain a much deeper understanding of the role of digital communication protocols, the metaphors used in object-oriented and flow-based programming languages, and the complex manufacturer/carrier relationship regarding security and application deployment. It has also allowed me to explore how previous media informed the current media utilized in the installation - from maps to tangible user 
interfaces or from orality to database-driven audio-walks.

The difference between process, tool and content has become blurred. Some of these discoveries made during the development process have been described and mixed in with the various other fictions narrated in the installation's audio-walk. The devices which make the installation possible are also highlighted and alongside stories that tie directly to places in the neighbourhood users encounter accounts which continually bring them back to the construction of the installation. Therefore, beyond providing an experience for the user which evokes the issues described in this report, the act of making this project has itself surfaced as an important way of critiquing and transforming my own relationship with space and technology. 


\section{APPENDIX A: STORIES \& LOCATIONS}

The following script includes a selection of the narrations available for playback in the installation (all read by Patricio Davila unless otherwise noted).

\section{Category: Space Place}

\section{Story: Scarborough}

Location: Start of Walk, at gallery OR in parking garage - make more of cars in landscape

\section{(AUDIO sound of highway fast heavy traffic)}

When I began thinking of the space for this installation I began thinking of other spaces. Spaces where I've been, places I wanted to go back to and places I wanted to leave. I revert back to my memory of elementary school in Spain where I had to memorize the poem by Antonio Machado. My father also remembers it from his school days:
(AUDIO read by Patrick Davila)
Caminante, son tus huellas
el camino, y nada más;
caminante, no hay camino, se hace camino al andar.
$\mathrm{Al}$ andar se hace camino, y al volver la vista atrás se ve la senda que nunca se ha de volver a pisar. Caminante, no hay camino, sino estelas en la mar.

It reminds us that paths are made though never retraced. They become elusive memories like a wake in the sea. It tells me that I can only look back and will feel a loss at not being able to walk the same path.

I didn't want to leave Spain. But I always wanted to escape Scarborough. Ever since I got there when I was 14. One of my first memories, when I arrived from Spain, was remarking on the abundance of green spaces. Everywhere there seemed to be grass - even between the highways, which at the time I thought was ridiculous for some reason. Grass was a luxury in the arid climate of southern Spain. The other memory was seeing teenagers in plaid lumberjack jackets and Kodiak boots walking along Victoria Park. My family and I arrived in Scarborough in an airport limo, a small luxury to compensate for leaving 
the warmth of Spain.

Enveloped in the comfort of the black car the new landscape was rushing past and it was hard to get a fix on anything. Few people anywhere. Long stretches of anonymous houses. No landmarks. Mostly parking lots. Once we unpacked and settled a bit I ventured out to see the surroundings. It seemed that everything moved much more slowly when I walked and the distances seemed even longer.

\section{Story: Shed (by Paul Hong)}

Location: Alley east of Ossington

\section{(AUDIO Rain on roof)}

The garage had been broken into almost a dozen times. No, that's an exaggeration but it's easy to exaggerate when it seems to happen to you over and over. Nobody stores anything of any value in there anymore. A box full of Styrofoam peanuts was taken once. A pair of old wooden skis that once belonged to someone's father was taken another time. The remnants of broken and cut padlocks and chains are always left behind. The shed grew out this situation like a boil on irritated skin. It is reachable only from inside the building through the side door or window.

Although it remains practically unused, we had barred the garage from the inside. Two-by-fours, thick chains, and angry bees were used to bar it from unlawful entry. Then the shed appeared. Then we realized that the garage had to remain easy to breach. It had to be full of possibilities, loot - a highly subjective designation, we've come to realize - and jangling with the heaviest and most challenging looking padlocks and chains. It had to appear we were still fighting.

While it seems to us as innocuous and unassuming, its presence was enough for someone to spend a few minutes or a few cents worth of spray paint on it. Having sacrificed the garage for the shed, it remains, so far, largely unmolested. We do plan on actually storing things in there. For now, I crash there on the odd occasion ready for surprises surrounded by the ebb and flow of sounds, noises and on occasion the silence.

\section{Story: Desire to Map}

Location: Alley east of Ossington
(AUDIO distance wind)
(AUDIO Borges reading in Spanish)
(followed by reading of English translation)

\section{Of the Exactitude in Science}

In that Empire, the craft of Cartography attained such Perfection that the Map of a Single province 
covered the space of an entire City, and the Map of the Empire itself an entire Province. In the course of Time, these Extensive maps were found somehow wanting, and so the College of Cartographers evolved a Map of the Empire that was of the same Scale as the Empire and that coincided with it point for point. Less attentive to the Study of Cartography, succeeding Generations came to judge a map of such Magnitude cumbersome, and, not without Irreverence, they abandoned it to the Rigours of sun and Rain. In the western Deserts, tattered Fragments of the Map are still to be found, Sheltering an occasional Beast or beggar; in the whole Nation, no other relic is left of the Discipline of Geography.

- From Travels of Praiseworthy Men (1658) by J. A. Suarez Miranda

\section{Story: Invisible Cities (by Italo Calvino)}

Location: Alley east of Ossington

(AUDIO birds in garden)

(AUDIO read by Patricia Pasten)

Excerpt from Calvino.

Category: Symbols

\section{Story: Jesus (by Paul Hong)}

Location: House on Brookfield St. (just north of Queen, west of Ossington)

A passer-by on a bike noticed Belial seated on the lawn grasping his ankle. A grocery bag lay on its side on the sidewalk, its contents radiating outward.

"You okay?" the passer-by asked slowing down to a stop.

"A nasty dog knocked me down and I hurt my ankle."

"Can I help?"

"See if you can go into this house and use their phone."

"Should I call the ambulance?"

"No, I'll come in and call my friend."

The budding good Samaritan put his bike down and approached the house. He paused to look at the image next to the door. "What does that mean?" he asked Belial who was watching him with great interest.

"That represents the person that resides in the house," Belial answered.

The passer-by studied the picture. "It looks like an image of Jesus."

"Who?"

"Jesus the son of God."

"No, that image identifies the resident of the house. Look around, all the houses have it." 
The passer-by looked around. Most of the houses seemed to have them. "Some of them look the same." "Are you suggesting these people all look alike?"

"No... but over there... that house has the same picture, I think."

"Knock on the door, please. My ankle is really hurting."

The passer-by opened the screen door and knocked. Soon, an elderly man opened it a crack.

"Can we use your phone? That fellow hurt himself and would like to call his friends."

The man shut the door momentarily and then pulled it wider. He looked over the shoulder of the would-be good Samaritan. "Who?"

"Him," the would-be-good-Samaritan-on-two-wheels replied turning around.

There was no one on the lawn. The shopping bag was gone as was his bike.

"He stole my bike," the would-be good Samaritan mumbled.

"Who?"

"The guy... it was all a rouse to take my bike from me."

The elderly man looked. "Wait," he said. He stepped back and closed the door behind him. The foolish passer-by walked back to the front lawn and looked up and down the street. He heard the door opening again and returned.

The elderly man was behind his door. He passed a plastic badge into his hand and then said, "This is St. Anthony. If you find your bike put St. Anthony on your handlebars." He closed the door.

The passer-by looked at the plastic badge of St. Anthony in his hand and then at the painted image next to the door. The man in the house looked nothing like the fellow painted on the ceramic tiles.

\section{Story: Whine Glass (by Jim Munroe)}

Location: Givins just north of Queen

(AUDIO busy Queen street, music and crowd noises)

I've been taking pictures lately, and they're all sorts. Guys, yeah, but young, old, white, black, rich, poor. Mostly drunk. The flash tends to scare them off.

I don't know why people think they can pee in my yard. It's not a brick design of a toilet on the front of my house. It's a long stemmed glass, maybe a chalice. Probably the previous owners were religious.

But I've been drunk before, so the thinking probably goes: what the hell is that? Looks like a wine glass... man I am drunk. I gotta piss. Hey, this guy doesn't care about his lawn, so why not here?

The fence doesn't help. If anything, it's a challenge. Guys will shoot an arc over it or between the rails. They don't think of my kid out there during the day, grabbing the fence with her pudgy little hands.

They don't think about this street at all during the day. It doesn't even exist for them. It's the anonymous space they walk through on the way home from the bar, to their car or to their apartment or to 
their tent.

But after pictures with them with their pants open appear on the internet, they'll think twice before doing it again.

\section{Story: Lonely Robot (by Jim Munroe)}

Location: Street Alley opposite Xspace

\section{(AUDIO alien soundscape)}

It's always nerve-wracking, coming to a new place. No one knows you. Why would anyone want to get to know you?

I remember back home, a conversation I had with a friend of mine that I think about a lot these days, usually when I'm alone at a party or pretending to look at the art in a gallery opening. Yaaar, my buddy, is a super friendly guy and he was talking about someone named Klathoon. I had lost the train of conversation.

"So Klathoon, she says..."

"Who's Klathoon again? The energy-being?"

"No, no, that's Klan-Hwar. Klathoon is a cyber-droid, like you! She just breached her first dimension to get here. You guys should totally meet."

"Sorry, my dance-card's full. Too busy. Got enough friends. Maybe try back next year."

Yaaar was scandalized by this. But making friends is practically his religion. Not to be racist, but Octosapiens are like that, gotta have someone for every arm.

I miss him. I miss them all, trying to make my way in this dimension full of barely mechanized apes.

\section{Story: Objects, maps and stories}

Location: Ossington Avenue (South of Argyle Street)

\section{(AUDIO mountain wildlife)}

The connection between objects, maps and stories for me came to a head on a visit to Cusco, Peru where I bought two carved stone maps that were each a map and myth combined. One is like a fat triangle and each end, I was told, represents one of the three peaks of the Andean mountain range in the Cusco region. Between each peak a symbol is located: a coca leaf, a fox, a snake, a something that looks like a top view of a pyramid - I forgot what he had said it was. The other object is more like a cube. Again each corner represents a mountain but this time one of them is the sun.

The objects are memory devices for a place. But not like a cheat sheet. More like a lock of hair. Part of a larger whole that you wish to closely hold on to when you are away or in unfamiliar territory. The 
stone maps really only make sense if you've been but are no longer there. Only if you've chewed coca leaves at the high altitudes of the Andean Sacred Valley. And only if you felt the sun make it's way between the Andean peaks.

The map table at the gallery is an attempt to unite map and myth through the physical walking of the territory, and digital delivery of story and place. But there is not one memento to guide the journey. Instead there are five objects, each representing the stories embedded in the neighourhood. And a surface that illuminates a subjective map of the psychogeographic landscape.

The parallel between a hand-carved stone map and a locative new media art installation may seem like a stretch. Or the contrast a little stark between the awesome, ancient vistas of the Andean mountains with the mundane urban grit of Queen and Ossington. Despite these obvious differences they share the embedded impulse to reiterate the connection between mythical space and physical place.

\section{Category: Constructions}

\section{Story: Sketchbook}

Location: next to InterAccess Gallery

\section{(AUDIO downtown street traffic, people walking and talking)}

The stories mapped in this installation are inspired by fact. Some take certain liberties in order to make a better story. Others are more literal in their connection to actual events. Some stories are really only notes on interesting features in the neighbourhood or the technology used in this installation. Rather than a story with a beginning, middle and end these stories are more reminiscent of flipping through, jumping back and forth, inspecting a sketchbook with ideas, notes, anecdotes, loose connections beside firm ones. The best sketchbooks tie together disparate concepts in a kind of discussion. They mingle illustration with text juxtaposing concepts that the reader can move quickly through — from one space to another space. They have portions of other texts by other people or images pasted in which retain some of the physical characteristics of their original context - the typeface, the paper, the wrinkles.

This walk provides a way of going over the collection of material by moving from space to space. Mingling fictions with physical facts.

\section{Story: Tracing}

Location: Fennings Street

The act of tracing involves a direct physical link between the original object and the evidence created like in the tracing of a photo or leaf - literally graphing or marking the contours of an object on a 
secondary surface. Tracing is the following of a path across a surface - touching and feeling the contours. The information is tactile and the presence of the object invokes a sensuous response. My body is involved in the following of this trace. By walking and following the trace I commit my body to space and action and perception becomes embodied, in other words, it uses mental, visual, aural, tactile, thermal physical processes. And in this sense the body acts as a bridge in between my interior mental space and the exterior physical world.

Along this walk the digital tracing that occurs involves the steps you take and the data sent to the light table at the gallery. The space between you and the gallery is roughly a block or two yet the link that ties the two amounts to several thousand kilometres - from satellite to GPS unit to mobile phone to cell network to internet to gallery to table. Despite the gaping distance a tracing is performed by a technological network in the attempt to impart some of the information achieved through a physical tracing and walking by specifying position, altitude, heading, velocity. This recalls the old McLuhan aphorism stating that the electrical network is an extension of the human nervous system.

Ultimately, this fails to impart the same emotional and tactile dimension of physically retracing a path. But rather than see our bodies as distanced from the tracing and taking away from the experience. I see this new digital tracing as adding to and complicating the relationship between me and the space around me. Revealing the nature of how I understand my place and what forces in the form of practices, technologies and power relationships have always stood between me and it.

\section{Story: Listening}

Location: Givins Street and Bruce Street

\section{(AUDIO air show \& walking in Dundas apartment)}

By using a Styrofoam head and two lapel microphones on each side I record sound in such a way that it more closely mimics our actual hearing sensation. The math is complicated but essentially the mass in between the mics makes the left side sound slightly different from the right side and therefore creates a three-dimensional sound. I hacked this together after listening to various artists record ambient sound with similar, albeit much more expensive professional, equipment.

I enjoy the effect of this recording technique because, if done well, it can immediately transport you to another place.

Right now I'm in my apartment. I've set myself up to record a few more stories and chunks for the installation. I now realize that the CNE Airshow is on today which will severely limit my ability to get any work done on the audio. I wait for the fighter planes to stop doing their "flybys". I'm listening intently for evidence of the noise furthering away.

I can't see the jet or jets - I don't know if there's more than one. They're rather deceiving that way because when you hear them closest they've already passed by. I have to apply more concentration than 
I'm used to to the act of listening trying to determine where the sound is coming from.

Now that the jets have gone away I can start recording the other audio I had scheduled for today. Before doing that I playback the recording of the sound of the jets as heard from my apartment and I can pick out the direction they were going in. I also become more aware of the sounds of the neighbourhood, the apartment and this very creaky floor.

\section{Story: Walking}

Location: Brookfield Street

Walking, according to many writers on the subject, creates a rhythm that helps the mind produce ideas. By engaging the body in an stroll around the neighbourhood you let your mind wander through unresolved conflicts and work on raw bits of thinking.

Philosophers often walk to work out ideas. Jean-Jacques Rousseau admitted that "There is something about walking that stimulates and enlivens my thoughts. When I stay in one place I can scarcely think; my body must be on the move to set my mind going."

The Ancient Greeks also loved to walk and talk. The Peripatetic Philosophers were followers of Aristotole who preferred the mode of inquiry that was iterative and took lines of thought that meandered to wherever the discussion led.

How the body moves can help provoke healthy thinking processes - mind and body are not so separate after all. Thinking in this sense is also linked to the speed of walking. Walking or moving too fast could potentially disrupt this fine balance. Writer Bruce Chatwin told the story of "a white explorer in Africa, anxious to press ahead with his journey, paid his porters for a series of forced marches. But they, almost within reach of their destination, set down their bundles and refused to budge. No amount of extra payment would convince them otherwise. They said they had to wait for their souls to catch up."

Besides thinking, the speed of walking lends itself to the perception of things at a smaller scale. It gives you a wider window of opportunity to take in the environment. And it lets things happen to you while you're still in relatively the same place. Consider the difference between riding in a car and noticing the landscape coming at you at $60 \mathrm{~km} / \mathrm{h}$ with walking at roughly $3 \mathrm{~km} / \mathrm{h}$ and noticing a lucky penny on the sidewalk. My focus, while driving, is usually directed towards the horizon, the traffic lights and not the sidewalk, the storefronts or people's facial expressions.

\section{Story: Map \& Territory}

Location: Queen Street (East of Ossington Avenue)

Now that you are walking the map who is back at the gallery looking at your progress? Do you trust them to retain the map you've configured? Will they erase all the spots or remove some and add 
others? The map is recording your movement, they are watching your steps and decisions and taking note of your behaviour. The data packets sent between you and the gallery through the network are meticulously counted and double-checked for accuracy. Your velocity is calculated from the amount of distance you cover in a set amount of time. Your attraction to place and stories is approximated by the amount of time you spend in any one location.

Others in the gallery can view your path and compare it to others in the past. They can also view how much traffic there is between the walkers and the table. They can check the speed of your walking. And they can anticipate the next story you're going to encounter.

The control and knowledge of space is the function of the map. There is an inherent power in looking - especially if it is at a map you are performing. Military strategists and security analysts visualize the movements of troops and civilians on maps much like the one in the gallery. The space has been rationalized where all "knowns" are plotted.

Naturally, the worm's-eye-view is not without its own advantages. By listening and walking, images and words come together creating fleeting connections that are difficult, if not impossible to represent in another form. Feeling the air, hearing the ambient noise and having the body indicate how far things are from each other — vast amounts of things escape translation to the map.

\section{Story: Coding}

Location: Queen \& Fenning

\section{(AUDIO rainforest animals)}

Two similar but separate environments interact in this installation. Both make use of objectoriented programming tools. Object-oriented simply means that programs are structured in a way that there is constant communication between small programs and that these programs are created in the first step by describing species of programs that can later mutate into variations. Not unlike a ultra-controlled ecology these bits of programming live in the hardware's memory and are activated once they are called upon by other programs. In this sense there are two ecologies working in this installation, one on the phone in your hand and one the table in the gallery.

The environment on the phone is necessarily more constricted than it would be on a desktop computer or server. The main reason for this is that the processing power of phones is still much lesser than larger hardware. Memory, where the code lives, and processors, where the code acts are limited therefore an economical approach needs to be applied in the programming process. Redundant loops and inefficient data structures are eliminated. The code is combed over and refactored in order to simplify structure and processes and shake out loose bits.

Apart from efficiency, security in this environment is a major overriding concern. Data such as contacts, billable services, physical location is deemed as sensitive information and there requires several 
security clearances in order to access. Unwilling to risk a consumer backlash in mobile phone applications phone companies and carriers devised a jumbled collection of security protocols to limit amateurs access to their own or other people's phones. Programs need to have a digital signature that verifies your identity before it can run in the phone's environment.

The phone environment is smaller and yet potentially more powerful than the desktop. Code objects operate within this portable ecosystem transferring messages amongst themselves and eventually sending messages to the larger system in which we find the gallery. The phone's ability to move along with the user in physical space gives it an ability to play intermediary between context and network.

The environment on the desktop computer that controls the table in the gallery is vastly more complex than the phone. Multiple applications are constantly running simultaneously and often in conflict with one another. One program controls the camera, another the display, another the recognition of movement and another the incoming data from the phones. Where the phone is a private garden the desktop computer is a cesspool of applications each vying for dominance over the other and some looking to burn the whole thing down entirely.

Within this ecosystem the various applications that take in optical data, network data, and audio data from various peripherals and coordinate their efforts by communicating across a common data channel. The visualization of data is accomplished through a high-level node-based visual programming environment. By connecting boxes with lines with your mouse you make a patch of objects that are in continual communication. A flow-based system that pumps signals from inputs into processors and then outputs the information visually or aurally.

The tabletop which depends on a desktop computer to display, retrieve and interpret information and constitutes a system that waits for messages to arrive. It only acts if these messages arrive from the phones roaming the neighbourhood or if objects are moved on it's surface. These inputs pass through objects each with it's function and each modifying the message for the next object in line until a sound or video is played or a trace marked.

\section{Story: Protocols}

Location: Argyle Street and Ossington Avenue

\section{(AUDIO buzzing insects)}

Specific rules of conduct allow me to virtually place a story in space. They are rules which you and I have to adhere to in order to pass information back and forth to each other. Now, obviously, I am not actually present in a physical sense but my intentions are recorded in a set of procedures that allow you to make various choices within a larger set of finite possibilities. So, essentially, you are communicating with my absence, or the record of my presence.

You being here and me being there at some point and us "interacting and communicating" is 
possible through the use of a few programming languages and the adherence to specific communication protocols. We have to, essentially, accept the language and modes of conduct created by engineers and scientists and employed by corporations, service providers, manufacturers in order to have this exchange. We also have to accept a contract with a service provider and manufacturer in order to use the technology that ultimately executes these interactions and communications.

Although we control what we say on a content layer we essentially have very little direct control on how we talk to each other on the technical layer.

Category: Time

\section{Story: Remembering Pharmacy, Eglinton and Lawrence}

Location: Close to a parkette between Argyle and Humbert

\section{(AUDIO footsteps and traffic)}

When I walk on Pharmacy Avenue in Scarborough, I see the Hydro field but I know how it connects to the parts that are located just past my vision. A mental map that joins specific places but that rarely manages to create an overview of the whole territory. I look at the path that leads from the field to the street. I remember the tackle football match in the middle of winter in the nearby parkette. A parkette similar to the one located here. I follow the links to the factory and remember where I worked as a teenager located just over the next pylon and down Warden past Eglinton.

\section{(AUDIO Dundas traffic)}

As I write this I can put myself in that place and recall features of the landscape and past events but I am still only sitting in my apartment on Dundas Street. When I hear the deep pumping bass of an SUV passing by it brings me back to the present time and place. Here Little Portugal, the up and coming hipster neighbourhood lined with old sports bars and new art galleries is slowing being wrested from the hands of the Portuguese and Azoreans. It seems a world away from the imposed emptiness of wide streets, subdivisions and open fields buzzing with electricity.

To record this audio backdrop I went to Scarborough and once again I felt an odd nostalgia through the bodily sensation of walking the distance between intersections, hardly a pedestrian in sight. The scale of the streetscape seemed so large - endless blocks of split-level bungalows or war-time houses.

Once again while writing this, I retrace my memory of that place as I look at the Google map of Scarborough. I'm not sure if my memory is destroyed by this satellite view of the land or made more real through a map of photographic evidence. From the vantage point of a thousands of meters above I can quickly trace the distance between my old apartment and my old high school. I don't feel the oppression I felt as a teenager by the distances between places - I can take it all in now. I realize that the parkette 
where we played football is called Wexford Park. I don't think I knew that or if I did I must have forgotten.

\section{Story: Walking on Queen \& Ossington}

Location: Queen \& Brookfield

I haven't walked the walk yet, so to speak. It's still winter even though it's March.

I can only imagine walking along the paths that I've walked along many times. My favourite time is in the summer when the smells are ripe and the heat of the city envelopes you. You swim through the heat and the air is solid.

I'm not sure I can describe the visual perspective on Queen and Ossington that I see when I recall it. It becomes very abstract when I try to remember it. It takes in everything as though I was looking from behind where the Buddhist temple used to be, now it's a sewing supply store, and through this building onto the street towards the Centre for Addiction and Mental Health. I "look" one way but, as if I had eyes in the back of my head, I 'see' the other way as well towards Givins Street and the alleys behind the storefronts.

I live within walking distance to this intersection. I pass by it a lot on my way to work, to school or friends' homes. When I do there are moments in front of me that make me think of the images and stories and people that I bring along everywhere I go. Most of the time I forget that I have them until I smell something or feel something on my skin. Then, all of a sudden, the memory becomes visceral and coexists with my physical present like a sensuous afterimage. The feel of the sun's heat on my face reminds me of last summer. Visual perspectives explode into smaller cues that no longer register a particular event, just the fleeting sense of warmth, colour and optimism before last winter.

The challenge is in conveying someone else's memory through this medium. It's not a well established medium like novels, radio, theatre, film or television. We haven't agreed to a set of cues that are particular to locative new media installations. The best we can do right now is borrow from other media to produce certain effects that hopefully mesh well with the experience of walking in the neighbourhood, fidgeting with a GPS receiver and cell phone. Although, I find the strength of this kind of experience is that it starts and stops, creates a momentary illusion and breaks it whether the designer willed it or not. A little frustrating and awkward perhaps but hopefully with one or two memorable moments.

A lot of pencil diagrams were made to plan out this installation. Cables, cameras, computers and code were wrangled in order to provide an altered experience of a space. Stories were written to add a layer to physical places. Some are true and some are fiction. Ambient sound was recorded to elicit a sense of another place and time while simultaneously experiencing the present. And these words are narrated. I find my voice to be higher and more nasal than I remember it being so I lowered it using audio software. 
In short this is a construction of a series of memories, thoughts and connections which are sorted and overlaid on a space. And it only really makes sense by being there and doing it.

\section{Story: Rolling a cigarette}

Location: Alley way where I saw a few people taking a smoke break

\section{(AUDIO air vents)}

Automatic, he's got so good at it that he does it with hardly paying any attention to it. He can talk, think and look elsewhere while he does it. At first the macho appeal of rolling your own cigarettes, fags as he calls them, must have pushed him to master the technique. Now it's mostly habit and muscle memory. Ambidextrously moving index and thumb to position the shreds of tobacco on a translucent patch of rolling paper.

Anywhere and anytime. This is his little ritual that he takes with him. Provides a short relief but more importantly creates a pause to regroup and ponder the day's events. I don't smoke anymore. I couldn't even if I tried. I gave it up at age 12. I had started smoking cigarettes shortly before that probably out of boredom, mostly out of doing something prohibited and definitely masculine - at least as far as I was concerned. But mostly for doing something for myself — enjoying my solitude. And now I'm drawn to this manly ritual for similar reasons as I was drawn to smoking as a child.

Smoking on sidewalk, sitting on the concrete pylon. Just like him. I saw someone taking a smoke break here. Not worth noting except for the fact that I could not see where she would have come from. No open doors. No busy workplace full of workers. Just back alley garages. She was alone. Smoking. Without a book to read. Nor a phone to talk to anyone. Smoking reinforced that she was on her own.

\section{Story: Garden of Forking Paths}

Location: Alley way off Humbert Street

\section{(AUDIO footsteps, walking on grass)}

A labyrinth presents the user with a series of choices along a path. The path splits into the possible and the actual. If you retrace your steps you can make other choices and take the other route. In fact you can do this endlessly and possible never arrive at the same destination.

Jorge Luis Borges wrote a short story called, "The Garden of Forking Paths" in which a book and a maze are one and the same. Each is discovered to be a work of art that corresponds to the other. The book is first discovered to be the work of an amateur author, a retired Chinese bureaucrat. In consists of a series of interrupted chapters where, in one, the protagonist dies, in the next, succeeds, in still another he dies. The maze is also first discovered as an intricate map of a labyrinth - a hobby of the old man. It is only later in the story that the two are seen as one. Only when the descendant of the Chinese bureaucrat comes 
across a replica of the maze and copy of the book.

“...The Garden of Forking Paths is an incomplete, but not false, image of the universe as Ts'ui Pên conceived of it. In contrast to Newton and Schopenhauer, your ancestor did not believe in a uniform, absolute time. He believed in an infinite series of times, in a growing, dizzying net of divergent, convergent and parallel times. This network of times which approached one another, forked, broke off, or were unaware of one another for centuries, embraces all possibilities of time. We do not exist in the majority of these times; in some you exist, and not I; in others I, and not you; in others, both of us. In the present one, which a favorable fate has granted me, you have arrived at my house; in another, while crossing the garden, you found me dead; in still another, I utter these same words, but I am a mistake, a ghost."

Category: Looking

\section{Story: On the threshold}

Location: School playground between Givins and Shaw

\section{(AUDIO children playing)}

Alvaro, whom I've known now for almost 15 years, loves to explore alleys. I don't see him often although we both live in Toronto but when we do we inevitably come to talk about hidden alleys or particularly interesting spots. He told me once that when he was walking down this particular alley he came to the end where this fence is. Usually alleys have two open ends which allow people to back out of tight spots or simply use it as a short cut.

Alone at a dead end, this tends to invite a philosophical moment. Not for Alvaro though, he's not really that kind of person. He's more about sensation - seeing, touching, smelling, tasting. He tells me that while inspecting the fence, grabbing the links and testing for weak points that could provide an exit he sees a some kids, mostly girls, on the other side. They're at a fair distance, right be the school's wall the grassy playground separating them from Alvaro and the fence.

Don't make a sound, he thinks, let me see these kids in their natural state.

\section{Story: Frames and Mirrors}

Location: Givins Street

\section{(AUDIO light rain then rolling thunder)}

One of the key features of suburban house design, the picture window was supposed to frame the outdoors and preferably a large expanse of nature for the owner sitting in the living room. A room for living and viewing a natural landscape flattened and cut apart from one's immediate reality. 
The picture window allows our gaze to venture out but it also allows eyes to peer into private life. We are on either sides of a portal looking for each other. I noticed that above the picture window of 12 Givins Street was an eight-sided Chinese mirror - a bagua mirror that is intended to reflect negative energy.

These objects, a frame that cuts and separates and mirror that contains and reflects reminds me of Jorge Luis Borges' story of the Animals that Live in the Mirror.

He writes...(Follow with Borges' excerpt of Animals that live in the mirror).

\section{Story: Situationist Reading of a City}

Location: Ossington Avenue and Argyle Street

Letting go. We need to loosen the rules by which we conduct our lives on a day to day basis so that we can discover an alternative view. Few things are more concrete and rules-based than urban living. I feel lodged within and yet apart from the structure the buildings, the streets, the signs. I follow its structure when trying to get home. I am encouraged to take main streets rather than small streets - join main flows rather than small flows to dead ends and one-way streets.

French philosopher, Guy Debord, describes a strategy to disrupt this imposed order - the dérive, literally the "drift". In order to drift one must let go of the assumptions that ground us to useful versions of reality. Instead of following the established and official order of urban space, he says, follow your nose or your heart. In essence, create an alternative map of the city using a completely different criteria. In one experiment he actually follows a scent for various blocks. In another, he uses a map of London to navigate the streets of Paris.

By following my own set of rules to navigate space I can open myself up to the variation of the city and more importantly to the unofficial connections between spaces, people and social practices.

\section{Story: Flaneur}

Location:

\section{(AUDIO Yves Montand singing Le ciel de Paris)}

The poet, the dandy, the collector, the gambler, the worker, the rag-picker, the prostitute and the flaneur. The flaneur touches upon all these characters by observing them and moving in their spaces.

Flaneur comes from the French word flaner which means "to stroll" and historically to stroll in Paris. And this term is often evoked when describing the pleasure of walking the streets. The flaneur is the urban participant-observer. Participating just enough to be able to observe. I've always found this construct too individualistic and too detached from its context to be useful. I've heard people disparagingly describe others as "he's too much of a flâneur for me." Referring to someone who takes 
pleasure at the whackiness of urban life but retreats to the ivory tower. Not unlike rich kids "slumming" it and then theorizing about it later with their friends.

Nonetheless, it is endlessly evoked to describe the experience of the urban walker. Perhaps because we reason through detecting difference - oneself and the other. A difference that can be emphasized by listening to something using headphones - creating a personal space where the soundtrack and your thoughts live and an external space were everything else lives. But at the same time the soundtrack can conflate difference by imposing itself on the surroundings and, in effect, occupy that space. Suddenly where you are walking slightly resembles another city. Maybe Paris. The city of the flanerie. 


\section{APPENDIX B: PROGRAMMING LANGUAGE COMPARISON}

The following examples are of "Hello World" programs written in Processing, Python, Java, Java Mobile, $\mathrm{C}++$ and Assembler (Rösler, 2008). Hello World is traditionally the first program one writes when learning a new language. It is also used widely to illustrate the basic syntax, structure and overall complexity of the language since all Hello World programs (including the examples below) do basically the exact the same thing — display the text "Hello World" on the screen.

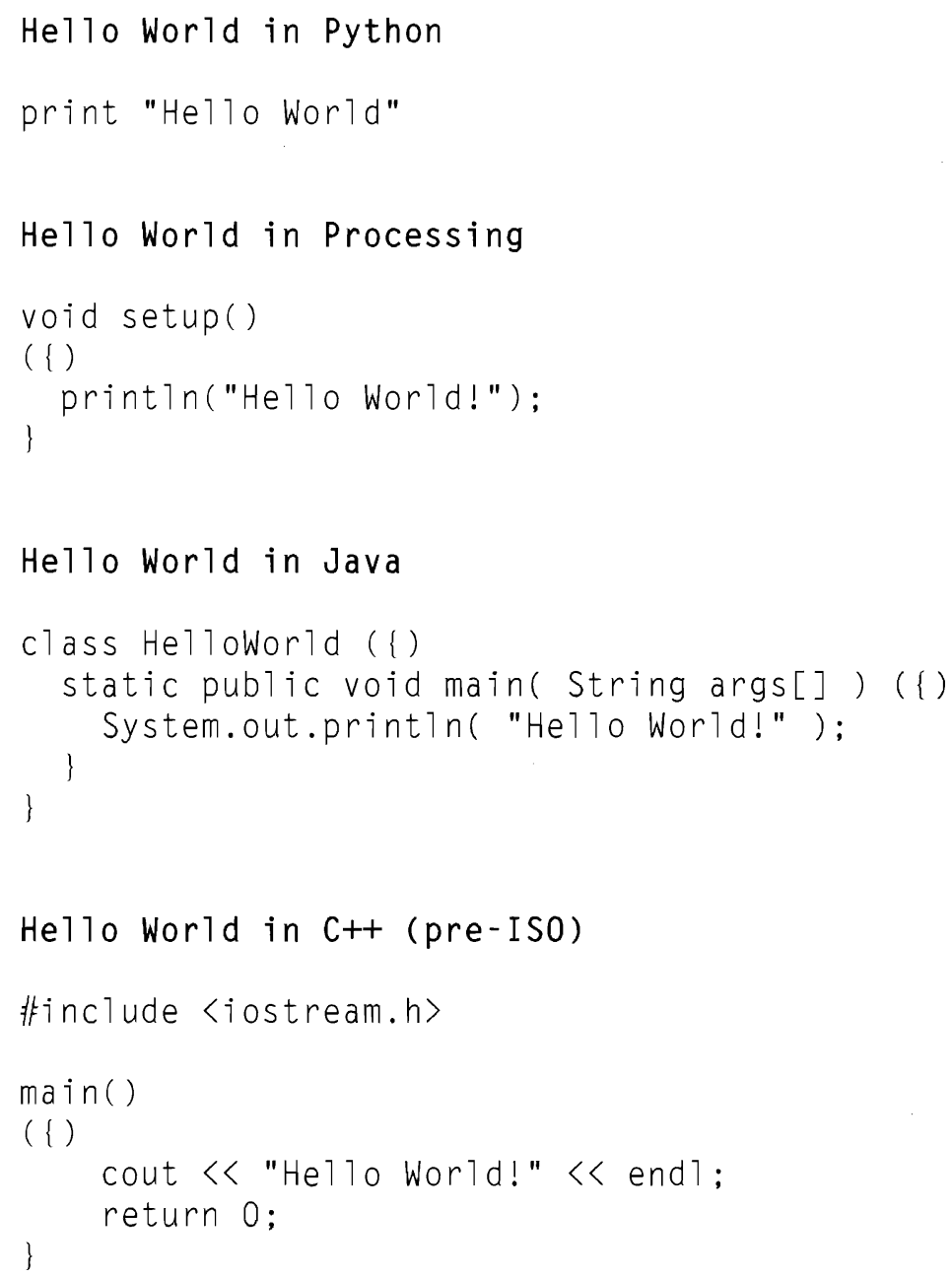




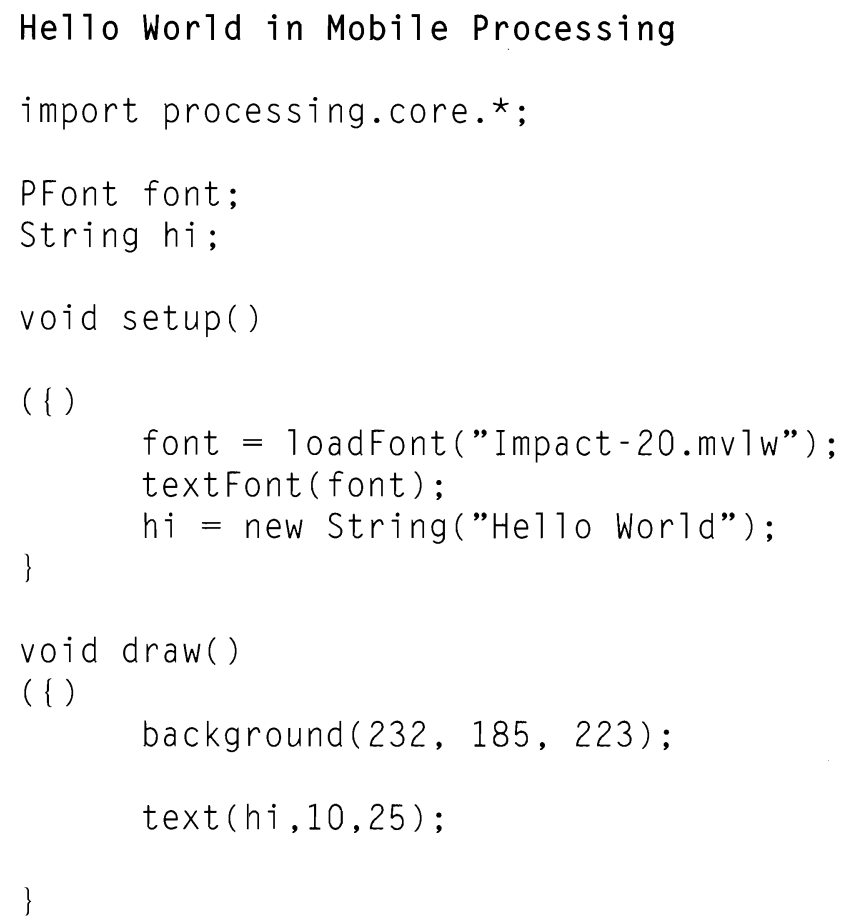


He110 World in Assembler for the MMIX Computer

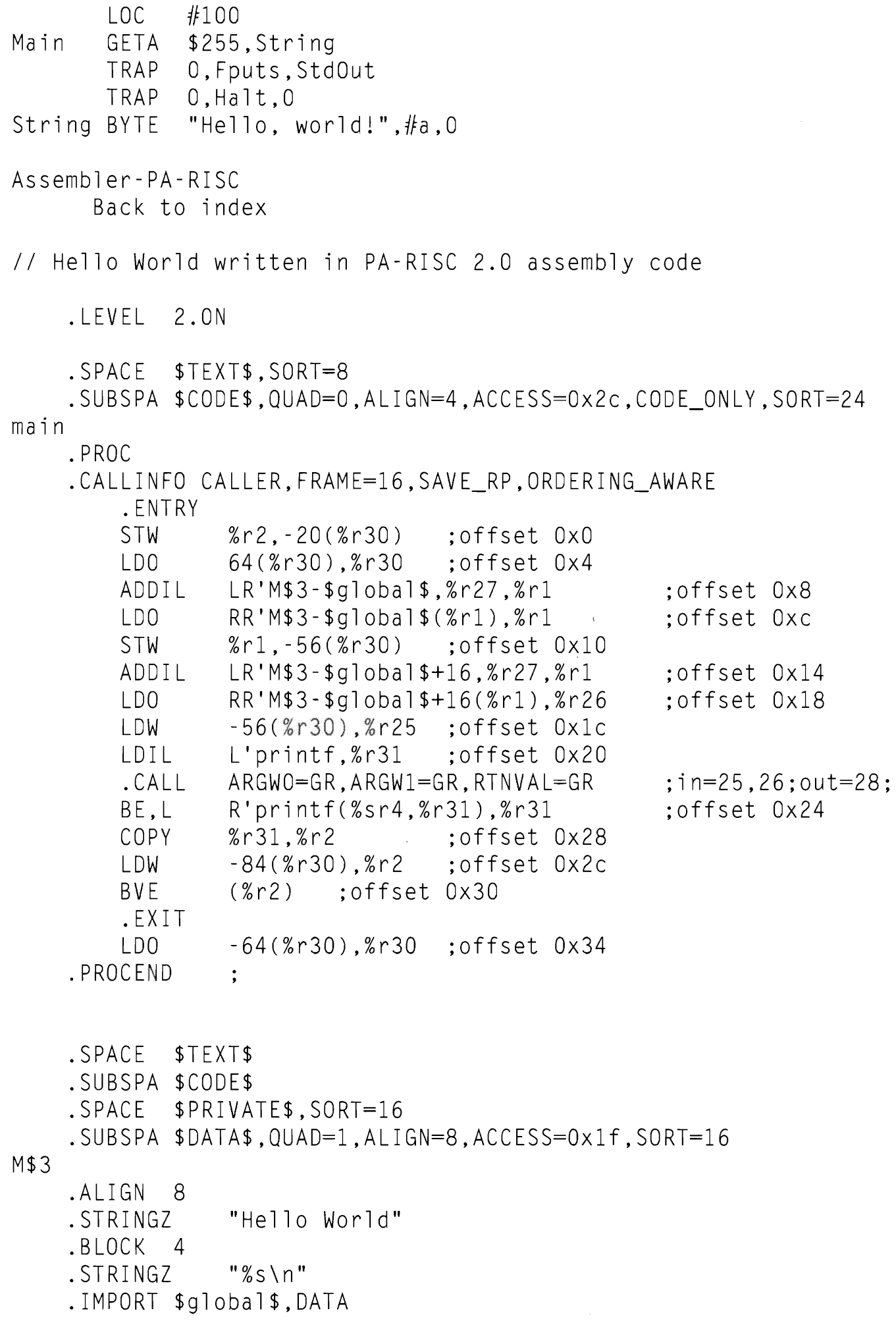


.SPACE \$TEXT\$

. SUBSPA \$CODE\$

.EXPORT main,ENTRY,PRIV_LEV=3, LONG_RETURN

. IMPORT printf, CODE

. END

Hello World in vvvv

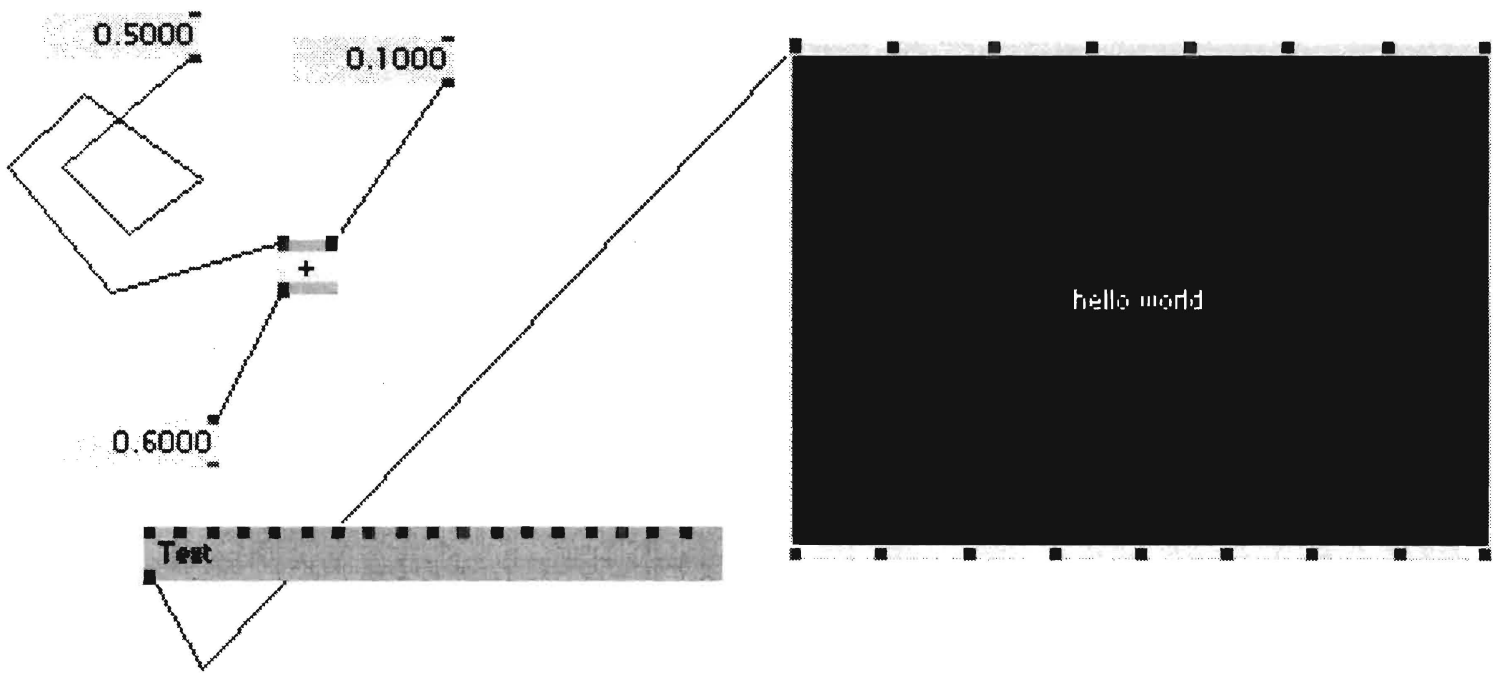


APPENDIX C: FIDUCIAL DESIGN

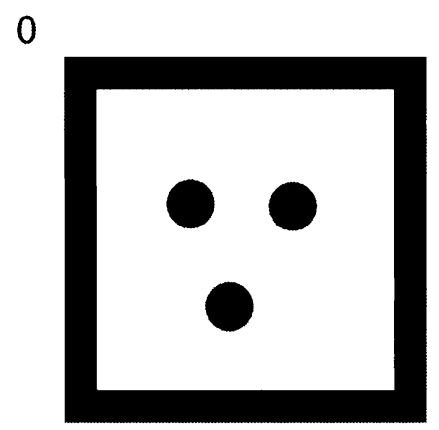

3

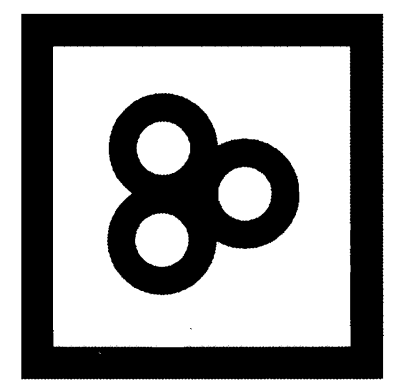

6

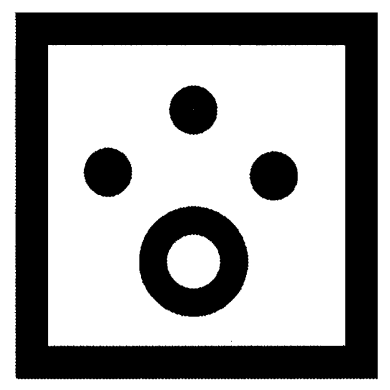

9

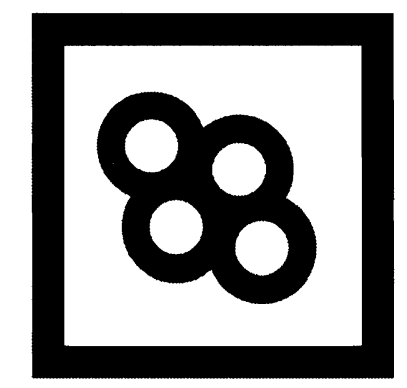

1

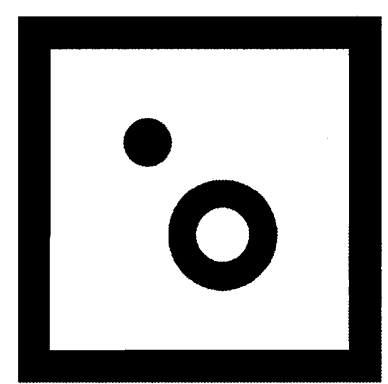

4

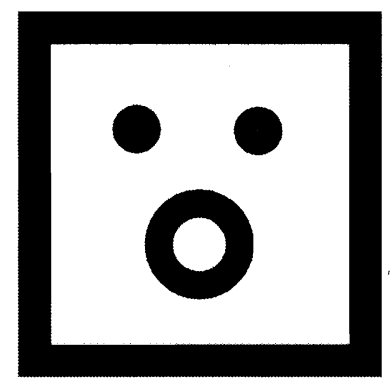

7

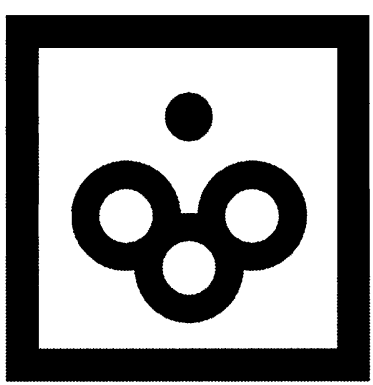

10

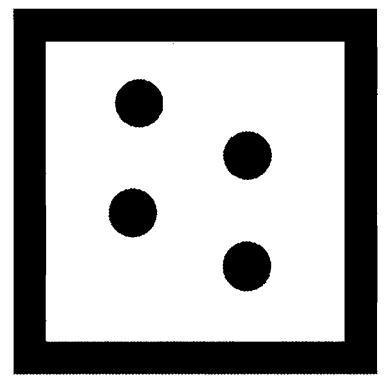

2

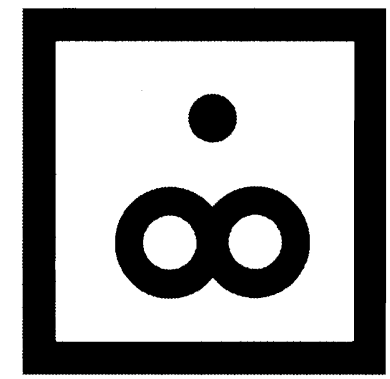

5

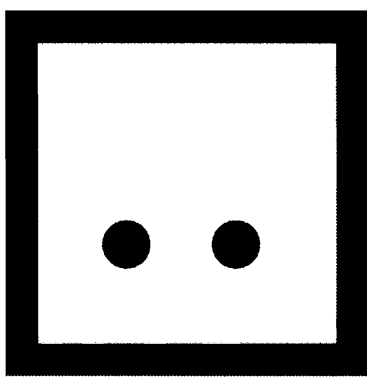

8

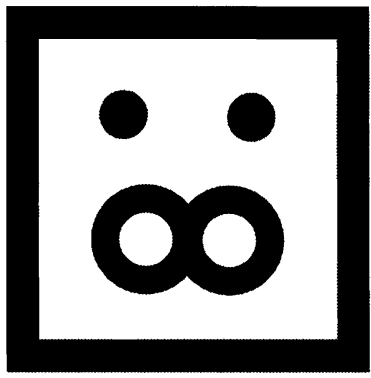

11

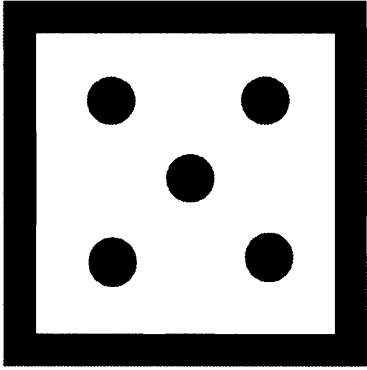




\section{APPENDIX D: XML DESCRIPTION OF STORY AND LOCATION}

$\langle$ ?xm1 version="1.0"?>

$\langle$ mapwa $1 k\rangle$

$\langle$ themes>

〈theme name="spaceplace" fiducial="4"〉

<hotspot name="scarborough" latitude="43.645833333333336"

longitude=" - 79.41833333333334" mediafile="scarborough.wav" mediatype="audio" $>$ boo

$\langle/$ hotspot $>$

<hotspot name="shed" latitude="43.646"

longitude="-79.41883333333334" mediafile="shed.wav" mediatype="audio" > boo

$\langle/$ hotspot $\rangle$

<hotspot name="desiremap" latitude="43.64516666666667"

longitude="-79.41816666666666" mediafile="desiremap.wav" mediatype="audio" $>$ boo

$\langle/$ hotspot $>$

<hotspot name="invisiblecities" latitude="43.644333333333336"

longitude=" - 79.41816666666666" mediafile="invisiblecities.wav"

mediatype=" audio">

boo

$\langle/$ hotspot $>$

<hotspot name="places" 1atitude="43.6445" 1ongitude=" - 79.4175"

mediafile="places.wav" mediatype="audio">

boo

$\langle/$ hotspot $\rangle$

$\langle/$ theme $>$

〈theme name="time" fiducial="3"〉

<hotspot name="cigarette" latitude="43.64633333333333"

longitude=" $-79.4205 "$ mediafile="cigarette.wav" mediatype="audio" $>$

boo

$\langle/$ hotspot $\rangle$

<hotspot name="nighttime" latitude="43.6455" 1ongitude=" $-79.422 "$

mediafi 1e="nighttime.wav" mediatype="audio">

boo

$\langle/$ hotspot $\rangle$

<hotspot name="wa1kingqo" 1atitude="43.644" 1ongitude=" - 79.42"

mediafile="walking.wav" mediatype="audio"> 


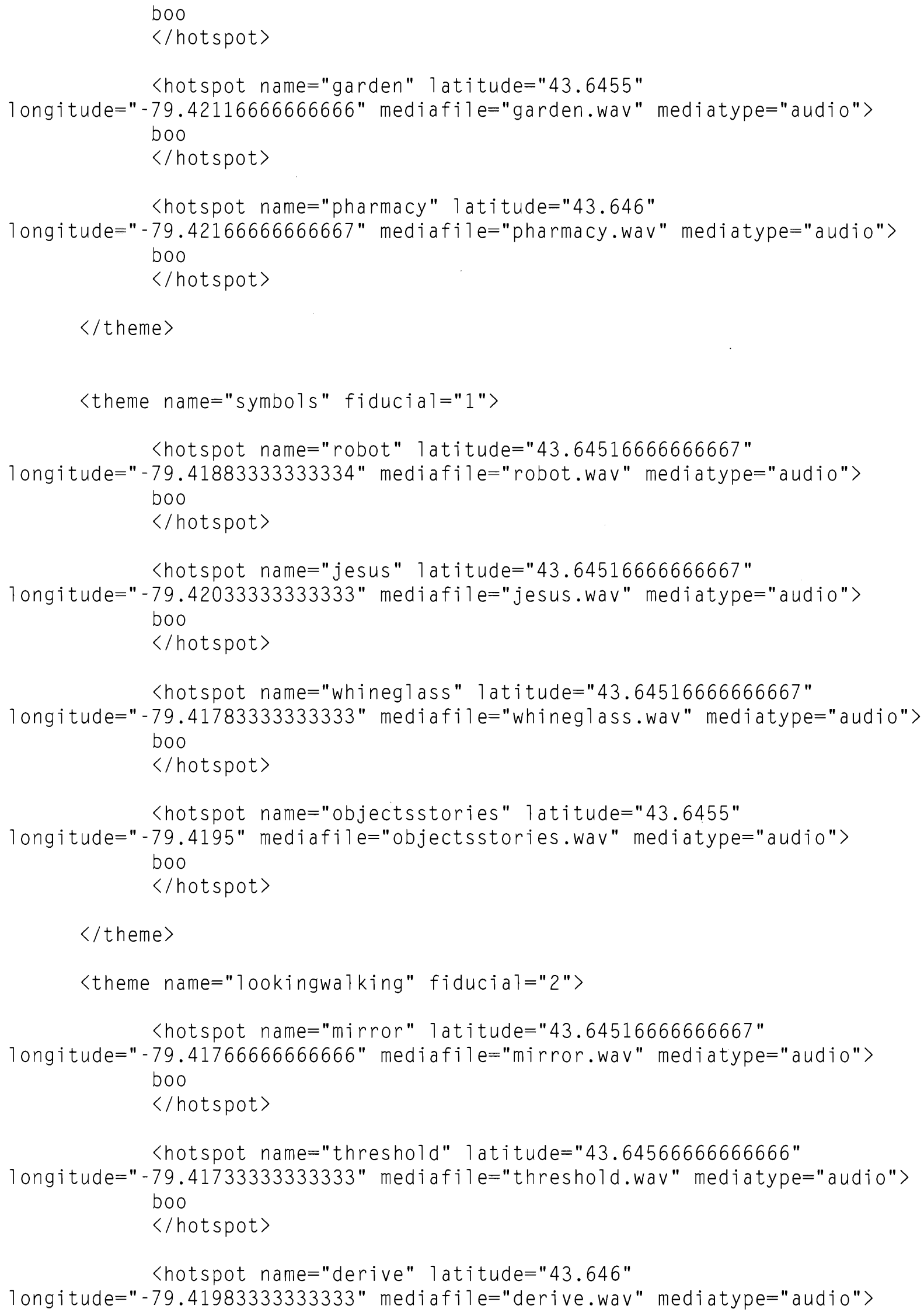




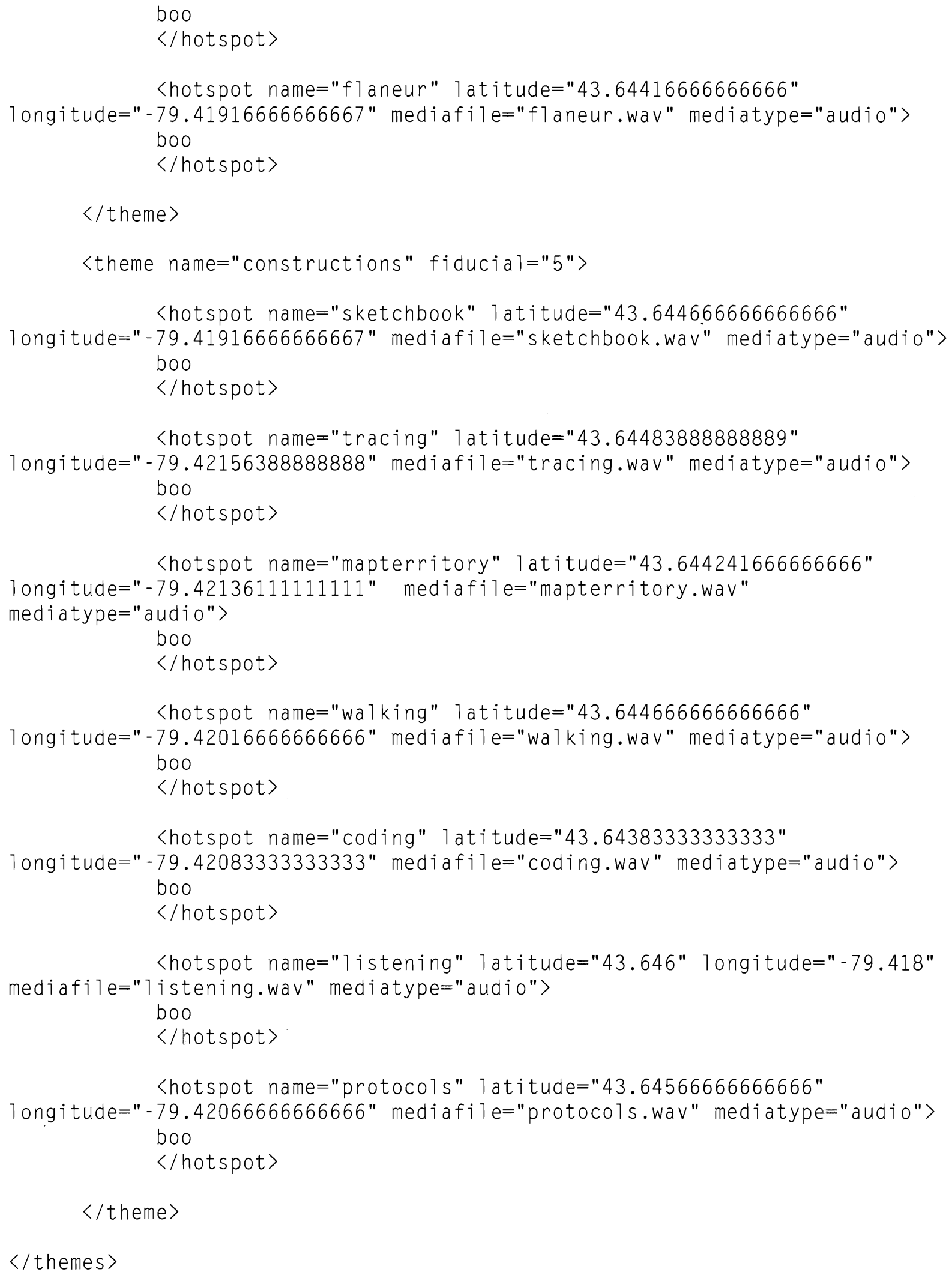


$\left\langle g p s \_b o u n d a r i e s\right\rangle$

$<$ latitude_boundaries northbound="43.646166666666666" southbound="43.64333333333333" >

$\langle/ 1$ atitude_boundaries $>$

<1ongitude_boundaries westbound=" - 79.423"

eastbound=" - 79.41733333333333" >

$\langle/$ gps_boundaries $>$

$\langle/ 1$ ongitude_boundaries $\rangle$

$\langle/ \operatorname{mapwa} 1 \mathrm{k}\rangle$ 


\section{APPENDIX E: CODE SIGNING PROCESS}

$(\{$ mykeystore $\})=$ jvkey08

$(\{$ mypassword $\})=f \mathrm{cl} f \mathrm{cl}$

$(\{$ myalias $\})=$ javakeystore

$(\{$ myjar $\})=$ the filename of your .jar file, e.g. helloworld.jar

$(\{$ myinputjad $\})=$ the filename of your .jad file, e.g. helloworld.jad

$(\{$ myoutputjad $\})=$ the filename of your .jad file, e.g. helloworld.jad

Before you start you must upload the .jar and .jad files of your application

into the following directory:

/cygdrive/c/Program\Files/Java/jdk1.6.0_06/bin

Step 1:

./jarsigner -keystore (\{mykeystore $\}$ ) -storepass (\{mypassword $\}$ ) ( $\{$ myjar\})

( $\{$ myalias $\})$

e.g.:

./jarsigner -keystore jvkey08 -storepass fclfcl helloworld.jar javakeystore

Step 1b:

The file size for the helloworld.jar file may change once it is signed so this needs to also be changed in the .jad file.

Open the helloworld.jad file in a text editor and adjust size of the helloworld.jar file to reflect its new size.

Step 2:

./java -jar JadTool.jar -addcert -alias (\{myalias\}) -storepass (\{mypassword\})

-keystore (\{mykeystore\}) -inputjad (\{myinputjad\}) -outputjad (\{myoutputjad\})

e.g.:

. /java -jar JadTool.jar -addcert -alias javakeystore -keystore jvkey08 storepass fclfcl -inputjad helloworld.jad -outputjad helloworld.jad

Step 3:

. /java -jar JadTool.jar -addjarsig -alias (\{myalias\}) -jarfile (\{myjar\}) storepass (\{mypassword \}) -keypass (\{mypassword \}) -keystore (\{mykeystore $\}$ ) -

inputjad ( $\{$ myinputjad\}) -outputjad (\{myoutputjad\})

- /java -jar JadTool.jar -addjarsig -jarfile helloworld.jar -alias javakeystore

-keystore jukey08 -storepass fclfcl -keypass fclfcl -inputjad helloworld.jad

- outputjad helloworld.jad

(to verify that it has been signed):

Optional A:

java -jar jadtool.jar -showcert -a11 -inputjad (\{myinputjadfile\}) 
e.g.:

./java -jar jadtool.jar -showcert -a11 -inputjad helloworld.jad

Option B:

./jarsigner -verify -verbose - certs ( $\{$ myjar\})

e.g.:

./jarsigner -verify -verbose -certs helloworld.jar

At the end of this process you should have a signed .jar and accompanying .jad file. To install the application onto the phone you must download this file from the server and send it to your phone via Bluetooth. 


\section{LIST OF REFERENCES}

Abrams, J. (2006). No Mouse Required. In J. Abrams \& P. Hall (Eds.), Else/where: Mapping New Cartographies of Networks and Territories (pp. 130-132). Minneapolis: University of Minnesota Design Institute.

Adams, P. C. (2001). Peripatetic Imagery and Peripatetic Sense of Place. In P. C. Adams, S. D. Hoelscher, \& K. E. Till (Eds.), Textures of place: exploring humanist geographies (pp. 186-206). Minneapolis: University of Minnesota Press.

Anderson, B. R. (1991). Imagined communities: reflections on the origin and spread of nationalism. London: Verso.

Arnheim, R. (1969). Visual thinking. Berkeley: University of California Press.

Bazin, A. (1967). What is cinema (H. Gray, Trans.). Berkeley: University of California Press.

Benjamin, W. (1969). The Work of Art in the Age of Mechanical Reproduction (H. Zohn, Trans.). In H. Arendt (Ed.), Illuminations (First ed., pp. 217-242). New York: Schocken Books.

Blauert, J. (1997). Spatial hearing: the psychophysics of human sound localization (Rev. ed.). Cambridge, Mass: MIT Press.

Bogue, R. (2003). Deleuze on cinema. New York: Routledge.

Bolter, J. D. \& Grusin, R. (2000). Remediation: Understanding New Media. Cambridge, Massachussetts: MIT Press. 
Borges, J. L. (1983). The Garden of Forking Paths (D. A. Yates, Trans.). In Labyrinths: selected stories \& other writings (1st Modern Library ed., pp. xxiii, 251 p). New York: Modern Library.

Borges, J. L. (1998). The Analytical Language of John Wilkins. Retrieved Oct. 8, 2008, from http://www.alamut.com/subj/artiface/language/johnWilkins.html

Borges, J. L. (1999). Collected fictions (A. Hurley, Trans.). London, England; New York, N.Y., USA: Allen Lane The Penguin Press.

Borges, J. L., Guerrero, M., \& Hurley, A. (2005). The book of imaginary beings. New York: Viking.

Broll, G., Benford, S., \& Oppermann, L. (2006). Exploiting Seams in Mobile Phone Games. Paper presented at the 3rd International Workshop on Pervasive Gaming Applications, Dublin, Ireland.

Bull, M. (2004). Sound connections: an aural epistemology of proximity and distance in urban culture. Environment and Planning D: Society and Space, 22, 103-116.

Buxton, W. (1985). A Multi-Touch Three Dimensional Touch-Sensitive Tablet. Paper presented at the CHI 1985.

Calvino, I. (1978). Invisible cities (W. Weaver, Trans. 1st Harvest/HBJ ed.). New York: Harcourt Brace Jovanovich.

Cardiff, J. (2004). Her Long Black Hair [Audio]. Retrieved March 22, 2008, from http:// www.cardiffmiller.com/artworks/walks/longhair.html

Carlson, M. (2006). Looking, Listening, and Remembering: Ways to Walk New York after 9/11. Theatre Journal, 58, 395-416. 
Chalmers, M. \& MacColl, I. (2003). Seamful and Seamless Design in Ubiquitous Computing. Technical Report Equator-03-005. Retrieved Sept. 2, 2008, from http://www.equator.ac.uk/ var/uploads/ChalmersTech2003.pdf

Chalmers, M., Bell, M., Hall, M., Sherwood, S., \& Tennent, P. (2004). Seamful Games. Paper presented at the Ubicomp 2004, Tokyo, Japan.

Chalmers, M. \& Galani, A. (2004). Seamful interweaving: heterogeneity in the theory and design of interactive systems. Paper presented at the DIS '04: Proceedings of the 5th conference on Designing interactive systems, Cambridge, MA, USA.

Chatwin, B. (1988). The songlines. New York, N.Y., U.S.A: Penguin Books.

Conley, V. A. (2001). Processual Practices. South Atlantic Quarterly, 100(2), 483-500.

Crampton, J. W. (2001). Maps as social constructions: power, communication and visualization. Progress in Human Geography, 25(2), 235-252.

Cresswell, T. (2004). Place: a short introduction (Short introductions to geography). Malden, MA: Blackwell Pub.

Critical Art Ensemble. (1994). The Electronic Disturbance. Retrieved August 12, 2008, from http://www.critical-art.net/books/ted/index.html

de Certeau, M. (1984). The practice of everyday life. Berkeley: University of California Press.

de Souza e Silva, A. (2006). Mobile Technologies as Interfaces of Hybrid Spaces. Space and Culture, 9(3), 261-278. 
Dietz, S. (2006). Mapping the Homunculus. In J. Abrams \& P. Hall (Eds.), Else/where: Mapping New Cartographies of Networks and Territories (pp. 200-205). Minneapolis: University of Minnesota Design Institute.

Eco, U. \& Weaver, W. (1994). On the Impossibility of Drawing a Map of the Empire on a Scale of 1 to 1 (W. Weaver, Trans.). In How to travel with a salmon \& other essays (1st ed., pp. 95-106). New York: Harcourt, Brace.

Egoyan, A. (2002). Janet Cardiff. Bomb Magazine, 79.

Elliman, P. (2006). Signal Failure. In J. Abrams \& P. Hall (Eds.), Else/where: Mapping New Cartographies of Networks and Territories (pp. 184-189). Minneapolis: University of Minnesota Design Institute.

Foucault, M. (2005). Space, Power and Knowledge. In S. During (Ed.), The Cultural Studies Reader (2nd ed., pp. 134-141). Cornwall: Routledge.

Foucault, M. (2007). The order of things: an archaeology of the human sciences. New York: Routledge Classics.

Galloway, A. R. (2004a). Protocol: How Control Exists After Decentralization. Cambridge, Massachussetts: MIT.

Galloway, A. (2004b). Imitations of Everyday Life. Cultural Studies, 18(2), 384-408.

Galloway, A. \& Ward, M. (2006). Locative Media as Socialising and Spatialising Practices: Learning from Archaeology. Leonardo Electronic Almanac, 14(3-4).

Han, J. (2007). Multi-Touch Interaction Research. Retrieved March 8, 2008, from http:// cs.nyu.edu/ jhan/ftirtouch/ 
Hayles, N. K. (1999). How we became posthuman : virtual bodies in cybernetics, literature, and informatics. Chicago, Ill: University of Chicago Press.

Helander, M. \& Helander, M. (2006). A guide to human factors and ergonomics (2nd ed ed.). Boca Raton, FL: CRC Taylor \& Francis.

Hubbard, P. (2002). Thinking geographically: space, theory, and contemporary human geography. London; New York: Continuum.

Hutterer, P. (2008). MPX: The Multi-Point X Server. Retrieved Aug. 21, 2008, from http:// wearables.unisa.edu.au/mpx/

Innis, H. A., Godfrey, D., \& Innis, H. A. (1986). Empire \& communications (Illustrated ed ed.). Victoria [B.C.]: Press Porcépic.

Kalden, R., Meirick, I., \& Meyer, M. (2000). Wireless internet access based on GPRS. IEEE Personal Communications, 7(2), 8-18.

Kaltenbrunner, M., Bovermann, T., Bencina, R., \& Costanza, E. (2005). Tuio: A Protokol for Table-Top Tangible User Interfaces.

Kaltenbrunner, M. \& Becina, R. (2007). reacTIVision: A Computer-Vision Framework for TableBased Tangible Interaction. Paper presented at the Tangible and Embedded Interaction (TEI07), Baton Rouge, Louisiana.

Kaltenbrunner, M., Becina, R., \& Jorda, S. (2005). Improved Topological Fiducial Tracking in the reacTIVision System. Paper presented at the Procams 2005: IEEE International Workshop on Projector-Camera Systems, San Diego, California, USA.

Kinder, M. (2003). Designing a Database Cinema. In J. Shaw \& P. Weibel (Eds.), Future cinema: the cinematic imaginary after film (pp. 346-353). Cambridge, Mass. ; London: MIT Press. 
Klipstein, D. (2008). Filters to Pass Visible Light and block IR and ones to Pass IR and Block Visible Light. http://members.misty.com/don/irfilter.html

Korzybski, A. (1958). Science and sanity; an introduction to non-Aristotelian systems and general semantics (4th ed.). Lakeville, Conn: International Non-Aristotelian Library Pub. Co.; distributed by Institute of General Semantics.

Latour, B. (1993). We have never been modern. Cambridge, Mass: Harvard University Press.

Lefebvre, H. (1991). The production of space. Oxford, OX, UK ; Cambridge, Mass., USA: Blackwell.

Levy, S. (1994). Hackers : heroes of the computer revolution ([Updated afterword] ed.). New York, N.Y: Penguin Books.

Lovink, G. \& Garcia, D. (1998). The ABC of Tactical Media. Retrieved August 6, 2008, from http://project.waag.org/tmn/frabc.html

Lunenfeld, P. (2000). Snap to grid: a user's guide to digital arts, media, and cultures. Cambridge, Mass: MIT.

Mackenzie, A. (2006). Cutting code : software and sociality (Digital formations ; v. 30). New York: Peter Lang.

Malzacher, F. (2005). Do You Find that Interesting too? An Interview with Helgard Haug and Daniel Wetzel. Retrieved Dec 20, 2007, http://www.goethe.de/kue/the/prj/cak/int/ enindex.htm

Manovich, L. (2002). The language of new media (1st MIT Press pbk. ed.). Cambridge, Mass: MIT Press. 
Manovich, L. (1999). Database as Symbolic Form. Millennium Film Journal, 34.

McCullough, M. (2004). Digital ground : architecture, pervasive computing, and environmental knowing. Cambridge, Mass: MIT Press.

McIntosh, D. \& Davila, P. (2008). Mobile Translocal Media Practices: Case studies of the intersection of art and new technologies in Cusco, Peru. Paper presented at the Inter(PR) axis: Mapping a practice of media art, Toronto.

McLuhan, M. \& Fiore, Q. (1967). The medium is the massage. New York: Random House.

Natural User Interface Group. (2008). Touchlib: A Multi-Touch Development Kit. Retrieved June 3, 2008, from http://www.nuigroup.com/touchlib/

Nokia, Inc. (2008a). Java Security Domains - Forum Nokia Wiki. Retrieved May 3, 2008, from http://wiki.forum.nokia.com/index.php/Java Security Domains\#Security domain information from other manufacturers than Nokia

Nokia, Inc. (2008b). API Access Rights on Phones, S60 3rd FP1 - Forum Nokia Wiki. Retrieved May 3, 2008, from http://wiki.forum.nokia.com/index.php/Java Security Domains\# Security domain information from other manufacturers than Nokia

Ong, W. J. (2002). Orality and literacy: the technologizing of the word. London; New York: Routledge.

Phalnikar, S. (2005). Giving Globalization a Coy Voice. http://www.dw-world.de/dw/article/ $\underline{0,1564,1555616,00 . h t m l}$

Python Software Foundation. (2008). Python: About Python. Retrieved June 11, 2008, from http://www.python.org/about/ 
Raymond, E. (2001). How To Become A Hacker. Retrieved June 14, 2008, from http://catb.org/ nesr/faqs/hacker-howto.html\#attitude

Raymond, E. (2003). The Jargon File. Retrieved June 14, 2008, from http://www.catb.org/jargon/

Reas, C. \& Fry, B. (2007). Processing: a programming handbook for visual designers and artists. Cambridge, Mass: MIT Press.

Rogers, Y. (2006). Moving on from Weiser's Vision of Calm Computing: Engaging UbiComp Experiences. Paper presented at the Ubicomp 2006.

Rosenberg, B. A. (1987). The Complexity of Oral Tradition. Oral Tradition, 2/1, 73-90.

Rösler, W. (2008). The Hello World Collection. Retrieved Oct. 8, 2008, from http://www.roeslerac.de/wolfram/hello.htm

Russell, B. (2004). Transcultural Media Online Reader Introduction, TCM Online Reader. http:// locative.net/tcmreader/index.php?intro;russell

Samjani, A. A. (2002). General Packet Radio Service (GPRS). IEEE Potentials, 21(2), 12-15.

Schaub, M. (2005). Janet Cardiff: The Walk Book. Walther Konig.

Shaw, J. \& Weibel, P. (2003). Future cinema: the cinematic imaginary after film. Cambridge, Mass.; London: MIT Press.

Sun Microsystems. (2004). Java Verified Program Home. Retrieved March 10, 2008, from http:// www.javaverified.com/jvProcess.jsp 
Sun Microsystems. (2008a). Sun Microsystems: Company Info. Retrieved Oct. 8, 2008, from http://www.sun.com/aboutsun/company/history.jsp\#1996

Sun Microsystems. (2008b). Sun Microsystems: Java Everywhere. Retrieved Oct. 8, 2008, from http://www.sun.com/java/everywhere/

Tuer, D. (2005). Mining the media archive: essays on art, technology, and cultural resistance. Toronto: YYZ Books.

Tversky, B. (1993). Cognitive Maps, Cognitive Collages, and Spatial Mental Models. In A. U. Frank \& I. Campari (Eds.), Spatial Information Theory: A Theoretical Basis for GIS, Proceedings COSIT '93 (pp. 14-24). Berlin: Springer.

van Loon, J. (2002). Social Spatialization of Everyday Life. Space and Culture, 5(2), 88-95.

Verisign, Inc. (2006). Code Signing for Digital IDs - for Authenticode from Verisign, Inc. Retrieved March 10, 2008, from https://www.verisign.com/products-services/securityservices/code-signing/digital-ids-code-signing/index.html

W3C. (2008). HTTP - Hypertext Transfer Protocol Overview. Retrieved Oct. 2, 2008, from http://www.w3.org/Protocols/\#Specs

Wark, M. (2004). A hacker manifesto. Cambridge, MA: Harvard University Press.

Weiser, M. (1994). Creating the invisible interface (Invited Talk). ACM Conference on User Interface Software and Technology (UIST94).

Weiser, M. \& Seely Brown, J. (1996). The Coming Age of Calm Technology. Retrieved Sept. 25, 2008, from http://www.ubiq.com/hypertext/weiser/acmfuture2endnote.htm 